Florida International University

FIU Digital Commons

FIU Electronic Theses and Dissertations

University Graduate School

$11-5-2009$

\title{
The Effectiveness of Explicit Individualized Phonemic Awareness Instruction By a Speech- Language Pathologist to Preschool Children With Phonological Speech Disorders
}

Susan L. Nullman

Florida International University, susan.nullman@gmail.com

DOI: $10.25148 /$ etd.FI09120820

Follow this and additional works at: https://digitalcommons.fiu.edu/etd

\section{Recommended Citation}

Nullman, Susan L., "The Effectiveness of Explicit Individualized Phonemic Awareness Instruction By a Speech-Language Pathologist to Preschool Children With Phonological Speech Disorders" (2009). FIU Electronic Theses and Dissertations. 125.

https://digitalcommons.fiu.edu/etd/125

This work is brought to you for free and open access by the University Graduate School at FIU Digital Commons. It has been accepted for inclusion in FIU Electronic Theses and Dissertations by an authorized administrator of FIU Digital Commons. For more information, please contact dcc@fiu.edu. 


\section{FLORIDA INTERNATIONAL UNIVERSITY}

Miami, Florida

THE EFFECTIVENESS OF EXPLICIT INDIVIDUALIZED PHONEMIC AWARENESS INSTRUCTION BY A SPEECH-LANGUAGE PATHOLOGIST TO PRESCHOOL CHILDREN WITH PHONOLOGICAL SPEECH DISORDERS

A dissertation submitted in partial fulfillment of the requirements for the degree of DOCTOR OF EDUCATION

in

EXCEPTIONAL STUDENT EDUCATION

by

Susan L. Nullman

2009 
To: Interim Dean Marie McDemmond

College of Education

This dissertation written by Susan L. Nullman, and entitled The Effectiveness of Explicit Individualized Phonemic Awareness Instruction by a Speech-Language Pathologist to Preschool Children with Phonological Speech Disorders, having been approved in respect to style and intellectual content, is referred to you for judgment.

We have read this dissertation and recommend that it be approved.

Elizabeth Cramer

Lynne Miller

Maureen Kenny

Patricia M. Barbetta, Major Professor

Date of Defense: November 5, 2009

The dissertation of Susan L. Nullman is approved.

Interim Dean Marie McDemmond
College of Education

Dean George Walker

University Graduate School

Florida International University, 2009 
(C) Copyright 2009 by Susan L. Nullman

All rights reserved. 


\section{DEDICATION}

I dedicate this work to my family. I wish to thank my parents who have led me to believe that I could accomplish anything that I put my mind to. A special thank you goes to my children, Steven, Michael, and Julie, who so lovingly echoed back all of the words of support they have heard from me. I really am grateful for all of your patience, confidence, and guidance. Thank you to Katie, Jenny, and Jake who brought extra joy into my life during this study. Much love and appreciation to my husband Jeff — thanks for taking this amazing and challenging journey with me! 


\section{ACKNOWLEDGMENTS}

I would like to thank the members of my committee: Major Professor Dr. Patricia M. Barbetta, Dr. Elizabeth Cramer, Dr. Lynne Miller, and Dr. Maureen Kenny for their excellent guidance and support. This project would not have been possible without them. I want to extend a special thank you to Dr. Judith Cohen who introduced me to teaching reading to children with exceptionalities. Her enthusiasm encouraged me to pursue my doctorate.

Throughout my tenure at Florida International University, I have found the faculty and my fellow students challenging and stimulating. I am grateful for everyone I have met while I worked on my doctorate and every experience this has entailed. 


\author{
ABSTRACT OF THE DISSERTATION \\ THE EFFECTIVENESS OF EXPLICIT INDIVIDUALIZED PHONEMIC \\ AWARENESS INSTRUCTION BY A SPEECH-LANGUAGE PATHOLOGIST TO \\ PRESCHOOL CHILDREN WITH PHONOLOGICAL SPEECH DISORDERS \\ by
}

Susan L. Nullman

Florida International University, 2009

Miami, Florida

Professor Patricia M. Barbetta, Major Professor

This study investigated the effects of an explicit individualized phonemic awareness intervention administered by a speech-language pathologist to 4 prekindergarten children with phonological speech sound disorders. Research has demonstrated that children with moderate-severe expressive phonological disorders are at-risk for poor literacy development because they often concurrently exhibit weaknesses in the development of phonological awareness skills (Rvachew, Ohberg, Grawburg, \& Heyding, 2003).

The research design chosen for this study was a single subject multiple probe design across subjects. After stable baseline measures, the participants received explicit instruction in each of the three phases separately and sequentially. Dependent measures included same-day tests for Phase I (Phoneme Identity), Phase II (Phoneme Blending), and Phase III (Phoneme Segmentation), and generalization and maintenance tests for all three phases.

All 4 participants made substantial progress in all three phases. These skills were maintained during weekly and biweekly maintenance measures. Generalization measures 
indicated that the participants demonstrated some increases in their mean total number of correct responses in Phase II and Phase III baseline while the participants were in Phase I intervention, and more substantial increases in Phase III baseline while the participants were in Phase II intervention. Increased generalization from Phases II to III could likely be explained due to the response similarities in those two skills (Cooper, Heron, \& Heward, 2007).

Based upon the findings of this study, speech-language pathologists should evaluate phonological awareness in the children in their caseloads prior to kindergarten entry, and should allocate time during speech therapy to enhance phonological awareness and letter knowledge to support the development of both skills concurrently. Also, classroom teachers should collaborate with speech-language pathologists to identify atrisk students in their classrooms and successfully implement evidence-based phonemic awareness instruction. Future research should repeat this study including larger groups of children, children with combined speech and language delays, children of different ages, and ESOL students. 


\section{TABLE OF CONTENTS}

CHAPTER

PAGE

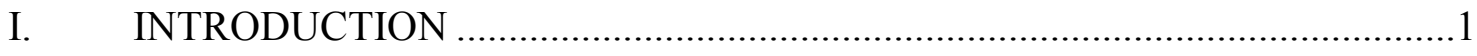

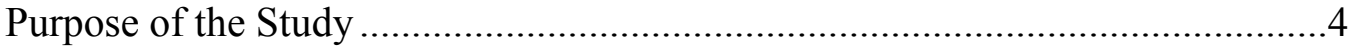

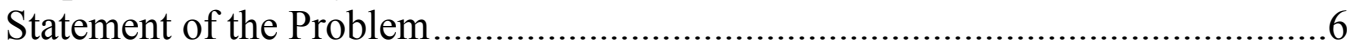

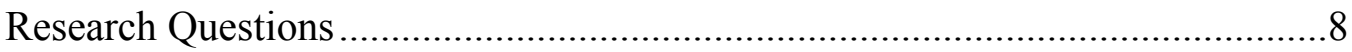

Delimitations of the Study ........................................................................

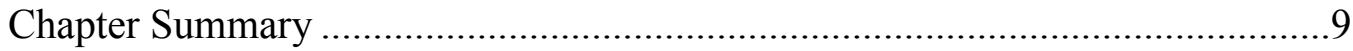

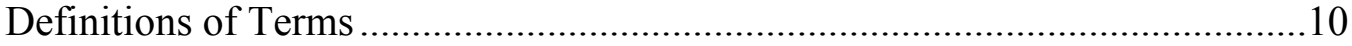

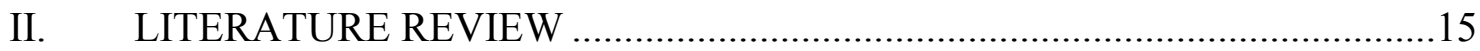

Speech, Language and Literacy Development....................................................15

Early Language and Literacy Development .............................................17

The Effects of Speech-Language Impairments on

Literacy Development............................................................................19

Summary of the Effects of Speech-Language Impairments on

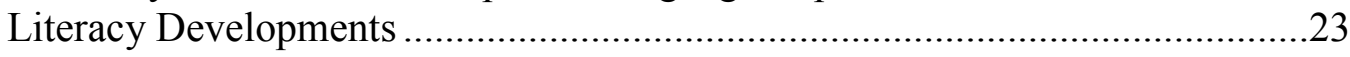

The Role of Phonological Processing in Literacy Development .........................24

Summary of the Role of Phonological Processing in

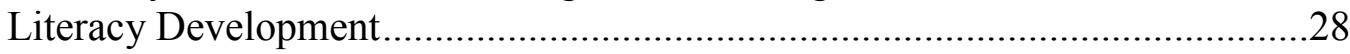

The Role of the Speech-Language Pathologist in Phonemic

Awareness Interventions ..................................................................................29

Summary of Phonemic Awareness Intervention Research on Children

With Speech-Language Impairments (SLI) ....................................................33

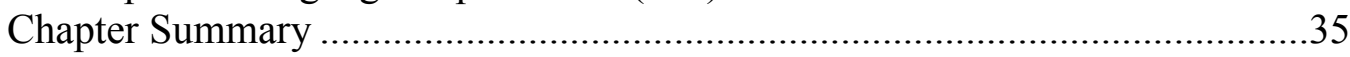

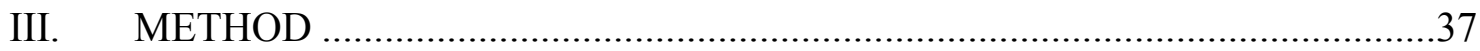

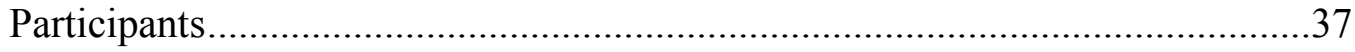

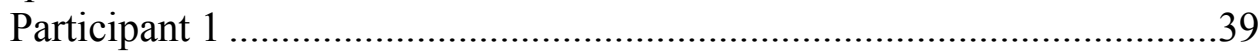

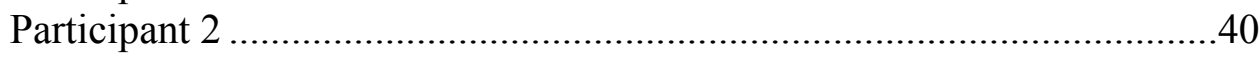

Participant 3 ..............................................................................

Participant 4 .................................................................................

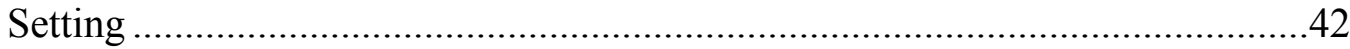

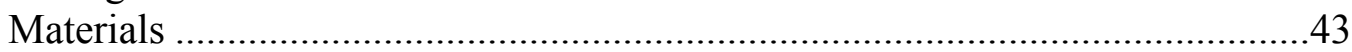

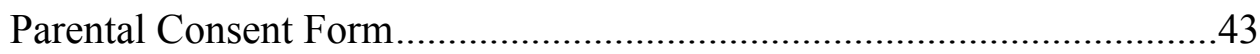

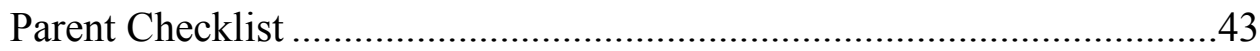

Standardized Tests and Test Forms ..........................................................44

Oral, Motor, Hearing, and Vision Assessment ...........................................44

Baseline, Intervention, and Same-Day Test Materials.................................44

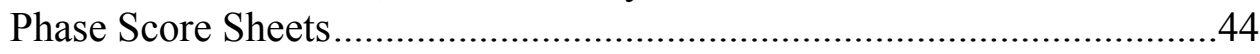

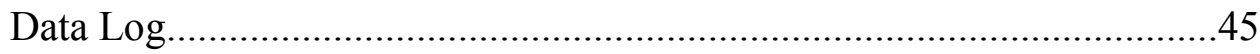

Interobserver Agreement Form and Treatment Integrity Checklists .........45 


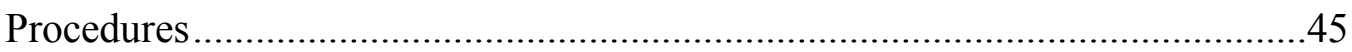

Pre-study Permission and Assessment Procedures ………………….........45

Research Procedures ............................................................................46

Phase I: Phoneme Identity ……………………...................................47

Phase II: Phoneme Blending ...............................................................50

Phase III: Phoneme Segmentation ........................................................53

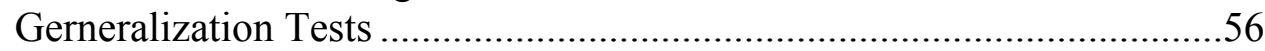

Maintenance and Posttests ………………………………..................56

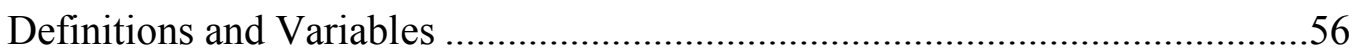

Phoneme Identity Same-Day Test …………………….......................57

Blending Same-Day Tests...................................................................58

Phoneme Segmentation Same-Day Test................................................58

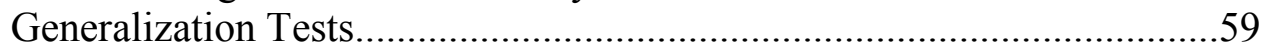

Phase I, II, and III Maintenance Tests ...................................................60

Interobserver Agreement Training...................................................................60

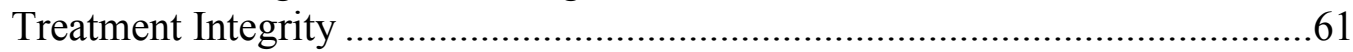

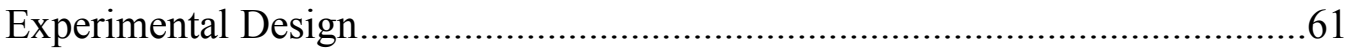

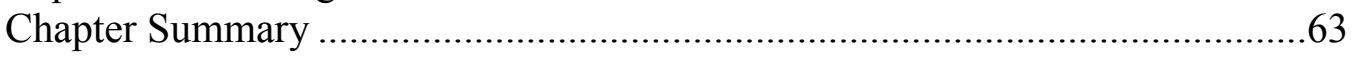

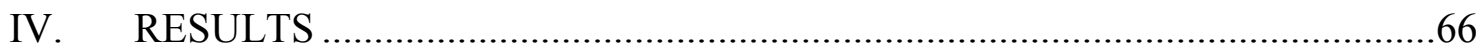

Interobserver Agreement ……………………………………………......67

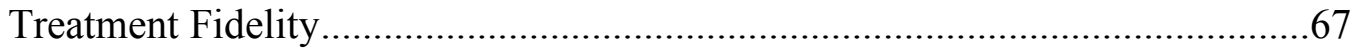

Phase I: Phoneme Identity ..........................................................................67

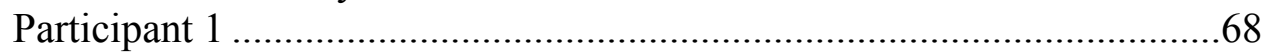

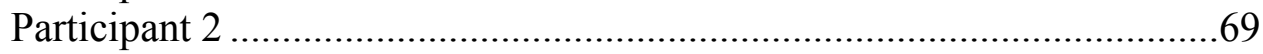

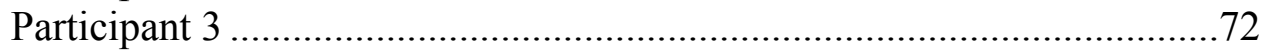

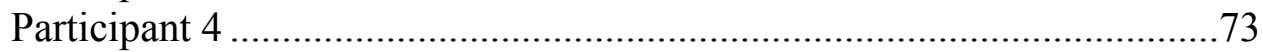

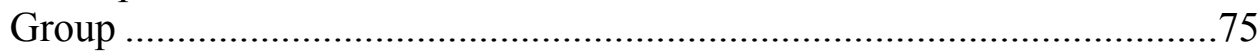

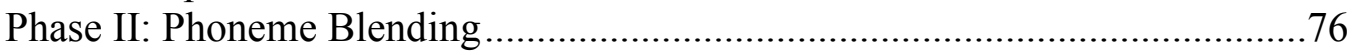

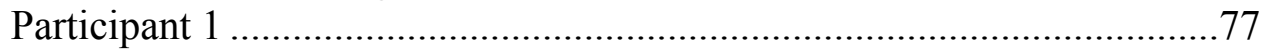

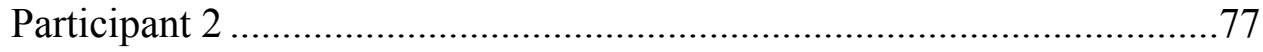

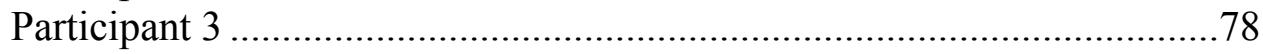

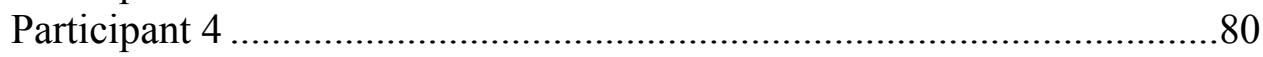

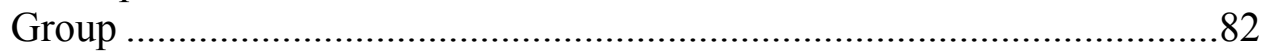

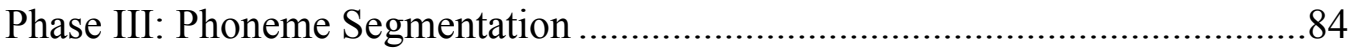

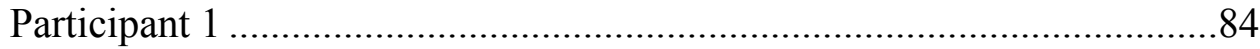

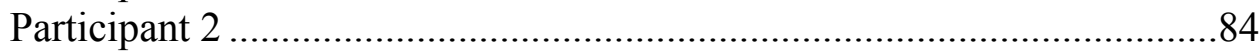

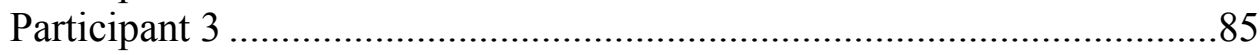

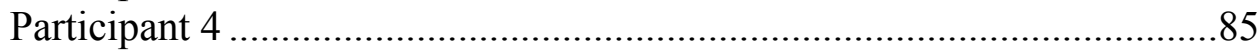

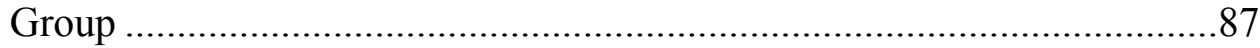

Results of Goldman-Fristoe 2 Test of Articulation..............................................87

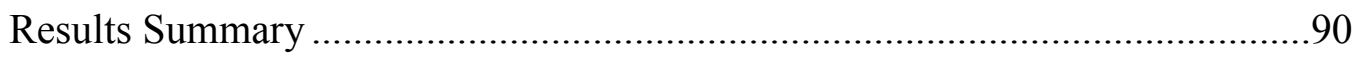




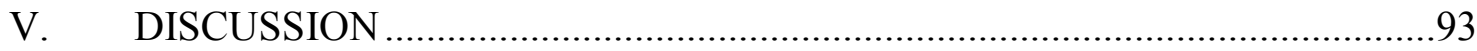

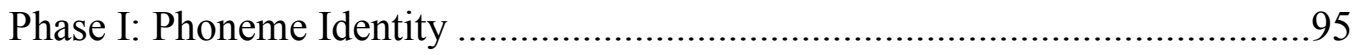

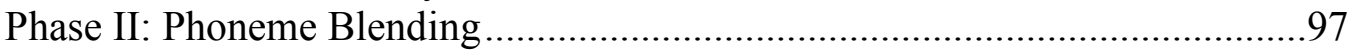

Phase III: Phoneme Segmentation ..............................................................98

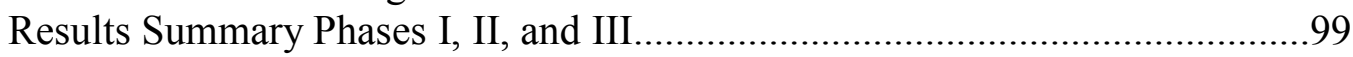

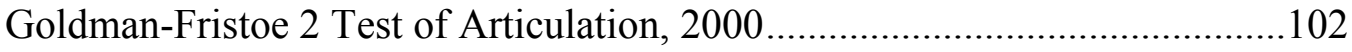

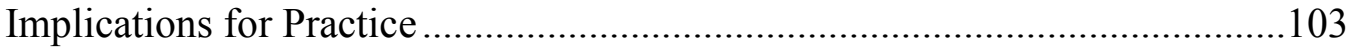

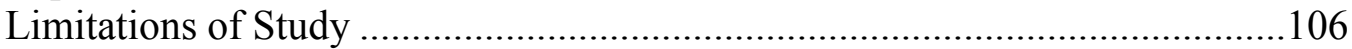

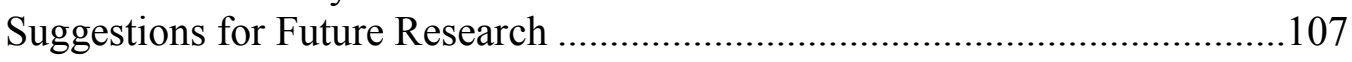

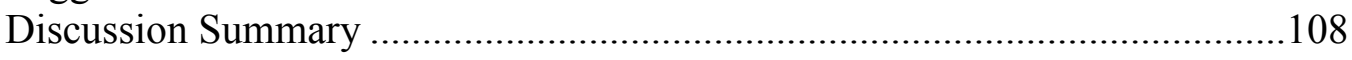

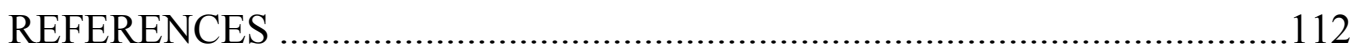

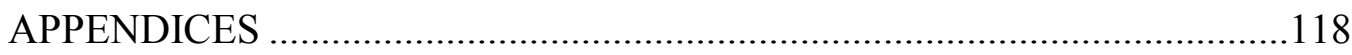

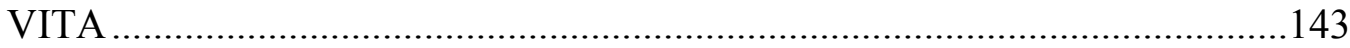




\section{LIST OF TABLES}

TABLE

PAGE

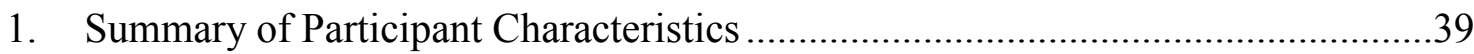

2. Phase I: Phoneme Identity Baseline, Intervention and Maintenance .....................71

3. Phase II: Phoneme Blending and Phase III: Phoneme Segmentation

Generalization Measures From Phase I Conditions ............................................. 73

4. Weekly and Biweekly Maintenance Probes on Phase I Phoneme Identity .............74

5. Phase II: Phoneme Blending Baseline, Intervention and Maintenance...................80

6. Phase III: Phoneme Segmentation Generalization Measures

From Phase II: Phoneme Blending Conditions ................................................ 81

7. Weekly Maintenance Probes on Phase II: Phoneme Blending .............................83

8. Phase III: Phoneme Segmentation Baseline, Intervention and

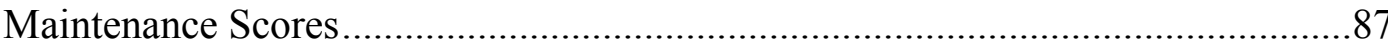

9. Weekly Maintenance Probes on Phoneme Segmentation ..................................8

10. Results of Pre-Study Post-Study Test of the Goldman-Fristoe 2

Test of Articulation 


\section{CHAPTER I}

\section{INTRODUCTION}

Current educational policies including No Child Left Behind (2001) emphasize the need for schools to reorganize in order to identify and implement preventative interventions for children showing early vulnerabilities for reading failure. This initiative has led to the call for evidence-based solutions to reduce disparities among children in their reading achievement. Evidence-based practice involves the integration of the best available research with clinical expertise and client values (Kamhi, 2006; Ratner, 2006). According to Justice (2006), response to intervention, an evidence-based initiative, can offer sustained and intensive preventative interventions during preschool, kindergarten, and first and second grades that can be effective for reducing reading difficulties among children who are at-risk for reading disabilities. The speech-language pathologist can play an important role in preventing reading difficulties for the children they are assigned, as well as for any child who shows sustained difficulties in reading development (Nation, 2005; Whitehurst \& Lonigan, 1998).

Traditionally, the role of the speech-language pathologist has been to support the development of receptive and expressive language including phonology, semantics, morphology, syntax and pragmatics. Most often, the students who they served were removed from their classrooms, and speech-language therapy was provided on a one-onone basis. Speech-language therapy was provided as an adjunct to learning and not in conjunction with learning. The speech-language pathologist had little involvement with the students' general education curriculum, including reading. 
Today, however, speech-language pathologists are becoming more involved in the reading curriculum due, in part, to the results of emerging research. Increasingly, experts understand that reading skills are built on a foundation of spoken language processing (Snowling, 2005), and that an initial delay in speech and language development, if untreated by the age of five, can develop into a disorder that can cause difficulties in learning, including reading (National Dissemination Center for Children with Disabilities, 2004). Literacy researchers are beginning to realize that literacy development including phonological awareness is intertwined with language acquisition from a very young age (Cramer, 2006; Pullen \& Justice, 2003) further reinforcing the need for the involvement of the speech-language pathologist in literacy instruction. The speech-language pathologist's role could include the early identification of reading and spelling problems, and subsequent interventions to prevent academic difficulties these children may otherwise encounter (Gillon, 2004). These may include interventions to improve decoding, syntax, fluency and comprehension difficulties.

In 2001, the American Speech-Language Hearing Association (ASHA, 2001) issued a position statement reporting that speech-language pathologists should play a critical and direct role in the development of literacy for children and adolescents with communication disorders. The speech-language pathologist has knowledge of normal and disordered language acquisition and clinical experience useful to assuming various roles related to the development of reading and writing. The speech-language pathologist who provides therapy to preschool children with speech and language delays could design interventions that address these developmental weaknesses in conjunction with the child's emerging literacy skills. 
Children with phonological speech and/or language impairments are at-risk for delayed acquisition of phonological awareness and reading skills (Bird, Bishop \& Freeman, 1995; Bishop \& Adams, 1990; Catts, 1993; Catts, Fey, Zhang, \& Tomblin, 2001; Larivee \& Catts, 1999; Lewis, Freebairn \& Taylor, 2000). According to Catts et al. (2001), children with a history of speech-language impairment are 4-5 times more likely to have reading problems than children from the general population. These children have poorer performance on word-level reading tasks (Rvachew, Ohberg, Grawburg \& Heyding, 2003), and the severity of the speech sound inaccuracies play a role in predicting reading skills.

The critical age hypothesis states that preschool children's literacy development will be developmentally appropriate if their expressive phonological difficulties have been resolved prior to literacy instruction in kindergarten (Bishop \& Adams, 1990; Larivee \& Catts, 1999; Nathan, Stackhouse, Goulandris, \& Snowling, 2004). This hypothesis suggests the need for early appropriate interventions that target remediation of expressive phonological difficulties while focusing on the development of the child's phonological awareness skills (Gillon, 2005a).

Typical interventions for phonological speech sound disorders have not been sufficient to prevent delayed reading and spelling weaknesses that may persist beyond the elementary school years (Gillon, 2005a; Lewis et al., 2000). This may be because phonological awareness knowledge is only indirectly targeted through articulating sounds in words or perceiving and producing sound contrasts. Current research has found that if developing phonological skills are not related explicitly to the sound structure of spoken language, it may result in insufficiently developed phoneme representations and 
phonemic awareness skills (Gillon, 2004). According to Torgesen (2005), it is possible to help children with core phonological weaknesses acquire the critical foundational skills in phonemic analysis and decoding through explicit, intensive instructional methods. Explicit intervention at the preschool level targeting phoneme awareness and letter knowledge in children with speech impairment can lead to the development of phonological awareness skills that are at least equal to that of their peers without speech impairment at school entry. These results can facilitate the development of accurate speech sound production by establishing more fully specified underlying phonological representations and allowing children to use print cues to self-correct speech errors (Gillon, 2005a).

\section{Purpose of the Study}

There is limited research that evaluates the role of the speech-language pathologist who provides intervention for phonological speech sound delays combined with phonemic awareness (e.g., Roth, Troia, Worthington \& Dow, 2002; Roth, Troia, Worthington \& Handy, 2006). Gillon (2000) studied the efficacy of 20 hours of an integrated phonological awareness/speech sound awareness program for children between the ages of 5 and 7 . The findings revealed that children with speech-language disorders have the ability to make gains in the skills underlying literacy acquisition while improving speech production skills. Few studies have been conducted with preschool children (e.g., Pullen \& Justice, 2003; Van Kleek, Gillam \& McFadden, 1998). Gillon (2005) conducted a 3-year longitudinal study to examine the phonological awareness and early literacy development of 12 preschool children with expressive phonological impairment at 3 years of age. The results indicated that for young children with speech 
impairment (a) phoneme awareness can be stimulated as early as 3 years of age, (b) phoneme awareness development can occur concurrently with improvement in speech intelligibility, and (c) developing phoneme awareness and letter knowledge during the preschool years is associated with successful early reading and spelling experiences. Two studies conducted by Roth et al. (2002) and Roth et al. (2006), investigated the effectiveness of explicit, individualized instruction with preschool children with speech and language disorders. A comprehensive curriculum developed by the authors (Promoting Awareness of Sounds in Speech-PASS) consisting of three independent, consecutive modules to promote rhyming, sound segmentation, and sound blending was used in both studies. The results of both studies demonstrated the effects of explicit, individualized instruction on phonemic awareness skill development of preschool children with speech and language disorders. In these studies, the results indicated that both rhyming and blending modules, when implemented in conjunction with systematic training in the alphabetic principle, were effective approaches to teaching phonological awareness instruction for the preschool children in their samples. In addition, both studies demonstrated little or no substantial improvement in the untrained areas, indicating the need for additional research.

Since $4-6 \%$ of children will not benefit from phonological awareness training (Torgesen, 2002), Roth et al. (2002) and Roth et al. (2006) state that future research should clarify the factors that differentially influence response to intervention. These factors may include the specific phonological awareness skills to be taught, age of the participants when these skills are taught, duration of the intervention, explicitness of the intervention, and the severity of the phonological speech and/or language disorder. 
Additional research is needed to develop the scientific evidence to support highly effective phonemic awareness intervention program, and to evaluate how these interventions impact reading achievement. According to Torgesen (2002), instructional approaches that are more phonemically explicit and intensive have the strongest impact on the reading growth of children at risk for reading disabilities. Yet, there is limited research that has experimentally demonstrated this with children with phonological speech delays. Since children with phonological speech sound delays will most often be delayed in the development of phonemic awareness skills, it is important that the speechlanguage pathologist target both skills explicitly and concurrently. The purpose of this study was to extend the findings of the Gillon studies (2000, 2005a), and determine whether explicit intervention in three phonemic awareness skills administered by a speech-language pathologist assisted children in establishing accurate phonological representations, thereby improving speech intelligibility and phonemic awareness concurrently.

\section{Statement of the Problem}

This study was designed to evaluate the effectiveness of an intensive, explicit intervention by a speech-language pathologist on the abilities of children with phonological speech delays to decode and analyze two-to three-letter words using three phonemic awareness tasks: phoneme identity, phoneme blending and phoneme segmentation. The speech-language pathologists' knowledge of phonology and phonological processing, as well as their training in developing individualized programs based upon each child's strengths and weaknesses, place them in a unique position to provide the appropriate interventions. 
This study extended the work of Gillon (2000, 2005), Roth et al. (2002), and Roth et al. (2006). It is unique in that it investigated a different group of children and varied the design and implementation of the intervention. More specifically, the participants in this study included four preschool age children, while most of the previous research was conducted with children with age ranges 5 to 7 . Unlike previous research studies (e.g., Roth et al., 2002; Roth et al. 2006), participants in this study exhibited normal language skills with the exception of an expressive phonological disorder. The intervention in this study was implemented individually for a short term, whereas in previous research, the intervention was implemented over several years (e.g., Gillon, 2005). All four children in this study received separate individual speech-language intervention one time per week based on their individualized goals (Roth et al., 2002; Roth et al., 2006). Further, the intervention systematically applied phonemic awareness instruction to three phonemic awareness skills (phoneme identity, phoneme blending and phoneme segmentation) for all of the participants. Unlike previous studies, this study investigated the effects of explicit instruction on the generalization and maintenance of phoneme skills. This was accomplished by probing performance in the second and third skill areas (blending and segmenting) while providing explicit instruction in the first skill area (phoneme identity), and by probing performance in the third skill area while providing explicit instruction in the second skill area. Maintenance data were collected weekly and/or biweekly from 3 to 10 weeks after the end of instruction in each phase. No previous work has been conducted with the same children across various skill areas, nor have generalization and maintenance measures been taken as defined in this study. 


\section{Research Questions}

Specifically, this study investigated whether an intervention using short-term intensive training in each of three phonemic awareness skills increased prekindergarten children's accuracy in these skills by investigating the following research questions:

1. Will participants given explicit one-to-one instruction in phoneme identity by a speech-language pathologist increase their accuracy in identifying initial and final phonemes in words on same-day tests?

2. Will participants given explicit instruction in phoneme blending by a speech-language pathologist increase their ability to blend isolated sounds together to read words on same day tests?

3. Will participants given explicit instruction in phoneme segmentation by a speechlanguage pathologist increase their ability to analyze and spell words at the phonemic level on same-day tests?

4. Will explicit instruction by a speech-language pathologist in the first skill area (phoneme identity) result in a generalization of skills to the second area (blending) and third area (segmentation), and will explicit instruction in the first and second areas result in generalization to the third skill area?

5. Will participants maintain phoneme identity, blending, and segmentation skills on maintenance tests given weekly and/or biweekly from 3 to 10 weeks after the end of instruction in each skill?

\section{Delimitations of Study}

The sample size used in single subject design research is small by the nature of the design and therefore limits the generalization of its findings. In order to determine 
the effects of a short-term intensive intervention in three phonemic awareness skills, phoneme identity, phoneme blending, and phoneme segmentation on children with phonological speech sound delays, direct and systematic replications are needed. For example, this study included prekindergarten children from middle class Anglo-American backgrounds. In addition, the children in this study exhibited a delay in phonological awareness accompanied by an expressive phonological speech sound disorder only. There were no accompanying language, hearing, motor or cognitive deficits. Therefore the results may not be generalized to children of different ages or grade levels, different cultural/economic backgrounds, or with other abilities or disabilities.

The intervention was developed by the researcher to develop the three skills, phoneme identity, phoneme blending and phoneme segmentation based upon some commercially available materials (Phonological Awareness Cards, Linguisystems, 2000), decodable books (Wright Group, 2007), and some researcher developed materials. While the participants appeared to enjoy listening and later "reading" the decodable books, and interacting with the materials each day, it is unknown whether other materials would have been more or less effective in teaching these skills.

\section{Chapter Summary}

Current educational policies have emphasized the need to identify and implement preventative interventions for children who appear to show early vulnerabilities for reading failure. Researchers (e.g., Justice, 2006; Torgesen, 1999) have stated that sustained and intensive preventative interventions between kindergarten and second grade can be effective in reducing reading difficulties for at-risk students. Since research has demonstrated that reading skills are based upon a foundation of spoken language 
processing, speech-language pathologists have become increasingly involved in the diagnosis and remediation of reading disorders. Children with phonological speech and/or language disorders are at risk for delayed acquisition of phonological awareness and reading skills. Research is beginning to suggest that interventions for phonological speech sound disorders conducted by speech-language pathologists should be related explicitly to the sound structure of spoken language in order to develop accurate phoneme representations and phonemic awareness skills (Gillon, 2004). However, only a limited amount of research has been conducted to demonstrate this.

The proposed study examined the effects of intensive, explicit instruction in phonemic awareness administered by a speech-language pathologist to prekindergarten children at risk for literacy disorders due to moderate to severe expressive phonological disorders. This study investigated- whether a short term, intensive intervention in three phonemic awareness skills: phoneme identity, phoneme blending and phoneme segmentation increased prekindergarten children's accuracy in these skills.

Generalization measures were probed during the intervention and maintenance measures were taken weekly and in some cases bi-weekly from 3 to 10 weeks after the completion of each intervention.

\section{Definition of Terms}

\section{Articulators}

The articulators are the parts of the oral cavity that are used in speech sound production. The lips, tongue, teeth and larynx (voice box) are considered articulators. 


\section{Evidence Based Practice}

Evidence-based practice refers to the integration of the most widely accepted research with clinical expertise and client values.

\section{Explicit Instruction}

Explicit instruction refers to instruction that is fully and clearly defined.

\section{Expressive Phonological Disorder}

An expressive phonological disorder, often referred to as a phonological speech sound disorder, refers to speech errors that result from some interference with the processing of linguistic information. In this case, the child learns to say (articulate) the speech sound as $\mathrm{s} / \mathrm{he}$ processes the information, or similar to the phoneme representation of the sound in memory. Gillon (2000) refers to this as an under-specified phonological representation.

\section{Generalization}

Generalization is used most often in the applied behavioral literature to indicate behavior changes that occur in nontraining conditions. According to Stokes and Baer (1977), generality occurs when the trained behavior occurs at other times without being taught or retaught. In this study, generalization was measured by probing Phase II:

Phoneme Blending and Phase III: Phoneme Segmentation while the participants were in Phase I: Phoneme Identity. In addition, generalization was measured by probing Phase III: Phoneme Segmentation while the participants were in Phase II: Phoneme Blending.

\section{Maintenance}

Maintenance refers to behavior changes that persist over time. It is the extent to which the learner continues to perform the target behavior after a portion or all of the 
intervention has been terminated (Cooper et al., 2007). In this study, maintenance was measured by administering the same-day test during weekly and biweekly assessments for all three phases after instruction had ended in each phase.

\section{Phoneme}

A phoneme is defined as the smallest unit of sound that influences the meaning of a word. If a phoneme is inserted, deleted or manipulated within a word, the meaning of the word will be altered. In this study, the participants were asked to identify initial and final phonemes, blend phonemes into words, and segment words into their component phonemes.

Phoneme Blending

Phoneme blending refers to the ability to blend phonemes into syllables and words.

\section{Phoneme Identity}

Phoneme identity refers to a child's ability to identify phonemes in words. In this study the participants were asked to identify initial and final phonemes in words.

\section{Phoneme Representation}

Phoneme representation refers to the accuracy (precision) of the speech sound codes (underlying representations) of the sounds within words in the lelcon. Weak phonological representations have been linked to poor phonological awareness and expressive phonological speech disorders. Researchers have speculated that the strengthening of weak phonological representations of lexical items in the mental lexicon might be important for the development of phonological sensitivity and phoneme awareness (Elbro, Borstrom \& Peterson, 1998). 


\section{Phoneme Segmentation}

Phoneme segmentation refers to the ability to segment syllables and words into the component phonemes.

\section{Phonemic Awareness}

Phonemic awareness, the highest level of phonological awareness, refers to the knowledge that words are comprised of individual sounds that can be identified, segmented, blended and manipulated. The three phases of this study, Phase I: Phoneme Identity, Phase II: Phoneme Blending, and Phase III: Phoneme Segmentation are three levels of phonemic awareness.

\section{Phonemic Decoding}

Phonemic decoding refers to the ability to connect phoneme awareness knowledge (sound segments in syllables and words) to the corresponding printed symbols (letters). Research has demonstrated that methods that integrate instruction in letter-sound correspondences in a way that directly links newly acquired phonemic awareness to reading and spelling produce stronger effects on reading than those that do not (Bradley \& Bryant, 1983; Catts \& Kamhi, 1999). Phase II: Phoneme Blending and Phase III: Phoneme Segmentation were taught using letter-sound correspondence.

\section{Phonological Awareness}

Phonological awareness is a subset of phonological processing and refers to an individual's implicit and explicit sensitivity to the sublexical structure of oral language. It is the ability to attend to, reflect on, or manipulate the speech sounds in words.

Developmentally, children are able to demonstrate sensitivity to linguistic units at a lower level of linguistic complexity (words and syllables) before they are able to demonstrate 
sensitivity to linguistic units at higher levels of linguistic complexity (phonemes). An informal assessment based upon the Phonological Awareness Test-2 (Robertson \& Salter, 2007) was used as an eligibility measure. Each participant needed to demonstrate functioning at the level of phonemic awareness to participate in this study.

Phonological Processing

Phonological processing refers to the use of phonological information in processing spoken and written language. It refers to three constructs: phonological awareness, coding phonological information in working memory, and retrieving phonological information from long-term memory (Mody, 2003). Children who have an impaired phonological processing system often exhibit under-specified phonological representations, evident in their omission and substitution of speech sounds (Gillon, 2000; Larivee \& Catts, 1999).

\section{Response to Intervention}

Response to intervention (RTI) is an educational policy and practice that is grounded in the accumulated literature that focuses on how schools might better organize themselves to assess and deliver multi-tiered preventive reading interventions to reduce children's risk for reading disability. Ideally, the multiple tiers of support are administered in the earliest stages of reading development, beginning in prekindergarten or kindergarten. 


\section{CHAPTER II}

\section{LITERATURE REVIEW}

This chapter reviews the research related to the relationship between speech, language and literacy development and the role of phonological processing in literacy development. These reviews are followed by the role of the speech-language pathologist in implementing explicit phonemic awareness intervention in conjunction with speech and language goals to minimize a child's risk of developing a reading disorder. The chapter ends with a summary of the literature related to this study.

\section{Speech, Language and Literacy Development}

Language is based upon the development of phonology, semantics and syntax skills. Deficits in any of these areas will impact on a child's reading development (Catts \& Kamhi, 1999). As a child's language develops, he or she begins to demonstrate a phonological sensitivity that leads to the development of the alphabetic principle, the development of phonemic awareness, and the ability to decode words in text (Silliman, Wilkinson \& Brea-Spahn, 2004; Torgesen \& Mathes, 1998). Some children, and especially children with speech and language deficits, are at an increased risk for developing phonological awareness skills according to developmental milestones (Gillon, 2005a). These children may need explicit instruction in phonological awareness skills in preschool so that they can begin kindergarten with age appropriate skills (Lonigan, Burgess, Anthony \& Barker, 1998). The speech-language pathologists' knowledge of normal and disordered language acquisition combined with their clinical experience 
places them in an excellent position to provide interventions to those children who have not mastered phonological awareness skills.

Most reading and language researchers agree that reading is a language-based skill (Catts \& Kamhi, 1999). Oral language provides the foundation for the development of literacy; this relationship is reciprocal in nature, with interconnections supporting the development of both skills beginning in early childhood (ASHA, 2001). The numerous similarities between spoken and written language are most apparent in the vocabulary and the common structural, prepositional and word knowledge similarities that they share. In addition, auditory attention and memory limitations can influence the ease with which both spoken and written language is processed.

The basic differences between oral and written language are based upon the fact that humans are biologically endowed to learn language (Catts \& Kamhi, 1999). According to Shaywitz (2003), humans are endowed with a genetically determined phonological module that automatically assembles phonemes into words for the speaker and disassembles the spoken word back into its underlying phonemes for the listener. According to this model, spoken language is innate and instinctive; all that is necessary to begin speaking is for humans to be exposed to their native language. In contrast, reading is not a biologically endowed human ability and, therefore, attention, instructional and motivational factors play a central role in learning to read (Catts \& Kamhi, 1999). The human's natural capacity for oral language must be adapted to written language through exposure to and explicit practice with the sound-symbol correspondence rules specific to each language (Mody, 2004; Torgesen \& Mathes, 1998). 


\section{Early Language and Literacy Development}

Language learning is genetically determined and begins at birth. During the first year of life, normally developing babies localize towards sounds and voices, babble and begin to understand their own names and simple expressions. Children normally begin speaking their first words at about one year, and are speaking in short sentences between 18 months and two years of age. Between ages two to three years, children's vocabularies increase exponentially, and their articulation skills are developing so that by age three, they can communicate their thoughts and feelings. Shared storybook experiences further develop children's language and provide an introduction into literacy. Some children who grow up in rich language and literate environments enter school with an advanced understanding of the concepts underlying reading, and in some cases know how to read prior to entering school (Catts \& Kamhi, 1999; Pullen \& Justice, 2003). Other children grow up in homes with minimal language and literacy enrichment, and begin formal schooling at a disadvantage.

The results of a large-scale study that followed kindergarten children through the third grade determined that the literacy achievement gaps present for many children when they enter kindergarten must be effectively closed in the early years of school (Foster \& Miller, 2007). These researchers stress the need for speech-language pathologists to assess emergent literacy skills in their caseloads and to develop appropriate literacy goals that could be taught in conjunction with speech and language goals as a means for reducing potential reading disorders in the future.

Emergent literacy consists of the skills, knowledge and attitudes that are presumed to be the developmental precursors to conventional forms of reading and 
writing. Research has indicated that three emergent literacy factors: oral language development, phonological awareness, and print awareness are associated with later reading achievement (Pullen \& Justice, 2003; Whitehurst \& Lonigan, 1998). Specifically, these areas of emergent literacy represent a significant source of the individual differences in later reading achievement (Lonigan, Burgess, Anthony \& Barker, 2000).

Several aspects of children's oral language skills are important at different points in the process of literacy acquisition. Initially, vocabulary is important. Reading is a process of translating visual codes into meaningful language. In the earliest stages, reading in an alphabetic system that involves decoding letters into their corresponding sounds and linking those sounds to single words in the child's vocabulary. Knowledge of the alphabet and the alphabetic principle in kindergarten are the strongest single predictors of reading success (Catts, Fey, Tomblin \& Zhang, 2002). Later, the child's semantic and syntactic abilities assume greater importance when the child is reading for comprehension. Children's understanding of text and story narratives is further facilitated by the development of decontextualized language, language that is used in written communication to convey novel information (Pullen \& Justice, 2003; Scarborough, 2005; Whitehurst \& Lonigan, 1998).

Emergent literacy development also includes the child's understanding of the conventions of print, emergent reading of environmental print, and linguistic awareness. Linguistic awareness is a developmental metalinguistic skill that involves the ability to discriminate units of language such as words, syllables and phonemes. Normally developing children are able to discriminate among and within these units of language 
during the late preschool period leading to the development of phonological and phonemic awareness skills (Anthony et al., 2002; Whitehurst \& Lonigan, 1998). The Effects of Speech-Language Impairments on Literacy Development

Since reading is language based, children with speech-language impairments are at risk for failures in learning to read. A child's difficulty learning to produce speech sounds may be referred to as an articulation disorder, or a phonological disorder when phonological deviations (e.g., stopping, cluster reduction, etc.) are involved despite no oral motor difficulties. According to Gillon (2004), a phonological disorder refers to speech errors that result from an interference with the processing of linguistic information. Language disorders are impairments in the ability to understand and/or use words in context as a result of reduced vocabulary development, inappropriate grammatical patterns, inability to express ideas, and difficulty following directions. Pullen and Justice (2003) state that children who show early difficulties with the development of vocabulary knowledge and grammatical skills are more likely to experience literacy problems relative to children acquiring oral language according to expected milestones. Many children exhibit combined speech and language deficits. Children with a history of speech-language impairment are 4-5 times more likely to have reading problems than children from the general population, and between $50-70 \%$ of these children present with academic difficulties throughout their school years (Catts et al., 2001; Gillon, 2004).

Specific language impairment (SLI) is a term that is often used in the literature to refer to language abilities that are below normal limits and nonverbal abilities that are within normal limits. This heterogeneous term represents children with both 
receptive/expressive language delays and/or phonological speech sound disorders and has led to confusion regarding the speech/language causality of reading disorders. For example, Bishop and Adams (1990) studied children with speech and language disorders (SLI) and determined that language problems unresolved by 5 years negatively affected reading development. According to these authors, phonological proficiency was not the main determinant of reading acquisition; at age 8.5 years, syntactic and semantic ability were responsible for the major variation in reading ability.

Catts (1993) studied the relationship between speech-language impairments and reading disabilities. Kindergarten children with speech and language disabilities and children with normal speech and language abilities were given a battery of speechlanguage, phonological awareness and rapid naming tests. These children were followed in first and second grades and given tests of written word recognition and reading comprehension. The findings indicated that measures of language ability in kindergarten were closely related to reading comprehension. However, phonological awareness and rapid naming skills were the best predictors of decoding in the first and second grade.

Bird et al. (1995) also examined the relationship between expressive phonology, phonological awareness and reading skills in a two year longitudinal study of children who were aged 5:0 to 7:4 at the onset of the study. The results indicated that when matched with a control group for age and nonverbal ability, the children with SLI demonstrated significantly poorer phonological awareness and reading skills regardless of whether there was an accompanying deficit in oral language skills. According to these authors, the children whose SLI had a phonological basis regardless of the presence of a language disorder were at particular risk for a reading disorder. 
Larrivee and Catts (1999) investigated a group of children with expressive phonological disorders and a group of children with normally developing phonological and language abilities. These children were administered measures of expressive phonology, phonological awareness and language ability at the end of kindergarten. At the end of first grade, these children were given tests of reading achievement. The children with expressive phonological disorders performed significantly below the control group on tests of reading achievement, but some children had a poorer reading outcome than others. For example, the children with expressive phonological disorders were divided into those with good and poor reading outcomes. The children with good reading outcomes performed significantly better on the composite measure of phonological awareness than did those who had poor reading outcomes. The children with poor reading outcomes had more severe expressive phonological disorders, poorer phonological awareness, and weaker language skills.

According to Bishop and Adams (1990), the discrepancy regarding the effects of a child's phonological speech sound disorder on reading ability can be explained by the "critical age hypothesis." According to this hypothesis, children who have speech difficulties that persist to the point at which they need to use phonological awareness skills for learning to read are at high risk for reading problems. In contrast, children whose speech difficulties resolve before this age will be at low risk of reading difficulties unless it is combined with a language disorder (Catts et al., 2002; Lewis et al., 2000). Nathan et al. (2004) tested the "critical age hypothesis" developed by Bishop and Adams (1990). The group consisted of 47 children from ages 4 to 7 years. These children were grouped into three groups: 19 children had speech difficulties, 19 children had speech and 
language difficulties, and 19 children had no speech or language difficulties. The findings indicated that the risk of literacy difficulties was greatest for the children with combined speech and language difficulties. However, in support of the "critical age hypothesis," the children whose speech was still poor at age 6.9 performed worse on reading, spelling and phonological awareness tests than their matched controls. In other words, the timing of remediation of the phonological speech sound disorder determined whether it would affect the development of the child's phonological awareness and reading development.

Rvachew et al. (2003) examined two groups of preschool children (4 years old) with age appropriate receptive vocabulary skills to determine whether an expressive phonological disorder alone in the absence of a language component can affect reading development. The findings support a relationship between expressive phonological skills and phonological awareness abilities, independent of the child's language skills. In another study, Rvachew, Chiang, and Evans (2007) examined the characteristics of speech errors produced by children in preschool and kindergarten with and without delayed phonological awareness skills. Their findings revealed that it was not any particular speech sound error patterns that affected phonological awareness ability, but rather that the children who achieved age appropriate articulation skills by the end of kindergarten, also achieved age appropriate phonological awareness skills. These researchers recommend that children who enter kindergarten with delayed articulation skills should be monitored to ensure age appropriate acquisition of phonological awareness skills.

Raitano, Pennington, Tunick, Boada and Shriberg (2004) examined the preliteracy skills of subgroups of children with speech sound disorders. The findings indicate that 5- 
to 6-year-old children with phonological speech sound disorders as a group performed worse that control participants on pre-literacy skills even if the disorder was normalized. In addition, the persistence of the speech sound production errors and the presence of a comorbid language impairment are additive in nature, with even greater potential effects on reading development. A recent study demonstrated that adolescents with persisting speech sound disorders, especially for the /s, $\mathrm{z}, \mathrm{r}$ and $\mathrm{l} /$ sounds may also exhibit a risk factor for phonological processing disorders (Preston \& Edwards, 2007).

\section{Summary of the Effects of}

Speech-language Impairments on Literacy Development

The findings of research on the effects of a speech and/or language impairment on the development of literacy are mixed. Some research indicates that expressive phonological speech sound disorders are not a risk factor unless they are accompanied by a language disorder (e. g., Bishop \& Adams, 1990; Catts, 1993), while other research suggests that moderate to severe expressive phonological delays are associated with delays in the acquisition of phonological awareness and/or reading skills (e. g., Bird et al., 1995; Larivee \& Catts, 1999; Preston \& Edwards, 2007; Raitano et al., 2004; Rvachew et al., 2005). Taken together, these studies suggest that children with more severe expressive phonology difficulties, especially those that persist to the time when formal reading instruction begins, will be delayed in the development of linguistic awareness leading to difficulties in both phonological awareness and reading. The results of these studies suggest that preschool children with delayed expressive phonological abilities should be screened for their phonological awareness skills even when their language skills are otherwise normally developing. If deficits in phonological awareness 
could be identified during the preschool period, intervention that targets both remediation of expressive phonological errors and phonological awareness could be provided earlier with the potential for developing fully specified phonological representations and preventing delayed acquisition of reading skills at school entry.

The Role of Phonological Processing in Literacy Development

Phonological processing refers to the use of phonological information in processing spoken and written language. There are three types of phonological processing skills: phonological awareness, phonological memory, and rapid automatized naming (Catts \& Kamhi, 1999). Children who have an impaired phonological processing system often exhibit under-specified phonological representations in memory (Elbro et al., 1998), evident in their difficulty acquiring phonological awareness skills, speech sound development, and ultimately reading and spelling (Gillon, 2000; Larivee \& Catts, 1999). A phonological speech sound disorder is a result of a weak representation in memory and/or a difficulty accessing this representation and properly sequencing the speech sounds to produce intelligible speech (Gillon, 2004; Sutherland \& Gillon, 2005). Reading disorders, including dyslexia, can also be traced to weak or poorly specified underlying phonological representations. Poor readers store words in their working memory as underspecified representations that interfere with their phonological processing of speech sound, morphology and vocabulary development (Boada \& Pennington, 2006; Manis \& Keating, 2005; Mody, 2003). In contrast, fluent readers draw on phonological awareness skills to access fully specified representations that are well-coded in articulatory detail, enabling them to sound out words. Carroll and Snowling (2004) compared 17 children (ages 4 to 6) with speech difficulties to 17 children with a family history of dyslexia and 
found that both groups of children showed deficits in the development of phonological representations.

Phonological awareness, a subset of phonology and linguistic theory, refers to an individual's awareness of the sound structure or phonological structure of a spoken word that occurs developmentally with the growth of oral language (Gillon, 2004). It is a metalinguistic ability that enables children to think about language as an object of thought separate from word meaning (Schuele \& Boudreau, 2008). Phonological awareness is the ability to attend to and make judgments about the general sound structure of language. It is a developmental skill; children are able to demonstrate sensitivity to linguistic units at a lower level of linguistic complexity before they are able to demonstrate sensitivity to linguistic units at a higher level of linguistic complexity. Earlier skills developmentally include dividing words into syllables, followed by identifying and generating rhymes and phoneme identity. A more complex-level skill, the ability to isolate and manipulate individual phonemes is referred to as phonemic awareness. A large scale study (Anthony et al., 2002) with 149 older preschool children (ages 4 to 5) and 109 younger preschool children (ages 2 to 3 ) indicated that children's sensitivity to words, syllables, rhymes, onset and rimes, and phonemes represent a single, underlying phonological ability. In addition, children were able to demonstrate sensitivity to linguistic units at lower levels of linguistic complexity (words and syllables) before they were able to demonstrate sensitivity to linguistic units at higher levels of linguistic complexity (phonemes). In a later study, Anthony, Lonigan, Driscoll, Phillips and Burgess (2003) supported a developmental model of phonological awareness, but added that children acquire these skills in overlapping rather than temporally discrete stages. 
Early research determined that the development of phonological awareness combined with instruction in the alphabetic principle significantly increased reading and writing ability. In a classic study, Bradley and Bryant (1983) investigated whether phonological awareness ability in preschool influenced later reading and spelling success. A significant relationship was found between scores on the preschool phonological awareness measure and scores on standardized reading and spelling tests 3 years later. Other researchers reported similar findings. For example, it has been demonstrated that preschoolers' and kindergarteners' performance on phonological awareness tasks, particularly phonemic awareness tasks, is the single best predictor of their first and second grade decoding skills (Roth, Speece \& Cooper, 2002; Scarborough, 2005; Torgesen, Wagner, \& Rashotte, 1994). Catts et al. (2001) reported that second-grade children with poor reading skills were four to five times more likely to have had problems in phonological awareness and rapid automatized naming in kindergarten than were second graders who were good readers. These researchers studied 604 children from kindergarten through second grade and indicated that five kindergarten variables (letter identification, sentence imitation, phonological awareness, rapid naming, and mother's education) uniquely predicted reading outcomes in second grade (Catts et al., 2001).

According to Torgesen (2002), the primary goal and the central issue for children with phonological awareness deficits should be to increase the efficiency with which they identify words in text. Increased phonological awareness combined with letter knowledge leads to increased reading fluency and improvements in reading comprehension (Snowling, 2005). 
In one of the first phonological awareness intervention studies, Ball and Blachman (1991) placed kindergarten children in one of three groups. The first group consisted of training in phonological awareness and letter names and sounds, the second group received training only in letter names and sounds, and the third group received no intervention. The findings indicated that phoneme awareness instruction combined with instruction in the alphabetic principle significantly improved the early reading and spelling skills of the children in the first group compared to the children in the other two groups. Another study by Qi and O'Connor (2000) placed 61 low-skilled kindergarteners in one of two strategy groups. Each group received 20-30 minutes of training twice a week for 10 weeks in either segmenting and blending, or first sound identification and rhyming. In both tasks, the intervention included training in letter names and sounds. Both treatment groups significantly improved their phonological awareness skills and letter knowledge. It appears that children who learn to connect phoneme awareness instruction and the sound segments in words to their corresponding printed symbols almost invariably become better readers than those who have difficulty acquiring these skills (Bradley \& Bryant, 1983; Qi \& O’Connor, 2000; Torgesen, 1998, 2002).

Torgesen (2002) studied the relative effectiveness of three instructional approaches on 180 kindergarten children who were in the bottom $12 \%$ in phonological processing skills. These children received 88 hours of one-to-one instruction from the second semester of kindergarten and extending through the second grade. The four groups consisted of the phonological awareness plus synthetic phonics condition, the embedded phonics condition, the regular classroom support condition, and a no treatment 
group. The most phonemically explicit condition produced the strongest growth in word reading skills, with scores in the middle of the average range for all children.

Torgesen (1998) suggests that it is possible to maintain critical word reading skills of most children at risk for reading failure at roughly average levels if phonemically explicit and intensive intervention is provided beginning some time during kindergarten or first grade. The National Reading Panel (2000) concurs with Torgesen (1998) and recommends early identification and remediation of phonological awareness deficits because their findings demonstrate that once a child falls behind, the success rate of remediation is low. The ability to identify and remediate deficient skills early on does not guarantee that the child will not need additional help later on, however the longer it takes to provide the proper remediation, the more likely we are moving from a preventative to a remedial model of intervention (Torgesen, 1998, 2002, 2005).

\section{Summary of the Role of Phonological Processing in Literacy Development}

Children with an impaired phonological processing system often exhibit underspecified phonological representations that lead to difficulty acquiring phonological awareness skills, speech sound accuracy, and reading development. Phonological awareness is a developmental linguistic skill that measures a child's sensitivity to the sound structure of language. Research has demonstrated that explicit instruction in phoneme awareness combined with the alphabetic principle in kindergarten and first grade has led to significantly improved early reading and spelling skills (Ball \& Blachman, 1991; Qi\& O’Connor, 2000; Torgesen, 2002). 
The Role of the Speech-Language Pathologist in

Phonemic Awareness Interventions

Previous research has demonstrated that children with speech-language

impairments are at an increased risk for the development of phonological awareness and reading disabilities (Larivee \& Catts, 1999; Raitano et al., 2005; Rvachew et al., 2003). Phonological awareness intervention studies have been conducted with children in the elementary school grades (Ball \& Blachman, 1991; Qi\& O’Connor, 2000; Torgesen et al., 1994. However, there are only a limited number of studies that measure the efficacy of phonological awareness intervention specifically for young children with speechlanguage impairments (Gillon, 2000).

Van Kleeck et al. (1998) studied the effects of a classroom-based phonological awareness treatment program on 16 preschool children with speech and/or language disorders. The children received instruction for 15 minutes twice a week for two semesters and focused on rhyming during the first semester and phoneme awareness during the second semester. These children were compared with a non-treatment group of older students who had speech and/or language disorders. The results revealed that preschool children with speech and/or language disorders made significant improvement in rhyming and phoneme awareness. The authors recommend the inclusion of phonological awareness training, especially phoneme awareness training into an intervention program for 4- to 5-year-old children with speech and/or language disorders.

Gillon (2000) investigated the efficacy of an integrated phonological awareness intervention approach for children with spoken language impairment (SLI) who demonstrated early reading delay. The study's first goal was to investigate the effects of 
20 hours of phonological awareness intervention provided by a speech-language pathologist on the phonological awareness ability of 61, 5- to 7-year-old children with speech and language disorders, and to observe any transfer effects to word recognition and reading comprehension. The second goal of this study was to investigate whether a phonological awareness intervention had a direct effect on the child's speech production abilities. The 61 children in this study were divided into three groups. The first group received 20 hours of integrated phonological awareness intervention including lettersound knowledge and speech sound instruction, the second group received traditional speech and language therapy, and the third group received minimal intervention. In addition, a group of 30 normally-developing children without speech-language impairments served as the control group. The results revealed that an integrated phonological awareness intervention approach had a significant effect on improving phoneme awareness, speech production, reading accuracy and reading comprehension skills of children with speech and language disorders. These findings suggest that children with speech and language disorders have the potential to make accelerated gains in the skills that underlie successful literacy acquisition while simultaneously demonstrating improvement in their speech production skills. Explicit phoneme awareness and knowledge of grapheme-phoneme relationships may assist children in establishing accurate phonological representations. Becoming consciously aware of the number and order of phonemes in a word can help the child realize the breakdown in his or her communication attempt and provide cues to repair that attempt.

In a follow up to this study, Gillon (2002) re-evaluated the children who had participated in the previous study, 11 months post-intervention. These results suggested 
that the integrated phonological awareness intervention administered in the previous study led to sustained growth in phoneme awareness, and these students were reading at, or above the level expected for their age on a measure of word recognition 11 months later.

Gillon (2005a) investigated whether early phonological awareness can be stimulated in children with phonological speech impairments during their preschool years (ages 3 to 5) when these children frequently receive therapy to improve speech intelligibility. The purpose was to determine whether intervention in early phonological awareness development could help prevent the reading and spelling difficulties that many children with speech impairment experience. The children in the experimental group consisted of 12 preschool (age 3 years) children with speech impairment. The control group consisted of 19 children with normally developing speech and language skills. Both groups of children continued in their regular preschool education program but did not receive individualized speech therapy. The development of all children was monitored from initial assessment through their first or second year at school. The results of this study demonstrated that the experimental group of children with speech impairment showed accelerated growth in phoneme awareness and letter knowledge as compared to the control group with typical development. At age 5, when the children started formal literacy instruction, there was no significant difference between children with or without speech impairment in phonological awareness skills at the syllable, onsetrime, or phoneme level. In addition, these results also demonstrate that early phoneme awareness and letter knowledge when combined with intervention to improve speech sound production can result in both skills improving concurrently. The children with 
speech impairment who participated in the experimental intervention were reading at or well above their expected reading age in the first few years of school as compared to a group of children with speech sound impairments who received speech therapy without combined phonological awareness and letter-knowledge intervention.

In a follow-up of this study, Kirk and Gillon (2007) demonstrated that the children with a history of speech impairment who participated in the experimental group (Gillon, 2005a) performed significantly better on non-word decoding and on the spelling of morphologically complex words than did children with a history of speech impairment whose intervention focused on speech remediation alone. The children in the experimental group demonstrated an ability to use morphological awareness in the spelling process that was similar to that of their peers without speech impairment. These studies (Gillon, 2005; Kirk \& Gillon, 2007) demonstrate the positive effects of early intervention (as young as 3 and 4 years of age) on early reading development and positive growth in spelling morphologically complex words.

Roth et al. (2002) and Roth et al. (2006) developed an intervention program for preschool children based upon the premise that early, explicit instruction in phonological awareness can be beneficial for children with speech and language impairments. The program, entitled Promoting Awareness of Sounds in Speech (PASS), was developed to build upon the existing approaches to phonological awareness instruction by providing a comprehensive curriculum for speech and language impaired preschoolers with detailed lessons and specific learning objectives ordered in a developmental sequence. PASS consists of three independent training modules that were created to promote rhyming, sound blending and sound segmentation capabilities in conjunction with systematic 
training in the alphabetic principle. In the first study, Roth et al. (2002) measured the efficacy of the rhyming portion of the PASS program for 8 children between the ages of 4 and 6 years with varying levels of speech and/or language competence who attended a university preschool program for children with communication disorders. The children participated in three half-days of classroom instruction and three, 30-minute individual treatment sessions per week for 6-8 weeks administered by speech-language pathologists. The results indicated that all children made substantial improvement in their rhyming ability without demonstrated improvement in the untrained areas. Roth et al. (2006) conducted a second study to measure the effects of the blending module on 11 children with speech and/or language delay between the ages of 4 and 6 years old. Again, each child participated in three half-days of classroom instruction and three 30-minute individual treatment sessions per week for 6-8 weeks administered by a speech-language pathologist. After intervention, all children demonstrated substantial improvement in their blending ability with little or no substantial improvement in the untrained areas.

These studies further support the role of the speech-language pathologist in monitoring and providing intervention to support the development of articulation and phonological awareness at the preschool level.

Summary of Phonemic Awareness Intervention Research on Children with Speech-Language Impairments (SLI)

A limited number of research studies have demonstrated the positive effects of phonological awareness intervention for preschool (and young elementary) children administered by a speech-language pathologist (e.g., Gillon, 2000, 2005; Roth et al., 2002; Roth et al., 2006; Van Kleeck et al., 1998). The children who received instruction 
in the most explicit conditions appeared to demonstrate the largest gains, along with improvement noted in phonological speech sound development.

In 2001, the American Speech-Language-Hearing Association (ASHA, 2001)

issued a position statement that speech-language pathologists should play a critical and direct role in the development of literacy for children and adolescents with communication disorders. The professional roles of speech-language pathologists include prevention, assessment and intervention of reading disorders in children.

The current amendments of The Individuals with Disabilities Education Improvement Act (2004) endorse Response to Intervention as an evidenced-based initiative that features research based assessment procedures and multiple tiers of preventative reading interventions beginning in the earliest stages reading development. Justice (2006) states that speech-language pathologists can best serve their students and other at-risk students by helping to design and deliver multi-tiered assessments and preventive reading programs from preschool onward. It is critical to design and implement phonological awareness interventions that are explicit and draw on best practice evidence to date (Schuele\& Boudreau, 2008). Research has demonstrated that sustained and explicit supplemental interventions in phonological awareness are needed to accelerate the reading growth of struggling readers (Torgesen, 1999). Speech-language pathologists that provide sustained and explicit pre-referral activities in phonological awareness through collaboration with teachers and reading specialists will ultimately reduce the number of students requiring special education services in reading (Justice, 2006). 


\section{Chapter Summary}

This chapter provided a review of the research in the areas of speech, language and literacy development, the role of phonological processing in literacy development, and the role of the speech-language pathologist in implementing phonemic awareness intervention. Research has demonstrated the relationship between language and literacy development. Oral language development is the basis for literacy development, and literacy development supports the continued development of oral language. The basic differences between speaking and reading are based upon the fact that humans have a natural capacity for speaking, and reading requires exposure and practice with the sound symbol correspondence rules specific to each language (Mody, 2004).

Children who exhibit speech and language deficits are at-risk for difficulties when learning to read. Recent research has demonstrated that a child with moderate to severe phonological speech sound disorders will be at risk for reading disabilities independent of the child's language skills. The presence of a language disorder is additive in nature, with even greater potential effects on reading development (Raitano et al., 2004; Rvachew et al., 2003). Children with phonological speech sound impairments are at increased risk for the development of phonological awareness skills due to the presence of under-specified phonological representations that affect the development of speech, reading and spelling skills (Elbro et al., 1998; Gillon, 2000; Larivee \& Catts, 1999).

Numerous studies have demonstrated the relationship between phonological awareness, letter-sound instruction and developing literacy skills. Kindergarten children with delayed phonological awareness skills were found to exhibit poor reading skills in second and third grades (Bradley \& Bryant, 1983; Catts et al., 1999). Although 
phonological awareness intervention studies have been conducted with children in the elementary school grades (Ball \& Blachman, 1991; Qi \& O’Connor, 2000; Torgesen et al., 1999), few studies have measured the efficacy of phonological awareness intervention specifically for young children with speech-language impairments (Gillon, 2000). In several studies, Gillon $(2000,2002,2005)$ demonstrated that children who received integrated phonological awareness intervention reached sustained levels of performance in phonemic awareness and early literacy skills similar to children with typically developing speech and language skills, while also improving their child's speech sound development. The Roth et al. (2002) and Roth et al. (2006) studies demonstrated the effectiveness of explicit, individualized instruction in rhyming and blending with preschool children.

The present study extended the work of Gillon $(2000,2005)$ and Roth et al. (2002) and Roth et al. (2006) by employing an individualized short-term, explicit and systematic intervention to teach three phonemic awareness skills (phoneme identity, phoneme blending and phoneme segmentation) to four prekindergarten children with expressive phonological speech sound disorders. In addition, each auditory task was linked to the letter(s) that represent each sound to encourage phonemic decoding (Torgesen, 1999). This study concurrently administered speech sound intervention along with explicit and systematic phonemic awareness intervention by a speech-language pathologist in order to prevent or minimize reading delays at school entry. 


\section{CHAPTER III}

\section{METHOD}

This study investigated whether a short-term intensive intervention in each of three phonemic awareness skills, phoneme identity, phoneme blending and phoneme segmentation, increased the accuracy of these skills in prekindergarten children with expressive phonological delays. In addition, this study examined the maintenance and generalization of these skills.

This chapter presents information about the study's participants, setting, and materials. The dependent variables are identified and defined. This is followed by a description of the experimental design used in this study. The general procedures section details the steps taken prior to and during the course of the study. This chapter concludes with a summary.

\section{Participants}

The participants consisted of four prekindergarten children, two boys and two girls, with chronological ages between 4 years, 7 months, and 5 years at the study's outset (see Table 1). Initial screening for potential participants was initiated during an annual speech and language-screening program that occurs each school year at a private nursery school program in the West Broward County in Southern Florida. Parental consent was required to participate in the study (see Appendix A). During the fall of their prekindergarten year, each potential participant was administered eligibility testing.

Several formal and informal assessments were given to determine eligibility and to determine background information for each participant (see Appendices C and D). 
First, a hearing assessment comprised of a screening audiogram and tympanogram was given to establish hearing ability. An audiogram measured hearing acuity and a tympanogram measured middle ear function. Eligibility tests revealed hearing and oral motor skills within normal limits for all participants as assessed by the researcher. Visual acuity was informally measured by the participants' ability to correctly match and identify letters and pictures. All participants exhibited normal visual acuity.

The Goldman-Fristoe 2 Test of Articulation (GFTA-2) was administered to identify the participants who exhibited a phonological speech delay that placed them at or below the 21st percentile. The Peabody Picture Vocabulary Test-4 (Form A) was administered to assess receptive vocabulary skills. The selected participants exhibited receptive vocabulary development at or above their chronological age expectations (see Table 1). An informal phonological awareness measure based upon the Phonological Awareness Test-2 (Robertson \& Salter, 2007) was administered to each participant. As a result of this assessment, all participants exhibited more than 50\% knowledge of the 26 letters of the alphabet (upper and lower case). Their knowledge of graphemes (the lettersound connection) varied from $6 / 33$ to $22 / 33$. In addition, the participants scored at or below the 50th percentile on the phoneme portion of the blending and segmentation sections. In sum, to be eligible, each participant needed to exhibit a phonological speech sound disorder, and normal receptive language, vision, hearing and oral motor skills. Each participant also had knowledge of at least $50 \%$ of letter identification (upper and lower case letters), and less than 50\% performance on blending and segmenting two- and three-letter words on an informal phonological awareness assessment. At the end of the study, the Goldman-Fristoe 2 Test of Articulation was readministered to all participants. 
A description of each participant and a summary of their characteristics can be found in

Table 1.

Table 1

Summary of Participant Characteristics

\begin{tabular}{cccccc}
\hline Participant & Gender & Age & Grade & $\begin{array}{c}\text { Articulation } \\
\text { Development } \\
\text { Percentile }\end{array}$ & $\begin{array}{c}\text { Vocabulary } \\
\text { Recognition Age }\end{array}$ \\
\hline 1 & F & 4 yrs, 8 mo. & PK & 13 th & $\begin{array}{c}8 \mathrm{yrs}, 5 \mathrm{mo} \\
99 \%\end{array}$ \\
2 & M & 5 years & PK & 12 th & $\begin{array}{c}7 \mathrm{yrs}, 4 \mathrm{mo} \\
91 \%\end{array}$ \\
3 & M & 4 yrs, 7 mo. & PK & $21 \mathrm{st}$ & $\begin{array}{c}5 \mathrm{yrs}, 11 \mathrm{mo}, \\
87 \% \\
5 \mathrm{yrs}, 1 \mathrm{mo} \\
61 \%\end{array}$ \\
\hline
\end{tabular}

Note. Each participant's receptive vocabulary was measured by the Peabody Picture Vocabulary Test-IV. This standardized test provides age equivalencies and percentiles.

\section{Participant 1}

Participant 1 was 4 years, 8 months old at the beginning of this research study (B.D. 04/23/04). She was a student in a traditional private prekindergarten classroom with 16 children in the class. She has attended this same preschool since she was been 2 years old. Participant 1 was initially identified as a possible participant during the speech, hearing and language-screening program in the fall of 2008. Articulation testing (GFTA2) revealed articulation development at the 13th percentile as compared with all children in her age group. Vocabulary development was in the 99 percentile with an age equivalency of 8 years, 5 months. Participant 1 identified all upper and lower case letters and 22 out of a possible 33 graphemes. She was able to indentify $8 / 10$ initial sounds in words, and 7/10 final sounds in words. She was able to blend 3 out of a possible 10 
words. Participant 1's parents identified some difficulties with word retrieval, and speech production. Hearing, vision, and oral motor skills were found to be within normal limits. Participant 1 received no prior speech therapy intervention. Speech therapy for Participant 1 focused on the /s/,/s blends/, /z/, /th/, /r/, /r blends/ and vocalic /r/ sounds. Participant 2

Participant 2 was 5 years old at the beginning of this research study. He was a prekindergarten student in a traditional private prekindergarten classroom with 15 children in the class. Participant 2 had attended this same preschool since he was 2 years old. He was originally identified as a possible participant during the speech, hearing and language-screening program in the fall of 2008. Articulation testing (GFTA-2) revealed articulation in the 12th percentile compared with all children in his age group. Vocabulary testing placed participant 2 in the $91 \%$ with an age equivalency of 7 years, 4 months. Participant 2 was able to identify 22 out of 33 graphemes. He was able to identify $5 / 10$ initial sounds in words, and no final sounds in words. He was unable to segment any words into sounds and was able to blend the sounds in 2 out of a possible 10 words. Hearing, vision and oral motor skills were within normal limits. Participant 2's parents identified difficulties with speech production and perception. Participant 2 receives occupational therapy for weak body tone (trunk), and fine motor difficulties. There was no prior speech therapy intervention. Speech therapy for Participant 2 focused on remediation of the $/ \mathrm{sh} /, / \mathrm{ch} /, \mathrm{j} /, / 1 /$, and $/ 1$ blends/. 


\section{Participant 3}

Participant 3 was 4 years 7 months at the beginning of this research study. He was a student in a traditional private prekindergarten classroom with 16 children in the class. Participant 3 has been a student at Preschool A since he was 2 years old. At that time he was identified as a child with speech and language delays, and has received speech and language therapy from this researcher since the age of 2. Initially therapy focused on language and speech delays. Once language skills were deemed to be age appropriate, this last year focused only on phonological speech sound delays. Participant 3 also received occupational therapy for sensory integration and fine motor weaknesses. He was chosen for this study because he met the criteria for inclusion in this study. Articulation testing (GFTA-2) revealed articulation in the 21 th percentile compared with all children in his age group. Vocabulary testing placed participant 3 in the $87 \%$ with an age equivalency of 5 years, 11 months. Participant 3 was able to identify 22/26 letters (upper and lower case). He was able to apply the alphabetic principle (the letter/sound connection) for 16 out of a possible 33 graphemes. He was able to identify $4 / 10$ initial sounds in words, and no final sounds in words. He was unable to segment any words into sounds $(0 / 10)$ and was unable to blend sounds into any of a possible 10 words. Hearing, vision and oral motor skills were within normal limits. Speech therapy for Participant 3 focused on the /s/, /z/, /th/, /j/, /ch/ and /1 blends/.

\section{Participant 4}

Participant 4 was 4 years and 10 months old at the beginning of this research study. She was a prekindergarten student in a traditional private prekindergarten classroom with 15 children in the class. Participant 4 had attended the same preschool 
since she was 2 years old. She was originally identified as a possible participant during the speech, hearing and language-screening program in the fall of 2008. Articulation testing (GFTA-2) revealed articulation in the 18th percentile compared with all children in her age group. Vocabulary testing placed Participant 4 in the $61 \%$ with an age equivalency of 5 years, 1 month. Participant 4 was able to identify 24/26 upper and lower case letters. She was able to apply the alphabetic principle (letter/sound connection) to 6 out of 33 graphemes. She was able to identify $2 / 10$ initial sounds in words, and 1/10 final sounds in words. She was unable to segment any words into sounds $(0 / 10)$. She was unable to blend 2-3 sounds together in any of a possible 10 words. Hearing, vision and oral motor skills were within normal limits. Participant 4's parents reported that in addition to the speech sound delay, their daughter appears to have difficulty learning sound-letter correspondences. Participant 4's twin brother has autism and because of this, they are less able to devote the necessary time to address her needs. Speech therapy for Participant 4 focused on the / s/, /s blends/, /z/, and /th sounds/.

\section{Setting}

The setting was the researcher's office for speech and language therapy in a preschool located in the West Broward area of South Florida. In each instance, the study took place in the same small, private room with minimal distractions. During all one-toone assessment and intervention procedures, participants were placed across a child-sized table from the researcher. Phonological speech sound intervention (speech therapy) occurred each Friday, one day a week for each child. Additional phonemic awareness intervention sessions were held 4 days a week, from Monday through Thursday, for 30 minutes each at approximately the same time each day (between the hours of 10 a.m. and 
noon). The researcher was responsible for conducting all of the assessment and instructional sessions.

\section{Materials}

The following is a description of materials that were used in the study. Pre-study materials included consent forms, checklists, standardized test forms, audiometer and oral motor and vision screening forms. Intervention materials included score sheets, phoneme identity cards, worksheets, picture cards for sound matching and sound blending,

articulation decks, wipe-off boards for writing words, single color blocks, consonant and vowel letter tiles, an Elkonin box separated into four spaces and printed on laminated paper, and decodable reading books. An example of all forms and a description of all materials can be found in Appendices A-K.

Parental Consent Form

Parents were provided with a consent form for their child to participate in the study. The form described the goals of the research, and the amount of time each week spent on the intervention and speech therapy sessions. In addition, researcher contact information was included on the form (see Appendix A).

\section{Parent Checklist}

Parents were asked to complete the Early Identification of LanguageBased Reading Disabilities: A Checklist (Catts, 1997). This checklist gave the researcher additional information about each participant that was used in the Results and Discussion sections of this study (see Appendix B). 


\section{Standardized Tests and Test Forms}

The standardized tests and test forms from The Goldman-Fristoe 2 Test of Articulation, and the Peabody Picture Vocabulary Test-4 (Form A), and an informal measure of phonological awareness based upon the Phonological Awareness Test-2 were used for eligibility measures (see Appendix C). The Goldman-Fristoe 2 Test of Articulation was readministered at the end of the study to assess growth in phonological speech sound development.

Oral Motor, Hearing, and Vision Assessment

A Maico MI24/MI26 Audiometer with generated printed results for the screening audiograms and tympanogram were used. Oral motor skills and visual acuity skills were assessed using informal measurements (see Appendix D). Baseline, Intervention, and Same-Day Test Materials

The materials used included same color one inch cubes, wooden letter tiles, Phonological Awareness Cards (Flahive \& Lanza, 2004), picture cards, worksheets, and wipe-off boards for writing words. An Elkonin box with three spaces printed and laminated was used along with decodable books (The Wright Group, 1999), paper and markers (see Appendix E).

Phase Score Sheets

Procedure sheets were used for scoring performances during same day tests, generalization, and maintenance tests. The same form was used across all three phases (see Appendix F). 


\section{Data $\log$}

Individual data logs were kept for each participant to keep track of the data. The data log was also used to supply data in order to graph each participant's performance on phoneme identity, blending, and segmentation (see Appendix G). Interobserver Agreement Form and Treatment Integrity Checklists

The Phase Score Sheets were used to compare scores obtained by the researcher with those of the independent rater (see Appendix F).The independent rater was a trained part-time receptionist at the children's preschool. A treatment integrity checklist was used to maintain procedural reliability (see Appendix H).

\section{Procedures}

This section reviews the overall procedures used to conduct the research. Included is a description of the prestudy permission and assessment procedures, general procedures related to the three phases of the study, specific procedures used in each of the three phases, and procedural details of how generalization and maintenance probes were taken.

Pre-study Permission and Assessment Procedures

Prior to beginning the study, parents of potential participants identified through an initial screening were mailed a permission form to sign (see Appendix A). This form described the goals of the intervention and the amount of time to be spent each week on the intervention and speech therapy sessions. Upon return of the signed permission forms, parents and teachers were asked to complete the Early Identification of Language-Based Reading Disabilities: A Checklist (Catts, 1997). This checklist gave the researcher additional information about each participant (see Appendix B). This checklist was sent 
to each home and reviewed with this researcher by telephone, so that any questions or concerns regarding the responses were discussed.

The researcher administered the eligibility measures, intervention procedures, and assessments (see Appendices C \&D). Each participant received a hearing assessment comprised of a screening audiogram and tympanogram. Oral motor and vision skills were informally assessed and scored. The Goldman-Fristoe Test of Articulation was used to assess phonological speech sound development as an eligibility measure and at the end of the intervention to measure speech sound development throughout the period of time of the study. The Peabody Picture Vocabulary Test-4 (Form A) was used to assess receptive vocabulary skills, and an informal assessment based upon the Phonological Awareness Test-2 was used to assess phonological awareness skills.

Research Procedures

This research had three distinct studies referred to as phases: phoneme identity (Phase I), phoneme blending (Phase II), and phoneme segmentation (Phase III). Each phase was its own study and included a baseline condition, an explicit instruction condition, and a same-day test. Once instruction was completed for each of the four participants in the first phase, each participant moved independently to the second phase, and then the third phase. The researcher developed each phase's intervention based on research by Gillon $(2000,2005)$ and Roth et al. (2002) and Roth et al. (2006). Each 30minute study session occurred at approximately the same time each day 4 days per week (between 10 a.m. and noon). The research lasted 17 weeks including the maintenance measurements. 
Probes were conducted on the phases that had not yet received explicit instruction to determine whether generalization of learning occurred. The term generalization refers to behavior changes that occur in conditions where no training has occurred. According to Stokes and Baer (1977), generality occurs when the trained behavior occurs at other times without being taught or re-taught. For example, during Phase I: Phoneme Identity, generalization probes were taken for the skill areas of the second and third phases, phoneme segmentation and phoneme blending. Also, during Phase II: Phoneme Blending, generalization probes were taken in phoneme segmentation. A maintenancetesting component was implemented weekly and/or biweekly from 3 to 10 weeks after the end of instruction for each student in each of the three phases. Maintenance refers to behavior changes that persist over time or the extent to which the learner continues to perform the target behavior after a portion or all of the intervention has been terminated (Cooper et al., 2007).

The following sections describe the specific procedures and materials used for baseline, intervention and testing for each of the three phases of the study. Each phase, Phoneme Identity, Phoneme Segmentation, and Phoneme Blending will be discussed separately.

\section{Phase I: Phoneme Identity}

Phase I: phoneme identity baseline. During baseline, all four participants participated in speech and language therapy sessions according to their individual treatment plan (one session per week administered each Friday). In addition, each participant attended his or her regular prekindergarten program. No explicit phoneme identity instruction was provided. However, phoneme identity performance probe data 
were collected on all participants at the study's outset, and periodic recordings of baseline levels (approximately every 3-4 sessions) were taken afterwards so that no substantial performance changes occurred before the introduction of the intervention. Prior to implementation of the phoneme identity intervention for each participant, a minimum of three successive data points were collected to assess steady state performance. Phoneme identity baseline probes were conducted using procedures identical to those used for phoneme identity same day tests (see phoneme identity same-day test description later in this chapter).

Phase 1: phoneme identity explicit instruction. Each explicit instruction session began with a warm-up activity, followed by explicit instruction in phoneme identify and a same-day test. The warm-up activity involved reading a decodable book chosen from a list of books that were used for all three phases. The researcher and the participant then selected words that began or ended with the same sound. For example, the researcher selected the final /g/ words bug, rug and tug from the book, A Bug in a Rug. The researcher then exaggerated the initial or final sounds while pointing to the letter emphasizing the phoneme-grapheme connection. The participant wrote the words on a wipe-off board, and underlined the initial/final words with the same sounds. During the warm-up activity, the participants were required to articulate the word after the researcher when identifying the phonemes. If the word was mispronounced, the researcher modeled the correct production and encouraged the participant to attempt a closer approximation of the target word.

Explicit instruction occurred directly after the warm-up activity and lasted 15 minutes. These activities varied and were based upon instruction in initial and final sound 
recognition. Explicit instruction was provided consistently in each intervention session. Explicit instruction activities in phoneme identity (Phase 1) included looking at cards with two pictures on it and determining if the words did or did not start/end with the same sound; worksheets that asked the participant to circle all the pictures that began or ended with a selected target sound; selecting the pictures of words that began or ended with a particular sound from a group of pictures with four pictures of training words and two foils; games that required the selection of odd-word-out based upon initial and final phonemes; memory games that involved finding pictures that begin/ end with the same sound. Refer to Appendices E-I for examples of phoneme identity intervention materials, a list of decodable books and testing materials including data collection and graphing forms.

Phase 1: phoneme identity same-day test. At the end of each explicit instruction session, the researcher conducted the same day test. The researcher randomly selected 10 cards with three pictures on each card (Linguisystems, 2004) from two pools of 30 picture cards (a beginning sounds pool and an ending sounds pool). The beginning sounds pool of cards was placed in a basket, and the ending sounds pool was placed in a different basket. Each day the researcher reached into the two baskets and randomly selected five cards from the beginning sounds pool and five cards from ending sounds pool. At the end of the day, all of the cards used were placed back into the basket so that a total of 30 cards remained in each basket. The picture cards contained vowel consonant (VC) and consonant vowel consonant (CVC) words. Words with consonant blends were excluded, and words were paired to minimize auditory confusion (i.e., sounds that are similar auditory: /p and b/,/s and z/; see Appendix I for sample cards selected). The 
researcher placed one card on the table for the participant to see and then said the names of the three pictures on the card. The participant was asked to repeat the name of each picture after the researcher. The researcher then asked the participant to select the two pictures that began with the same sound. This procedure was used for the five initial sound cards. A similar procedure was used for the second five cards, except the participants were asked to select the two pictures on the card that ended with the same consonant sound. Each participant's response was scored as correct if he or she was able to correctly identify the two pictures that began with the same sound within 5 seconds for the five initial sound cards, and ended with the same sound within 5 seconds for the five final sound cards. The time was monitored using a stopwatch. The response was scored as incorrect if he or she did not respond within 5 seconds or did not respond at all. No feedback was provided for accuracy of responses. The number of correct responses was recorded on the tracking form and later graphed (see Appendices F-G).

\section{Phase II: Phoneme Blending}

Phase II: phoneme blending baseline. During baseline, all four participants participated in speech and language therapy sessions each according to his or her treatment plan (one session each Friday for all participants). In addition, each participant attended his or her regular prekindergarten program. No explicit phoneme blending instruction was provided. However, phoneme blending performance probe data was collected on all participants at the study's outset, and periodic recordings of baseline levels (approximately every 3-4 sessions) were taken afterwards so that no meaningful changes occurred before the introduction of the intervention. Prior to implementation of the phoneme blending intervention for each participant, a series of a minimum of three 
successive data points were collected to assess steady state performance. To conduct the probes, the researcher randomly selected 10 cards from a pool of $70 \mathrm{CV}$ or CVC cards. Probes were taken throughout the baseline for all four participants using procedures similar to the blending same-day test.

Phase II: phoneme blending explicit instruction. Each session began with a 10minute warm-up activity followed by explicit instruction in phoneme blending, and a same day test. This included reading a short picture book story selected from a list of decodable books and selecting familiar words from phase I. Three printed words were placed in front of the participant at a time. The researcher sounded out the desired word into the component two or three individual phonemes separated by one-second intervals. The participant then attempted to blend the phonemes together and choose the printed correct word. If a phoneme was mispronounced, the researcher modeled the correct production and encouraged the participant to attempt a closer approximation of the target phoneme, and then attempt to blend the word. After the researcher determined that the task became too simplistic for the participant and it was changed. The participant was then asked to sound out the word without the picture prompt.

Explicit instruction in phoneme blending occurred directly after the warm up activity and lasted 15 minutes. The activities included taking a picture card not previously used in the warm-up activities and placing it face down so that the participant did not see the card. The researcher then named the picture by saying the phonemes with one-second intervals. The participant then placed a block for each sound heard. The child repeated the sounds associated with the blocks (and later letters) until the participant was willing to guess the picture that has been placed face down. Another activity gave the 
participants three-letter cards. They were asked to blend the three sounds into a word. Once they made an attempt, they turned over the cards, and the three cards formed a puzzle of the word that was blended. The last activity emphasized the short vowel sounds. The participants were presented with letter blocks, and the short vowel sounds were reviewed. The researcher and the participant then chose vowel-consonant and consonant-vowel-consonant letter combinations and practiced blending them into real and nonsense words. This activity was varied and asking the participants to write the letters and then blend the sounds into words on a wipe-off board. Each explicit instruction session included the warm-up activity and two of these activities. If a sound was misarticulated, the researcher modeled the correct production and encouraged the participant to attempt a closer approximation of the sound in the target word. Refer to Appendices $\mathrm{E}-\mathrm{H}$ and $\mathrm{K}$ for a list of decodable books, examples of phoneme blending intervention materials, and testing materials including data collection and graphing forms.

Phase II: phoneme blending same-day test. At the end of each explicit instruction session, the researcher conducted the same day test. After an initial demonstration of the task, the researcher presented the participant with two or three same color blocks placed 2 inches apart. The researcher pointed to each block in the first set and said a sound (phoneme). The participant repeated the sounds that he or she heard. The researcher then pushed the two or three blocks together and asked the participant to say the word these sounds made. The response was scored correct on the tracking form if he or she was able to blend all the sounds into a word in the correct order in 5 seconds. The response was scored as incorrect if he or she did not blend all the sounds correctly or in the correct order. This was repeated until all five sets of blocks were scored. For the second five test 
items, the researcher presented the participant with five sets of two to three-letter tiles placed 2 inches apart. The researcher said the sounds and the participant repeated what he or she heard. The letters were then pushed together and the participant was asked to blend the sounds into a word. The participant received a correct score if he or she correctly blended the letter sounds into a word within 5 seconds. The participant received an incorrect score if he or she did not correctly blend the sounds into a word, or if $\mathrm{s} / \mathrm{he}$ did not complete the task within 5 seconds. The words were selected from a pool of 60 words (see Appendix J). The total number of words correctly blended using blocks and letters combined were recorded on the tracking form (see Appendices F-G) and later graphed.

\section{Phase III: Phoneme Segmentation}

Phase III: phoneme segmentation baseline. During baseline, all four participants received speech and language therapy sessions according to their treatment plan (one session each Friday for all participants). In addition, each participant attended his or her regular prekindergarten program. No explicit phoneme segmentation instruction was provided. However, phoneme segmentation probe data were collected on all participants at the study's outset, and periodic recordings of baseline levels (approximately every 3-4 sessions) were taken afterwards so that no significant changes occurred before the introduction of the intervention. Prior to implementation of the segmentation intervention for each participant, a minimum of three successive data points were collected to assess steady state performance. Probes were conducted identical to the phoneme segmentation same-day tests for all four participants.

Phase III: phoneme segmentation explicit instruction. Each session began with a 10-minute warm-up activity followed by explicit instruction in 
segmentation and a same-day test. This included reading a short decodable book and selecting familiar words from the previous phases. For example, after rereading the decodable book, $A$ Cup for a $C u b$, words such as cup, cub, big and hug were selected because of their familiarity to the participants. The researcher then demonstrated exaggerating and separating the words into phonemes using the selected consonant-vowel-consonant (CVC) or vowel-consonant (VC) words. The participants were asked to look at their mouths in a mirror when they said the words to help get an understanding of the position of the articulators from one phoneme to another. If the sound was mispronounced, the researcher modeled the correct production and encouraged the participant to attempt a closer approximation of the sound. After repeated demonstrations by the researcher, the participants were asked to clap for each sound heard in a word and then segment the word into its component phonemes.

Explicit instruction occurred directly after the warm-up activity and lasted 15 minutes. One phoneme segmentation activity asked the participant to choose a $\mathrm{CVC}$ or $\mathrm{VC}$ picture from a pile of cards and say the name of the picture. The researcher then repeated the word with one-second intervals between the phonemes. The participants were then asked to clap for the number of phonemes heard. This task was varied by using same colored blocks and then letters to designate the number of phonemes heard. An Elkonin box with three spaces was used to separate the individual phonemes one from the other. For example, if the word was bat, the researcher said each sound (b-a-t) while placing a same colored block for each sound into the corresponding space in the Elkonin box. After 
several examples, the participant selected a picture and then sequenced same colored blocks, one for each sound heard into the Elkonin box. Then the researcher demonstrated the same task using letter tiles and the participant practiced this task using letter tiles and the Elkonin box. Refer to Appendices E-H and $\mathrm{J}$ for examples of phoneme segmentation intervention materials, and testing materials including data collection and graphing forms.

Phase III phoneme segmentation same-day test. At the end of the explicit instruction session, the researcher conducted the same day test. After a demonstration of the task, the researcher randomly selected 10 cards out of a pool of 60 cards (see Appendix K). The researcher presented one card from the pile of 10 cards that contained pictures representing $\mathrm{CVC}$ or $\mathrm{VC}$ words. On the table, an Elkonin box separated into three spaces was placed in front of the participant. Five same-colored blocks were placed on the top portion of the Elkonin box. For the first five cards, the researcher said a word and the participant was asked to repeat the word and then push a block into one of the spaces for each sound that he or she heard. The participant's response was scored as correct if he or she placed the correct number of same colored blocks into the spaces within 5 seconds on a stopwatch, or incorrect if he or she did not place the correct number of blocks into the spaces, or did not do it within the allotted time. The time was monitored using a stopwatch. For the second five cards, a total of three consonant and two vowel letter choices were placed on the top portion of the Elkonin box. The researcher then said a word, the participant repeated the word and he or she responded by pushing the correct letter tile into the appropriate box. The participant's response was marked correct if he or she placed the correct number of letters in the correct order into 
the spaces within 5 seconds, or incorrect if he or she did not place the correct number of letters in the right order within the 5 second time limit. The total number of correct responses for the block and letter task combined was recorded on the tracking form and later graphed (see Appendices F-G).

\section{Generalization Tests}

Generalization tests were given to the participants in the untrained skill areas during intervention in each of the phases. For example, when a participant received explicit instruction in phoneme identity, periodic assessments (approximately every 3-5 days) or generalization probes were taken in phoneme segmentation and phoneme blending. Further, when instruction occurred in phoneme segmentation, generalization probes were taken in phoneme blending. The procedures for the generalization probes were identical to those of the same-day tests for each phase.

\section{Maintenance and Posttests}

Maintenance tests were given to each participant weekly or biweekly from 3 to 10 weeks after the participant reached a 100\% criterion for a minimum of 5 consecutive days. Due to the logistics of moving from one phase of the study to the next, some participants were given more maintenance tests than others. In addition, participants on the third and fourth tiers were given fewer maintenance tests due to the need to end the study. Posttesting at the end of the treatment and maintenance phases included readministration of the Goldman-Fristoe 2 Test of Articulation (see Appendix C).

\section{Definitions and Variables}

Same-day and maintenance tests were given for each of the three phases:

Phoneme Identity, Blending and Phoneme Segmentation. Generalization tests were given 
for Blending and Phoneme Segmentation. A description of each same-day, generalization and maintenance test is described below.

Phoneme Identity Same-Day Test

At the end of each explicit instruction session, the researcher conducted the sameday test. The researcher randomly selected 10 cards with three pictures on each card from two pools of 30 picture cards (a beginning sounds pool and an ending sounds pool). The picture cards contained $\mathrm{CVC}$ and $\mathrm{VC}$ words, consonant blends were not included, and words were paired to minimize auditory confusion (i.e., sounds that are similar auditorily: $/ \mathrm{p}$ and $\mathrm{b} /$, /s and $\mathrm{z} /$; see Appendix I for sample cards selected). The researcher placed one card on the table for the participant to see and then said the names of the three pictures on the card. The participant was asked to repeat the name of each picture after the researcher. Then the researcher asked the participant to select the two pictures that began with the same sound. This procedure continued for the five initial sound cards. A similar procedure was used for the second five cards, except the participant was asked to select the two pictures on the card that ended with the same consonant sound. Each participant's response was scored as correct if he or she was able to correctly identify the two pictures that began with the same sound within 5 seconds for the five initial sound cards, and ended with the same sound within 5 seconds for the five final sound cards. The time was monitored using a stopwatch. The response was scored incorrect if he or she did not respond within 5 seconds or did not respond at all. No feedback was provided for accuracy of responses. The number of correct responses was recorded on the tracking form (see Appendices F-G) and graphed. 


\section{Blending Same-Day Test}

At the end of each explicit instruction session, the researcher conducted the sameday test. After an initial demonstration of the task, the researcher presented the participant with two or three same color blocks placed 2 inches apart (see Appendix J for

a pool of words). The researcher pointed to each block said each sound (phoneme), and the participant repeated the sounds that he or she heard. The researcher then pushed the two or three blocks together and asked the participant what word those sounds made. The response was scored correct if he or she was able to blend all the sounds into a word in the correct order in 5 seconds. The response was scored as incorrect if he or she did not blend all the sounds correctly in the correct order or within the time limit. This procedure was repeated until five sets of blocks were scored. For the second five test items, the researcher presented the participant with five sets of 2-to-3 letter tiles placed 2 inches apart. The researcher said the sounds and the participant repeated the sounds that he or she heard. The letters were then pushed together and the participant was asked to blend the sounds into a word. The participant received a correct score if he or she correctly blended the letter sounds into a word within 5 seconds. The participant received an incorrect score if he or she did not correctly blend the sounds into a word, or if he or she did not complete the task within 5 seconds. The total number of words correctly blended using blocks and letters combined was recorded on the tracking form (see Appendices FG) graphed.

\section{Phoneme Segmentation Same-Day Test}

At the end of the explicit instruction session, the researcher conducted the same day test. After demonstrating the task, the researcher randomly selected 10 cards out of a 
pool of 60 cards (see Appendix K). The researcher presented one card from a pile of 10 cards that contained pictures representing consonant-vowel-consonant (CVC) or vowelconsonant (VC) words. On the table an Elkonin box separated into three spaces was placed in front of the participant. For the first five cards, the researcher said the word and the participant was asked to repeat the word and then push a block into one of the spaces for each sound that he or she heard. The participant's response was scored as correct if he or she placed the correct number of same colored blocks into the spaces within 5 seconds on a stopwatch, or incorrect if he or she did not place the correct number of blocks into the spaces, or did not do it within the allotted time. For the second five cards, the researcher said the word and the participant repeated the word. Then he or she responded by pushing the correct letter tile into the appropriate box (out of a total of three consonant and two vowel letter choices). The participant's response was marked correct if he or she placed the correct number of letters in the correct order into the spaces within 5 seconds, or incorrect if he or she did not place the correct number of letters in the right order within the 5 second time limit. The total number of correct responses for the block and letter task combined was recorded on the tracking form (see Appendices F-G) and graphed.

\section{Generalization Tests}

Generalization tests were given to the participants in the untrained skill areas during intervention in each of the phases. For example, when a participant received explicit instruction in phoneme identity, periodic assessments (approximately every 3-5 days) or generalization probes were taken in phoneme segmentation and phoneme blending. Further, when instruction occurred in phoneme segmentation, generalization 
probes were taken in phoneme blending. The procedures for the generalization probes were identical to those of the same-day tests for each phase, and were given immediately after same-day tests.

\section{Phase I, II, and III Maintenance Tests}

Maintenance tests were given to each participant weekly or biweekly from 3 to 10 weeks after the participant reached a $100 \%$ criterion for a minimum of 5 consecutive days. Due to the logistics of moving from one phase of the study to the next, some participants were given more maintenance tests than others. In addition, participants on the third and fourth tiers were given fewer maintenance tests due to the need to end the study.

\section{Interobserver Agreement Training}

An independent second observer was trained to score the baseline, same-day tests, generalization and maintenance tests on the three dependent variables: phoneme identity, phoneme segmentation, and phoneme blending. The independent observer was a parttime receptionist at the preschool attended by the participants. The researcher provided the training during one session. The independent observer was trained to score correct and incorrect responses for the baseline, generalization, same day and maintenance tests. During training the researcher compared her results with those of the independent observer using the phase score sheets. When there was disagreement between the scores, it was discussed, and further training continued until a 100\% interobserver agreement rate was achieved. Interobserver agreement measures were calculated by dividing the number of agreements by the number of agreements plus disagreements and then multiplying by 100. Throughout the study, the interobserver scored approximately $30.4 \%$ of the baseline, 
same-day tests, and generalization and maintenance conditions with over $98 \%$ interobserver agreement. In the event that a disagreement occurred, the researcher's score was used. According to Cooper et al. (2007), when independent observers obtain high agreement regarding the occurrence or nonoccurrence of behaviors, confidence in the study increases.

\section{Treatment Integrity}

A daily treatment integrity checklist was used to record the occurrence and nonoccurrence of the treatments as planned (see Appendix H). The researcher trained the observer on treatment integrity procedures until 100\% accuracy was attained. Approximately $30.4 \%$ of the instructional sessions and same-day tests were randomly observed by the trained observer so that the conditions were being implemented as described. The researcher provided the observer with a checklist of the intervention components. Then the researcher and observer independently scored the occurrence or nonoccurrence of the components of the observed instructional sessions. A total percentage of occurrences of components were recorded.

\section{Experimental Design}

The research design chosen for this study was a single subject multiple probe design across subjects (Horner \& Baer, 1978). In this design, predictions based on one subject's behavior are verified by the behavior of the other subjects, and replication of effect is dependent on the behavior of other subjects. Verification is evident if the data path changes in a predictable manner through a phase change, as from baseline to intervention for each participant. Replication of this prediction and verification may 
occur when the data paths of the other participants follow patterns similar to the first participant.

In contrast to a multiple baseline design, in which baseline data are collected throughout the baseline condition, the multiple probe baseline design uses periodic measures (or probes) of behavior to limit practice effects. Practice effects occur when there is improvement due to the increased opportunities to emit the target behavior (Cooper et al., 2007). By collecting probe (occasional) data during baseline instead of data per session, the number of opportunities for the student to respond was limited, thereby reducing the practice effects. The probes provide the basis for prediction and determining whether behavior change has occurred during baseline. A series of three continuous baseline measures are taken prior to beginning intervention.

In a multiple probe baseline design across subjects, one behavior (dependent variable) is selected for two or more participants in the same setting. In this design, data are collected across all subjects at the study's outset. After criterion-level or steady state responding occurs in baseline (determined by periodic measures or probes), a series of consecutive baseline sessions to assess steady state performance are conducted. The intervention (independent variable) is then applied to one of the participants while the other participants are probed in baseline. When criterion-level or steady state responding occurs for the first participant, a series of consecutive baseline sessions are conducted just before the independent variable is applied to the second participant, and so on (Horner \& Baer, 1978). In this study, the design was implemented separately for all three areas (phoneme identity, phoneme segmentation, phoneme blending). 
The multiple probe baseline design has several advantages: (a) withdrawal of the treatment is not required, (b) sequential implementation of the independent variable parallels the practice of teachers and (c) the design is easily conceptualized and used (Cooper et al., 2007). A multiple baseline design demonstrates the effectiveness of the intervention with more than one participant in need of developing the same skill and data are collected on each participant and individually analyzed. Experimental control in this study was obtained by introducing the intervention to only one student at a time while maintaining baseline conditions for the other students.

During baseline, speech and language therapy sessions were administered to each participant according to each child's treatment plan (one session for each participant every Friday). In addition, each participant continued to attend his or her regular prekindergarten program. When stable baseline responding occurred for the first participant, the intervention phases began as described in the general procedures section. When the behavior for the first participant stabilized, the independent variable was applied to the second participant while periodic baseline probes continued for the other two participants. The same procedure continued for the remaining participants. Identical procedures were used for all three of the study phases.

\section{Chapter Summary}

This study examined the effect of explicit, individualized instruction in phonemic awareness administered by a speech-language pathologist to prekindergarten children who were at risk for literacy development delays because of moderate to severe expressive phonological disorders. The study measured the sequential effects of intensive, explicit instruction in three phonemic awareness tasks, phoneme identity, 
phoneme blending, and phoneme segmentation. Participants included four students, two boys and two girls who received intervention for moderately to severe expressive phonological disorders in the absence of a language delay. The setting was the researcher's office in a private preschool in the West Broward area. The study took place in a small private room with minimal distractions normally used for speech-language intervention. The participants were placed across the child-sized table from the researcher, and the intervention was conducted individually.

The research design chosen for this study was a single subject multiple probe design across subjects. This design was implemented separately for all three phases, phoneme identity, phoneme segmentation and phoneme blending. In this design, predictions based on one subject's behavior are verified by the behavior of the other subjects, and replication of effect is dependent on the behavior of other subjects. Materials used in this study included norm-referenced tests, informal assessments, decodable books, cards, wipe-off board and marker, same color blocks, and letter tiles. Dependent measures included same-day tests for Phase I: Phoneme Identity, Phase II: Phoneme Blending, Phase III: Phoneme Segmentation, generalization measures, and maintenance tests for all three phases.

The participants received explicit instruction in each of the three phases (dependent measures) after pretesting and warm-up activities. Each 30-minute session ended with a same-day test. Participants' performances on same-day tests were graphed daily. Each day a decodable book was introduced to the participants. Warm-up and explicit instruction activities were developed around each story. Some books were repeated in the different phases. The selected decodable books are listed in Appendix E. 
Generalization probes were taken periodically throughout the study. Maintenance tests were administered weekly and/or biweekly from 3 to 10 weeks after completion of each phase for all participants. In order to attain procedural reliability, an independent observer conducted the interobserver observations and completed the treatment integrity checklist during each observation. 


\section{CHAPTER IV}

\section{RESULTS}

This chapter presents the findings of a study that used a multiple probe baseline design to examine the effects of a short-term intensive intervention in three phonemic awareness skills; phoneme identity, phoneme blending, and phoneme segmentation on prekindergarten children with expressive phonological delays. This study sought to answer the research questions by measuring the participants' ability to identify initial and final phonemes, blend phonemes together to form two and three letter words, and analyze and spell words at the phonemic level. This research had three distinct studies referred to as: (a) Phase I: Phoneme Identity, (b) Phase II: Phoneme Blending, and (c) Phase III: Phoneme Segmentation. Each phase had its own multiple-baseline design that included baseline, intervention (explicit instruction), and maintenance conditions. Once instruction was completed for each of the four participants in the first phase, each participant moved independently to the second, and then the third phase. Periodic probes of the phases that had not yet received instruction were measured to determine whether generalization of learning occurred. Maintenance tests were given to each participant weekly or biweekly from 3 to 10 weeks after the participant reached a $100 \%$ criterion for a minimum of 5 consecutive days. Due to the logistics of moving from one phase of the study to the next, some participants were given more maintenance tests than others were. In addition, participants on the third and fourth tiers were given fewer maintenance tests due to the need to end the study. 
Interobserver agreement (IOA) and treatment fidelity data are presented first followed by the results on each of the participant's performances and group on each of the dependent variables. This chapter concludes with a summary of the results.

\section{Interobserver Agreement}

The trained observer collected interobserver agreement data for $30.40 \%$ of all sessions across all dependent variables (all three phases). The mean observer agreement for phoneme identity, phoneme blending, and phoneme segmentation were $98.90 \%$ (range 98.00-100.00\%), 98.40\% (range 96.00-100.00\%), and 98.60\% (range 96.00$100.00 \%$ ), respectively.

\section{Treatment Fidelity}

The researcher and one trained independent observer collected treatment fidelity data to help determine whether procedures were followed as designed. The researcher collected procedural data during every session for each participant in each condition. The researcher data indicated that procedures were followed an average of $99.16 \%$ of the time (range 97.80-100.00) throughout all of the sessions in all three phases. The independent observer collected treatment fidelity data on $30.4 \%$ of the total number of sessions in all three phases. The independent observers data indicated that procedures were followed an average of $99.90 \%$ of the time (range $97.80-100.00$ ).

\section{Phase I: Phoneme Identity}

The first phase of this study was conducted to examine the effects of an intensive, explicit intervention in phoneme identity on four preschool children with phonological speech sound disorders. A same-day test consisting of 10 items in which the participant selected words with the same beginning or ending sounds was administered during 
baseline, intervention, and maintenance. The number correct out of 10 was recorded on the data $\log$ and graphed. Figure 1 displays the graphed data of all four participants per session. Table 2 provides data on each student's and the group's mean performances on phoneme identity same-day tests during baseline, intervention, and maintenance. In addition, while each participant was in Phase I: Phoneme Identity, generalization probes (approximately every 3-5 days) were taken to determine whether the effects of training in phoneme identity had an effect on the baseline and intervention performance of Phase II: Phoneme Blending and Phase III: Phoneme Segmentation. Further, generalization probes were taken in Phase III: Phoneme Segmentation) when participants were in Phase II. Table 3 provides data on each participant's generalization data from Phase I to Phase II and Phase III.

Participant 1

During baseline, Participant 1 had a mean score of 4.75 correct out of 10.00 (range 4-5) on phoneme identity same-day tests (see Figure 1, Table 2). When the explicit instruction intervention was introduced, Participant 1's mean score rose to a mean of 9.60 correct (range 8-10). This represents a mean increase of 4.85 correct from baseline to intervention. Following a series of 9 days of $10 / 10$ performances (see Table 4), Participant 1 entered into maintenance where a mean score of 10.00 (range 10-10) was achieved on seven weekly or biweekly maintenance tests (see Table 4). The mean maintenance score for Participant 1 was .40 more correct than her mean intervention same-day test scores.

While Participant I was in Phase I, Phase II probes revealed a mean score of 4.50 (range 4-5). When Participant I moved into Phase I intervention, the mean score for 
Phase II baseline generalization probes was 5.00 (range 5-5), representing an increase of 0.50. Additionally, when Participant 1 moved into Phase I maintenance, the mean Phase II baseline generalization score was 6.33 (range 6-7), representing an increase of 1.83 in Phase II baseline prior to intervention (see Table 3).

While Participant 1 was in Phase I baseline, Phase III probes revealed a mean score of 2.50 (range 2-3). When Participant 1 moved into Phase I intervention, the mean score for Phase III baseline generalization probes was 1.50 (range $0-4$ ) representing a decrease of 1.00. Additionally, when Participant 1 moved into Phase I maintenance, the mean Phase III generalization score was 3.25 (range 2-4) representing an increase of .75 in Phase III baseline prior to intervention (see Table 3).

\section{Participant 2}

During baseline, Participant 2 had a mean score of 4.67 correct out of 10.00 (range 3-5) on phoneme identity same-day tests (see Figure 1, Table 2). When the explicit instruction intervention was introduced, Participant 2's mean score rose to a mean of 8.61 correct (range 5-10). This represents a mean increase of 3.94 correct from baseline to intervention.

Following a series of 5 days of 10/10 performances (see Table 4), Participant 2 entered into maintenance where perfect performance (an average score of 10.00 with a range of 10-10) was achieved on six weekly or biweekly maintenance tests (see Table 4). Participants 2's mean maintenance score was 1.39 more correct than his mean intervention same-day test scores. 
Phase I: Phoneme Identity
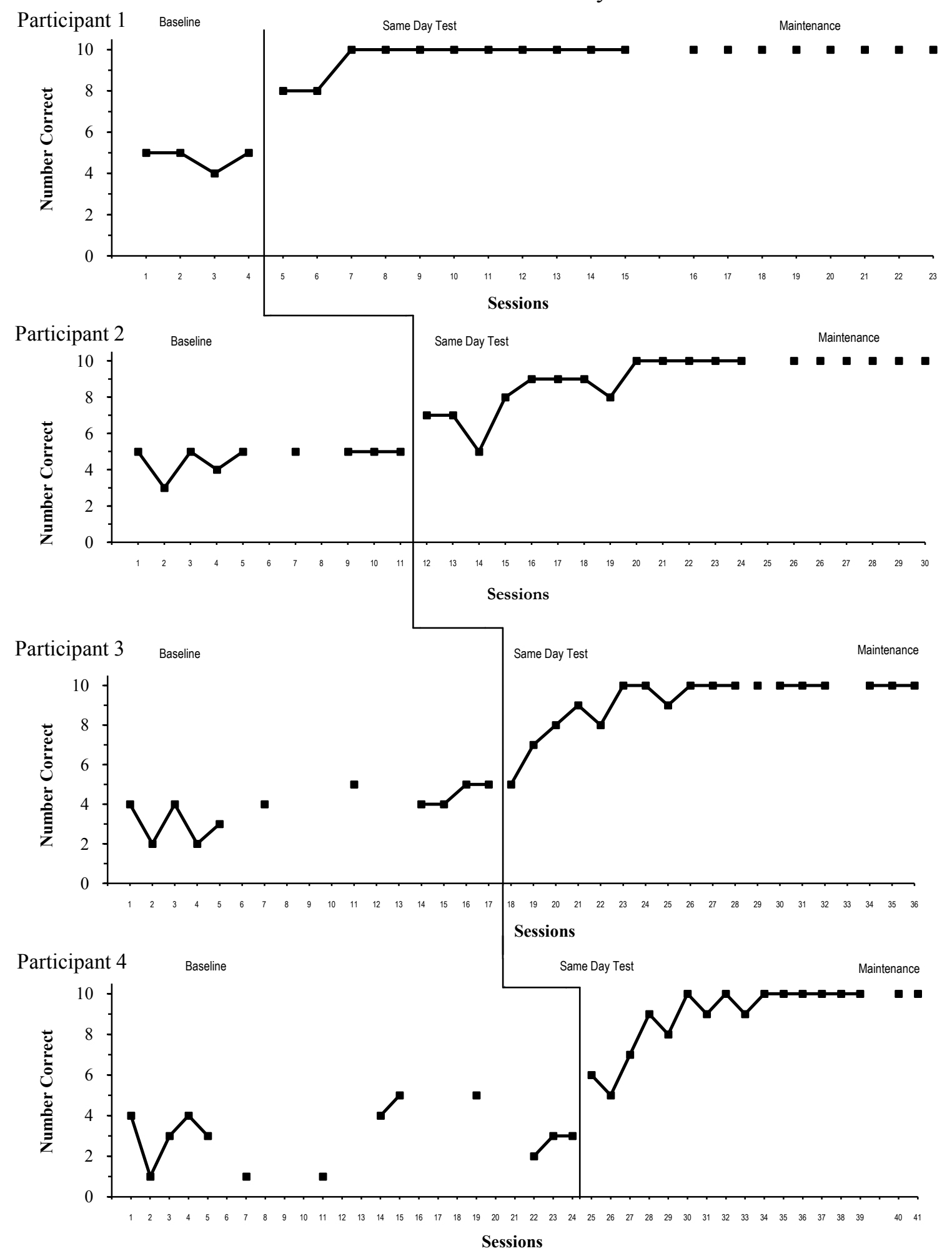

Figure 1. Phoneme Identity as measured by the number correct out of a total of 10 on baseline, intervention, and maintenance. 
Table 2

Phase 1: Phoneme Identity Baseline, Intervention, and Maintenance

\begin{tabular}{cccc}
\hline Participant & Baseline & Intervention & Maintenance \\
\hline \multirow{2}{*}{1} & 4.75 & 9.60 & 10.00 \\
& $(4-5)$ & $(8-10)$ & $(10-10)$ \\
& & & \\
& 4.67 & 8.61 & 10.00 \\
& $(3-5)$ & $(5-10)$ & $(10-10)$ \\
3 & & & \\
& 3.81 & 9.06 & 10.00 \\
4 & $(2-5)$ & $(5-10)$ & $(10-10)$ \\
& & & 10.00 \\
& 3.00 & 8.87 & $(10-10)$ \\
Group & $(1-5)$ & $(5-10)$ & 10.00 \\
& 4.06 & & $(10-10)$ \\
\end{tabular}

Note. The top scores indicate individual means of number correct. The bottom rows represent the range of scores.

While Participant 2 was in Phase I baseline, Phase II probes revealed a mean score of 3.50 (range 1-5). When Participant 2 moved into Phase I intervention, the mean score for Phase II baseline generalization probes was 5.33 (range 5-6), representing an increase of 1.83. Additionally, when Participant 2 moved into Phase I maintenance, the mean Phase II baseline generalization score was 5.75 (range 5-6), representing an increase of 2.25 in Phase II baseline prior to intervention (see Table 3).

While Participant 2 was in Phase I baseline, Phase III probes revealed a mean score of 1.33 (range 0-2). When Participant 2 moved into Phase I intervention, the mean 
score for Phase III baseline generalization probes was 2.67 (range 2-3) representing an increase of 1.34. Additionally, when Participant 2 moved into Phase I maintenance, the mean Phase III generalization score was 4.5 (range 4-5) representing an increase of 3.17 in Phase III baseline prior to intervention (see Table 3).

Participant 3

During baseline, Participant 3 had a mean score of 3.81 correct out of 10 (range 25) on phoneme identity same-day tests (see Figure 1, Table 2). When explicit instruction intervention was introduced, Participant 3's mean score rose to 9.06 (range 5-10). This represents a mean increase of 5.25 correct from baseline to intervention. Following a series of 6 days of 10/10 performances, Participant 3 entered into maintenance where a mean perfect score of 10 (range 10-10) was achieved on three biweekly maintenance tests (see Table 4). The mean maintenance score for Participant 3 was .94 more correct than his mean intervention same-day test scores.

While Participant 3 was in Phase I baseline, Phase II probes revealed a mean score of 0 (range 0-0). When Participant 3 moved into Phase I intervention, the mean score for Phase II baseline generalization probes was 0.80 (range $0-2$ ), representing an increase of 0.80. Additionally, when Participant 3 moved into Phase I maintenance, the mean Phase II baseline generalization score was 1.33 (range 1-2), representing an increase of 1.33 in Phase II baseline prior to intervention (see Table 3).

While Participant 3 was in Phase I baseline, Phase III probes revealed a mean score of 3.00 (range 0-5). When Participant 3 moved into Phase I intervention, the mean score for Phase III baseline generalization probes was 4.00 (range 2-5) representing an increase of 1.0. Additionally, when Participant 3 moved into Phase I maintenance, the 
mean Phase III generalization score was 5.00 (range 5-5) representing an increase of 2.00 in Phase III baseline prior to intervention (see Table 3).

Table 3

Phase II Phoneme Blending and Phase III Phoneme Segmentation Generalization Measures From Phase I Conditions

\begin{tabular}{|c|c|c|c|c|c|c|}
\hline \multirow{3}{*}{$\begin{array}{c}\text { Participant } \\
1\end{array}$} & \multicolumn{3}{|c|}{ Phase II Baseline Generalization } & \multicolumn{3}{|c|}{ Phase III Baseline Generalization } \\
\hline & \multirow{2}{*}{$\begin{array}{c}\text { Baseline } \\
4.5 \\
(4-5)\end{array}$} & \multicolumn{2}{|c|}{ Intervention Maintenance } & \multirow{2}{*}{$\begin{array}{c}\text { Baseline } \\
\begin{array}{c}2.50 \\
(2-3)\end{array}\end{array}$} & \multicolumn{2}{|c|}{ Intervention Maintenance } \\
\hline & & $\begin{array}{l}5.00 \\
(5-5)\end{array}$ & $\begin{array}{l}6.33 \\
(6-7)\end{array}$ & & $\begin{array}{c}1.50 \\
(0-4)\end{array}$ & $\begin{array}{l}3.25 \\
(2-4)\end{array}$ \\
\hline 2 & $\begin{array}{l}3.50 \\
(1-5)\end{array}$ & $\begin{array}{l}5.33 \\
(5-6)\end{array}$ & $\begin{array}{l}5.75 \\
(5-6)\end{array}$ & $\begin{array}{c}1.33 \\
(0-2)\end{array}$ & $\begin{array}{c}2.67 \\
(2-3)\end{array}$ & $\begin{array}{l}4.50 \\
(4-5)\end{array}$ \\
\hline 3 & $\begin{array}{c}0.00 \\
(0-0)\end{array}$ & $\begin{array}{c}0.80 \\
(0-2)\end{array}$ & $\begin{array}{c}1.33 \\
(1-2)\end{array}$ & $\begin{array}{c}3.00 \\
(0-5)\end{array}$ & $\begin{array}{l}4.00 \\
(2-5)\end{array}$ & $\begin{array}{l}5.00 \\
(5-5)\end{array}$ \\
\hline 4 & $\begin{array}{c}.29 \\
(0-1)\end{array}$ & $\begin{array}{l}2.80 \\
(1-5)\end{array}$ & $\begin{array}{l}4.50 \\
(3-5)\end{array}$ & $\begin{array}{c}1.14 \\
(0-3)\end{array}$ & $\begin{array}{c}1.50 \\
(0-5)\end{array}$ & $\begin{array}{c}3.50 \\
(3-4)\end{array}$ \\
\hline Group & $\begin{array}{l}2.07 \\
(0-5)\end{array}$ & $\begin{array}{l}3.48 \\
(0-6)\end{array}$ & $\begin{array}{l}4.48 \\
(1-7)\end{array}$ & $\begin{array}{c}1.99 \\
(0-5)\end{array}$ & $\begin{array}{l}2.42 \\
(0-5)\end{array}$ & $\begin{array}{l}4.94 \\
(2-5)\end{array}$ \\
\hline
\end{tabular}

Note. Top numbers refer to the mean performance in Phase II and III baseline generalization measures while in Baseline, Intervention, and Maintenance in Phase I. The bottom numbers refer to the range.

\section{Participant 4}

During baseline, Participant 4 had a mean score of 3.00 correct out of 10.00 (range 1-5) on phoneme identity same-day tests (see Figure 1, Table 2). When the explicit instruction intervention was introduced, Participant 4's mean score rose to 8.87 correct (range 5-10). This represents a mean increase of 5.87 correct from baseline to intervention. 
Table 4

Weekly and Biweekly Maintenance Probes on Phase I: Phoneme Identity

\begin{tabular}{|c|c|c|c|c|c|c|c|c|c|c|}
\hline \multirow{2}{*}{ Participant } & \multirow{2}{*}{$\begin{array}{l}\text { Last Intervention } \\
\text { Score }\end{array}$} & \multicolumn{9}{|c|}{ Week } \\
\hline & & 1 & 2 & 3 & 4 & 5 & 6 & 7 & 8 & 9 \\
\hline 1 & 10.00 & 10.00 & 10.00 & 10.00 & 10.00 & 10.00 & $\mathrm{x}$ & 10.00 & $\mathrm{x}$ & 10.0 \\
\hline 2 & 10.00 & 10.00 & 10.00 & 10.00 & 10.00 & $X$ & 10.00 & $\mathrm{x}$ & 10.0 & $\mathrm{x}$ \\
\hline 3 & 10.00 & $\mathrm{x}$ & 10.00 & $\mathrm{x}$ & 10.00 & $X$ & 10.00 & $\mathrm{x}$ & $\mathrm{x}$ & $\mathrm{x}$ \\
\hline 4 & 10.00 & $\mathrm{x}$ & 10.00 & $\mathrm{x}$ & 10.00 & $X$ & 10.00 & $\mathrm{x}$ & $\mathrm{x}$ & $\mathrm{x}$ \\
\hline Group & 10.00 & 10.00 & 10.00 & 10.00 & 10.00 & 10.00 & 10.00 & 10.00 & 10.0 & 10.0 \\
\hline
\end{tabular}

Note. After receiving a minimum of 5 days of 10 out of 10 on the phoneme identity same-day test, the participant entered into weekly and biweekly maintenance probes to determine if the skills taught were maintained over time. An " $\mathrm{x}$ " represents no maintenance probe taken. 
Following a series of 6 days of 10/10 performances, Participant 4 entered into maintenance where an average score of 10.00 (range 10-10) was achieved on three maintenance tests (see Table 4). The mean maintenance score for Participant 4 was 1.13 more correct than her mean intervention same-day test scores.

While Participant 4 was in Phase I baseline, Phase II probes revealed a mean score of 0.29 (range $0-1$ ). When Participant 4 moved into Phase I intervention, the mean score for Phase II baseline generalization probes was 2.80 (range 1-5), representing an increase of 2.51. Additionally, when Participant 4 moved into Phase I maintenance, the mean Phase II baseline generalization score was 4.50 (range 3-5), representing an increase of 4.21 in Phase II baseline prior to intervention (see Table 3).

While Participant 4 was in Phase I baseline, Phase III probes revealed a mean score of 1.14 (range 0-3). When Participant 4 moved into Phase I intervention, the mean score for Phase III baseline generalization probes was 1.50 (range 0-5) representing an increase of 0.36 . Additionally, when Participant 4 moved into Phase I maintenance, the mean Phase III generalization score was 3.50 (range 3-4) representing an increase of 2.36 in Phase III baseline prior to intervention (see Table 3).

Group

During baseline, the Group had a mean score of 4.06 correct out of 10.00 (range 1-5) on phoneme identity same day tests (see Figure 1, Table 2). When the explicit instruction intervention was introduced, the Group's mean score rose to a mean of 9.03 correct (range 5-10). This represents a mean increase of 4.97 correct from baseline to intervention. The Group's maintenance mean score was 10.00 (range 10-10). The 
Group's mean maintenance score was .97 more correct than their mean intervention same-day test scores.

While the Group was in Phase I baseline, Phase II probes revealed a Group mean score of 2.07. When the Group moved into Phase I intervention, the Group mean score for Phase II baseline generalization probes was 3.48, representing an increase of 1.41 . Additionally, when the Group moved into Phase I maintenance, the mean Phase II baseline generalization score was 4.48, representing an increase of 2.41 in Phase II baseline prior to intervention (see Table 3).

While the Group was in Phase I baseline, Phase III probes revealed a mean score of 1.99. When the Group moved into Phase I intervention, the mean score for Phase III baseline generalization probes was 2.42 representing an increase of 0.43 . Additionally, when the Group moved into Phase I maintenance, the mean Phase III generalization score was 4.94 representing an increase of 2.52 in Phase III baseline prior to intervention (see Table 3).

\section{Phase II: Phoneme Blending}

The second phase of this study was conducted to examine the effects of an intensive, explicit intervention in phoneme blending on four preschool children with phonological speech sound disorders. Each day a same-day test consisting of 10 items was administered following explicit instruction in phoneme blending. The number correct out of a total of 10 was recorded on the data $\log$ and graphed. Figure 2 displays the graphed data of all four participants. Table 5 provides data on each student's and the group's mean performance on phoneme blending same-day tests during baseline, intervention and maintenance. In addition, while each participant was in Phase II: 
Phoneme Blending, generalization probes (approximately every 3-5 days) were taken to determine whether the effects of training in phoneme blending had an effect on the baseline measurements of Phase III: Phoneme Segmentation. Table 6 provides data on generalization from Phase I to Phase II and Phase III.

Participant 1

During baseline, Participant 1 had a mean score of 5.38 correct (range 4-7) out of a total of 10.00 on the phoneme blending same-day tests (see Figure 2, Table 5). When the explicit instruction intervention was introduced, Participant 1's mean score rose to a mean of 10 correct (range 10-10). This represents a mean increase of 4.62 correct from baseline to intervention. Following a series of 12 days of 10/10 performances, Participant 1 entered into maintenance where a mean score of 10 (range 10-10) was achieved on 10 weekly maintenance tests (see Table 7). Participant 1's mean maintenance score was identical to her mean intervention same-day test scores.

While Participant 1 was in Phase II baseline, Phase III probes revealed a mean score of 2.44 (range 0-4). When Participant 1 moved into Phase II intervention, the mean score for Phase III baseline generalization probes was 6.8 (range 5-8), representing an increase of 4.36. Additionally, when Participant 1 moved into Phase II maintenance, the mean Phase III baseline generalization score was 9.00 (range 9-9), representing an increase of 6.56 in Phase III baseline prior to intervention (see Table 6).

\section{Participant 2}

During baseline, Participant 2 had a mean score of 4.82 correct (range 1-6) out of a total of 10 on the phoneme blending same-day tests (see Figure 2, Table 5). When the explicit instruction intervention was introduced, Participant 2's mean score rose to a 
mean of 9.67 correct (range 8-10). This represents a mean increase of 4.85 correct from baseline to intervention. Following a series of 8 days of $10 / 10$ performances, Participant 2 entered into maintenance where a mean score of 10 (range 10-10) was achieved on eight weekly maintenance tests. The mean maintenance score for Participant 2 was .03 more correct than his mean intervention same-day test scores (see Table 7).

While Participant 2 was in Phase II baseline, Phase III probes revealed a mean score of 2.88 (range 1-5). When Participant 2 moved into Phase II intervention, the mean score for Phase III baseline generalization probes was 7.33 representing an increase of 4.45. When Participant 2 moved into Phase II maintenance, a mean baseline score for Phase III could not be computed, as Participant 2 had already started intervention in Phase III (see Table 6).

Participant 3

During baseline, Participant 3 had a mean score of 0.62 correct (range 1-2) out of a total of 10.00 on the phoneme blending same-day tests (see Figure 2, Table 5). When the explicit instruction intervention was introduced, Participant 3's mean score rose to a mean of 7.25 correct (range 1-10). This represents a mean increase of 6.63 correct from baseline to intervention. Following a series of 6 days of 10/10 performances, Participant 3 entered into maintenance where a mean score of 9.83 (range 9-10) was achieved on 6 weekly maintenance tests (see Table 7). The mean maintenance score for Participant 3 was 2.58 more correct than his mean intervention same-day test scores. 
Phase 2: Phoneme Blending
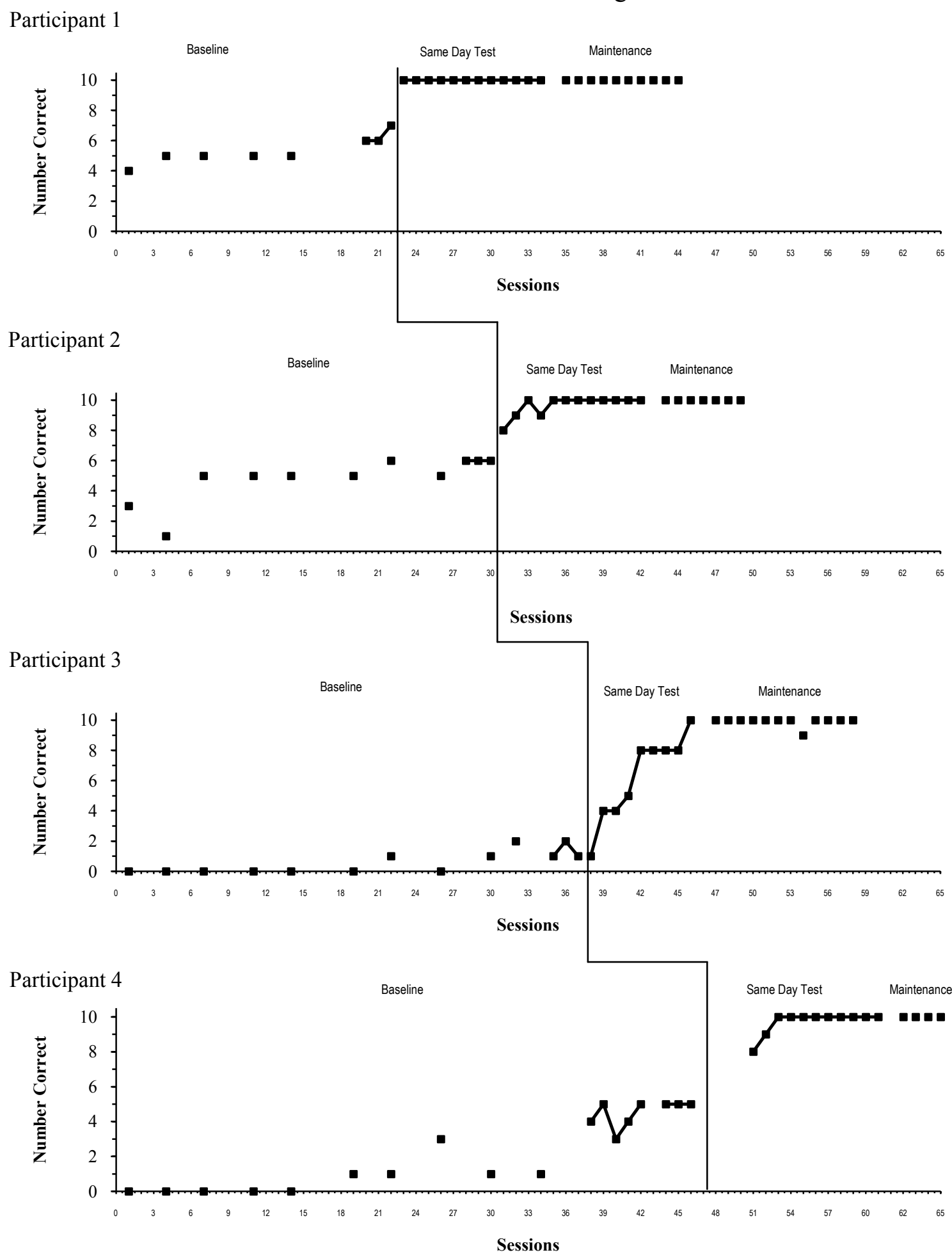

Figure 2. Phoneme Blending as measured by the number correct out of a total of 10 on baseline, intervention, and maintenance. 
While Participant 3 was in Phase II baseline, Phase III probes revealed a mean score of 3.88 (range 2-5). When Participant 3 moved into Phase II intervention, the mean score for Phase III baseline generalization probes was 5.00 representing an increase of 1.12. When Participant 3 moved into Phase II maintenance, a mean baseline score for Phase III could not be computed, as Participant 3 had already started intervention in Phase III (see Table 6).

Table 5

Phase II Phoneme Blending Baseline, Intervention and Maintenance

\begin{tabular}{|c|c|c|c|}
\hline Participant & Baseline & Intervention & Maintenance \\
\hline 1 & $\begin{array}{l}5.38 \\
(4-7)\end{array}$ & $\begin{array}{c}10.00 \\
(10-10)\end{array}$ & $\begin{array}{c}10.00 \\
(10-10)\end{array}$ \\
\hline 2 & $\begin{array}{l}4.82 \\
(1-6)\end{array}$ & $\begin{array}{c}9.67 \\
(8-10)\end{array}$ & $\begin{array}{c}10.00 \\
(10-10)\end{array}$ \\
\hline$/ 3$ & $\begin{array}{c}0.62 \\
(0-2)\end{array}$ & $\begin{array}{c}7.31 \\
(1-10)\end{array}$ & $\begin{array}{c}9.83 \\
(9-10)\end{array}$ \\
\hline 4 & $\begin{array}{l}2.39 \\
(0-6)\end{array}$ & $\begin{array}{c}9.70 \\
(8-10)\end{array}$ & $\begin{array}{c}10.00 \\
(10-10)\end{array}$ \\
\hline Group & $\begin{array}{l}3.30 \\
(0-6)\end{array}$ & $\begin{array}{c}9.17 \\
(8-10)\end{array}$ & $\begin{array}{c}9.96 \\
(9-10)\end{array}$ \\
\hline
\end{tabular}

Note. The top scores indicate individual means of number correct. The bottom rows represent the range of scores.

\section{Participant 4}

During baseline, Participant 4 had a mean score of 2.50 correct (range 0-6) out of a total of 10.00 on the phoneme blending same-day tests (see Figure 2, Table 5). When the explicit instruction intervention was introduced, Participant 4's mean score rose to a 
mean of 9.70 correct (range 8-10). This represents a mean increase of 7.31 correct from baseline to intervention.

Following a series of 8 days of 10/10 performances, Participant 4 entered into maintenance where a mean score of 10.00 (range 10-10) was achieved on 4 weekly maintenance tests (see Table 7). The mean maintenance score for Participant 4 was 0.30 more correct than her mean intervention same-day test scores.

Table 6

Phase III: Phoneme Segmentation Generalization Measures From

Phase II Phoneme Blending Conditions

\begin{tabular}{cccc}
\hline & \multicolumn{3}{c}{ Phase III Generalization Conditions } \\
\hline Participant & Baseline & Intervention & Maintenance \\
\hline 1 & 2.44 & 6.80 & 9.00 \\
& $(0-4)$ & $(5-8)$ & $(9-9)$ \\
2 & 2.88 & 7.33 & $\mathrm{x}$ \\
& $(1-5)$ & $(6-8)$ & $\mathrm{x}$ \\
3 & 3.88 & 5.00 & $\mathrm{x}$ \\
& $(2-5)$ & $(4-6)$ & \\
4 & 1.62 & 5.75 & $\mathrm{x}$ \\
& $(0-5)$ & $(5-7)$ & $\mathrm{x}$ \\
& & & 9.00 \\
Group & 2.57 & 6.31 & $(9-9)$ \\
\hline
\end{tabular}

Note. Top numbers refer to the mean performance in Phase III baseline generalization measures while in Baseline, Intervention, and Maintenance in Phase II. The bottom numbers refer to the range. An " $x$ " represents no probe taken.

While Participant 4 was in Phase II baseline, Phase III probes revealed a mean score of 1.62 (range 0-5). When Participant 4 moved into Phase II intervention, the mean 
score for Phase III baseline generalization probes was 5.75 representing an increase of 4.13. When Participant 4 moved into Phase II maintenance, a mean baseline score for Phase III could not be computed, as Participant 4 had already started intervention in Phase III (see Table 6).

Group

During baseline, the Group had a mean score of 3.30 (range 0-6) correct out of a total of 10.00 on the phoneme blending same-day tests (see Figure 2, Table5). When the explicit instruction intervention was introduced, the Group's mean score rose to a mean of 9.16 (range 8-10) correct. This represents a mean increase of 5.87 correct from baseline to intervention. The Group's maintenance mean score of 9.96 (range 9-10) was achieved on 10 weekly maintenance tests (see Table 7). The Group's mean maintenance score was .80 more correct than the mean intervention same-day test scores.

While the Group was in Phase II baseline, Phase III probes revealed a mean score of 2.57. When the Group moved into Phase I intervention, the mean score for Phase III baseline generalization probes was 6.31 representing an increase of 3.71. Additionally, when the Group moved into Phase II maintenance, only one generalization score for participant 1(9.0) was available (see Table 6). This is because as Participants 2, 3 and 4 moved into Phase II maintenance, a mean baseline score for Phase III could not be computed, as Participants 2, 3 and 4 had already started intervention in Phase III (see Table 6). 


\section{Table 7}

Weekly Maintenance Probes on Phase II: Phoneme Blending

\begin{tabular}{|c|c|c|c|c|c|c|c|c|c|c|c|}
\hline \multirow{2}{*}{ Participant } & \multirow{2}{*}{$\begin{array}{c}\text { Last Intervention } \\
\text { Score } \\
\end{array}$} & \multicolumn{10}{|c|}{ Week } \\
\hline & & 1 & 2 & 3 & 4 & 5 & 6 & 7 & 8 & 9 & 10 \\
\hline 1 & 10.00 & 10.00 & 10.00 & 10.00 & 10.00 & 10.00 & 10.00 & 10.00 & 10.00 & 10.00 & 10.00 \\
\hline 2 & 10.00 & 10.00 & 10.00 & 10.00 & 10.00 & 10.00 & 10.00 & 10.00 & 10.00 & $\mathrm{x}$ & $\mathrm{x}$ \\
\hline 3 & 10.00 & 10.00 & 9.00 & 10.00 & 10.00 & 10.00 & 10.00 & $\mathrm{x}$ & $\mathrm{x}$ & $\mathrm{x}$ & $\mathrm{x}$ \\
\hline 4 & 10.00 & 10.00 & 10.00 & 10.00 & 10.00 & 10.00 & $\mathrm{x}$ & $\mathrm{x}$ & $\mathrm{x}$ & $\mathrm{x}$ & $\mathrm{x}$ \\
\hline Group & 10.00 & 10.00 & 9.75 & 10.00 & 10.00 & 10.00 & 10.00 & 10.00 & 10.00 & 10.00 & 10.00 \\
\hline
\end{tabular}

Note. After receiving a minimum of 5 days of 10 out of 10 on the phoneme blending same-day test, the participant entered into weekly maintenance probes to determine if the skills taught were maintained over time. An "x" represents no maintenance probe taken. 


\section{Phase III: Phoneme Segmentation}

The third phase of this study was conducted to examine the effects of an intensive, explicit intervention in phoneme segmentation on four preschool children with phonological speech sound disorders. Each day a same-day test consisting of 10 items was administered following explicit instruction in phoneme segmentation. The number correct out of a total of 10 was recorded on the data log and graphed. Figure 3 displays the graphed data of all four participants. Table 8 displays data on each student's and the group's mean performance on phoneme segmentation same-day tests during baseline, intervention, and maintenance.

\section{Participant 1}

During baseline, Participant 1 had a mean score of 4.33 correct (range $0-9$ ) out of a total of 10.00 on the phoneme segmentation same-day tests (see Figure 3, Table 8). When the explicit instruction intervention was introduced, Participant 1's mean score rose to a mean of 10 correct (range 10-10). This represents a mean increase of 5.67 correct from baseline to intervention. Following a series of 11 days of 10/10 performances, Participant 1 entered into maintenance where a mean score of 10.00 (range 10-10) was achieved on 8 weekly maintenance tests (see Table 9). Participant 1's mean maintenance score was identical to her mean intervention same-day test scores.

\section{Participant 2}

During baseline, Participant 2 had a mean score of 4.33 correct (range $0-8$ ) out of a total of 10.00 on the phoneme segmentation same-day tests (see Figure 3, Table 8). When the explicit instruction intervention was introduced, Participant 2's mean score rose to a mean of 9.88 correct (range 9-10). This represents a mean increase of 5.55 
correct from baseline to intervention. Following a series of 12 days of 10/10

performances, Participant 2 entered into maintenance where a mean score of 10 (range 10-10) was achieved on 4 weekly maintenance tests (see Table 9). Participant 2's mean maintenance score was .12 higher than his mean intervention same-day test scores. Participant 3

During baseline, Participant 3 had a mean score of 4.06 correct (range 0-6) out of a total of 10.00 on the phoneme segmentation same-day tests (see Figure 3, Table 8). When the explicit instruction intervention was introduced, Participant 3's mean score rose to a mean of 8.92 correct (range 9-10). This represents a mean increase of 4.86 correct from baseline to intervention. Following a series of 6 days of $10 / 10$ performances, Participant 3 entered into maintenance where a mean score of 9.67, (range 9-10) was achieved on 3 weekly maintenance tests (see Table 9). Participant 3's mean maintenance score was .75 higher than his mean intervention same-day test scores.

\section{Participant 4}

During baseline, Participant 4 had a mean score of 2.53 correct (range $0-7$ ) out of a total of 10.00 on the phoneme segmentation same-day tests (see Figure 3, Table 8). When the explicit instruction intervention was introduced, Participant 4's mean score rose to a mean of 9.43 correct (range 9-10). This represents a mean increase of 6.90 correct from baseline to intervention. Following a series of 5 days of $10 / 10$ performances (see Table 9), Participant 4 entered into maintenance where a mean score of 10 (range 1010) was achieved on 3 weekly maintenance tests (see Table 9). Participant 4's mean maintenance score was .57 higher than her mean intervention same-day test scores. 
Phase III: Phoneme Segmentation
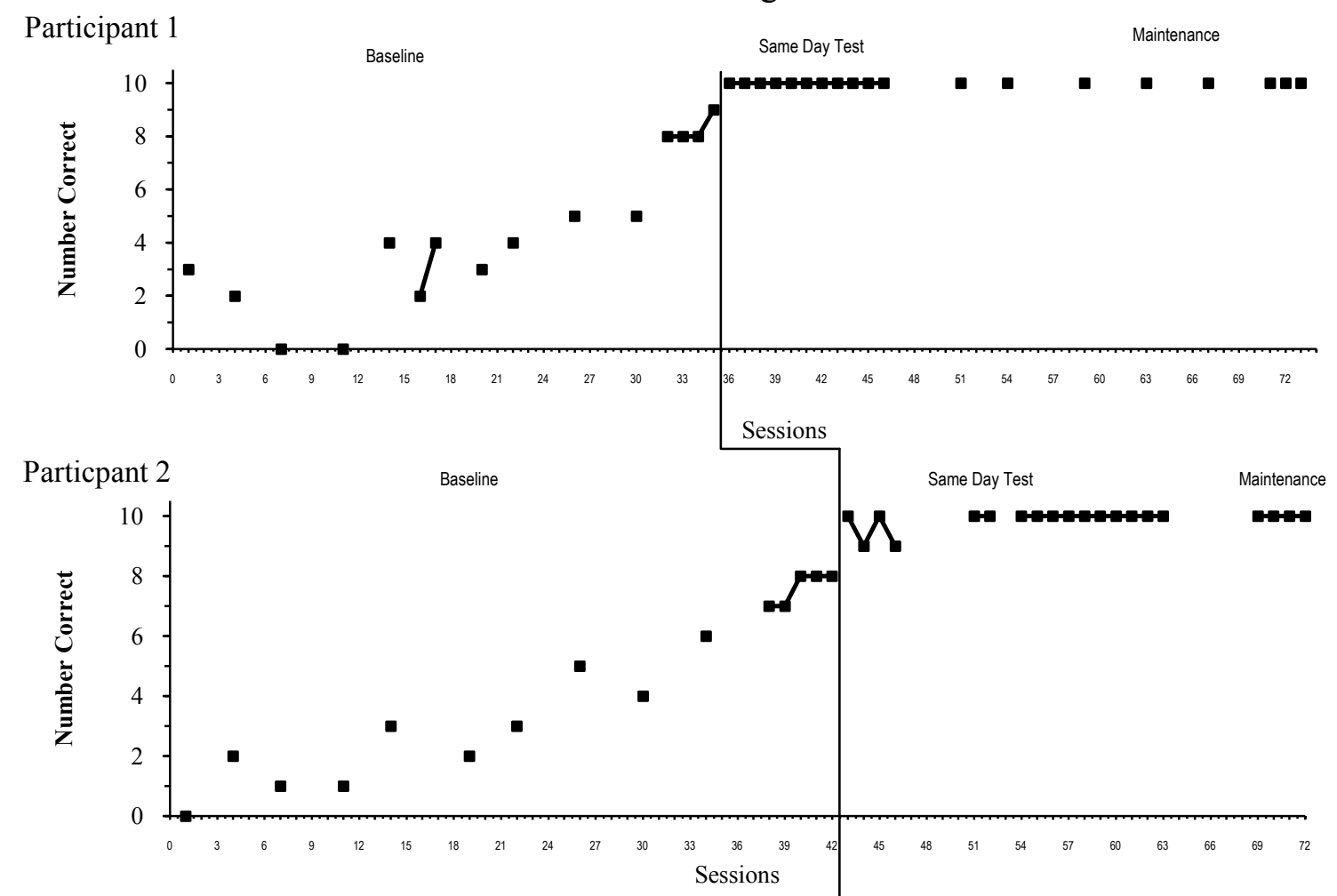

Particpant 3

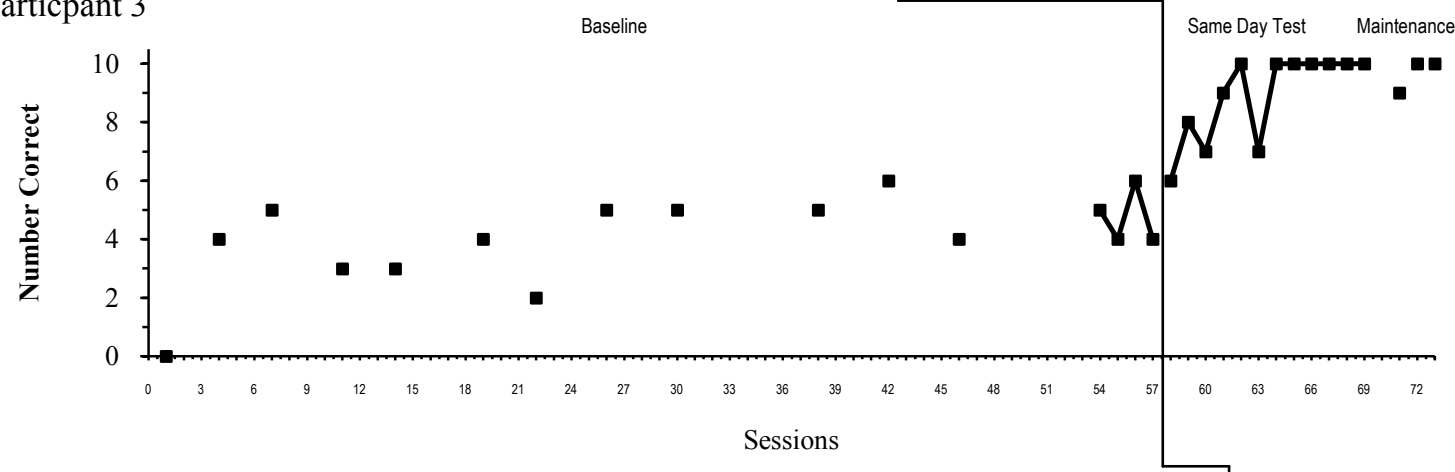

Participant 4

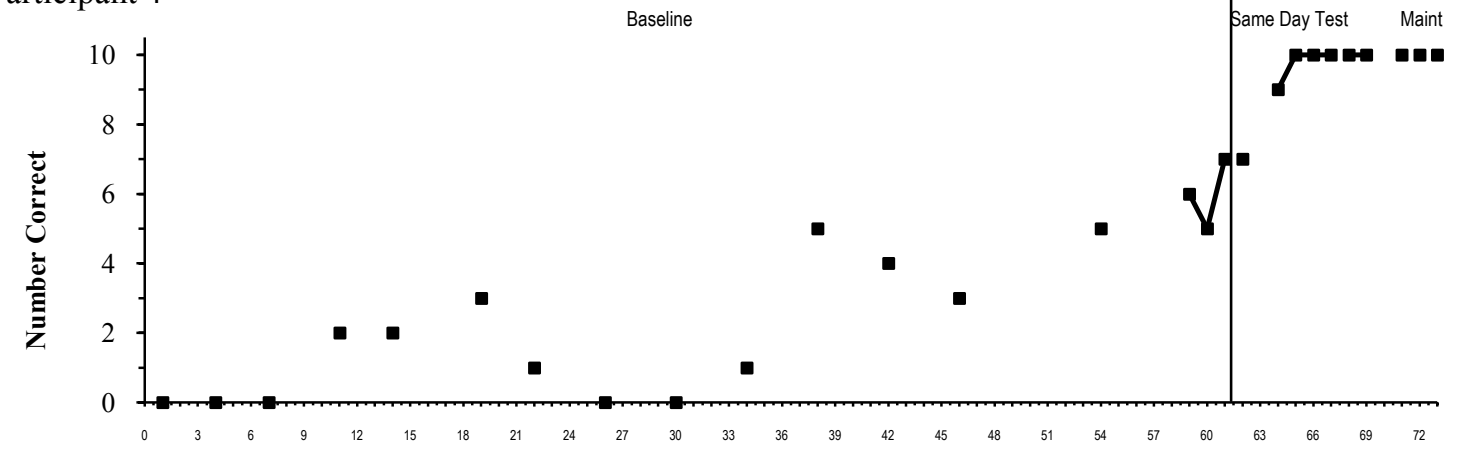

Figure 3. Phoneme Segmentation as measured by the number correct out of a total of 10 on baseline, intervention and maintenance. 
Table 8

Phase III: Phoneme Segmentation Baseline, Intervention and Maintenance Scores

\begin{tabular}{cccc}
\hline Participant & Baseline & Intervention & Maintenance \\
\hline \multirow{2}{*}{1} & 4.33 & 10.00 & 10.00 \\
& $(0-9)$ & $(10-10)$ & $(10-10)$ \\
2 & 4.33 & 9.88 & 10.00 \\
& $(0-8)$ & $(9-10)$ & $(10-10)$ \\
3 & 4.06 & 8.92 & 9.67 \\
& $(0-6)$ & $(6-10)$ & $(9-10)$ \\
4 & 2.53 & 9.43 & 10.00 \\
& $(0-7)$ & $(9-10)$ & $(10-10)$ \\
& 3.81 & 9.56 & 9.92 \\
Group & $(0-9)$ & $(6-10)$ & $(9-10)$ \\
& & & \\
\hline
\end{tabular}

Note. The top scores indicate individual means of number correct. The bottom rows represent the range of scores.

Group

During baseline, the Group had a mean score of 3.81 correct out of a total of 10 on the phoneme segmentation same-day tests (see Figure 3, Table 8). When the explicit instruction intervention was introduced, the Group's mean score rose to a mean of 9.56 correct. This represents a mean increase of 5.75 correct from baseline to intervention. The Group's mean score of 9.92 (range 9-10) was achieved on 8 weekly maintenance tests. The Group's mean maintenance score was .36 higher than their mean intervention sameday test scores (see Table 9).

\section{Results of Goldman-Fristoe 2 Test of Articulation}

Prior to the beginning of the study and at the study's completion, all four participants were given the Goldman-Fristoe 2 Test of Articulation. At the pre-study 
Table 9

Weekly Maintenance Probes on Phoneme Segmentation

\begin{tabular}{|c|c|c|c|c|c|c|c|c|c|}
\hline \multirow{2}{*}{ Participant } & \multirow{2}{*}{$\begin{array}{c}\text { Last Intervention } \\
\text { Score }\end{array}$} & \multicolumn{8}{|c|}{ Week } \\
\hline & & 1 & 2 & 3 & 4 & 5 & 6 & 7 & 8 \\
\hline 1 & 10.00 & 10.00 & 10.00 & 10.00 & 10.00 & 10.00 & 10.00 & 10.00 & 10.00 \\
\hline 2 & 10.00 & 10.00 & 10.00 & 10.00 & 10.00 & $\mathrm{x}$ & $\mathrm{x}$ & $\mathrm{x}$ & $\mathrm{x}$ \\
\hline 3 & 10.00 & 9.00 & 10.00 & 10.00 & $\mathrm{x}$ & $\mathrm{x}$ & $\mathrm{x}$ & $\mathrm{x}$ & $\mathrm{x}$ \\
\hline 4 & 10.00 & 10.00 & 10.00 & 10.00 & $\mathrm{x}$ & $\mathrm{x}$ & $\mathrm{x}$ & $\mathrm{x}$ & $\mathrm{x}$ \\
\hline Group & 10.00 & 9.75 & 10.00 & 10.00 & 10.00 & 10.00 & 10.00 & 10.00 & 10.00 \\
\hline
\end{tabular}

Note. After receiving a minimum of 5 days of 10 out of 10 on the phoneme segmentation same-day test, the participant entered into weekly maintenance probes to determine if the skills taught were maintained over time. An " $\mathrm{x}$ " represents no maintenance probe taken. 
assessment, each participant placed at or below the 21 st percentile in articulation development (Goldman-Fristoe 2 Test of Articulation, 2000) as compared to all children in his or her age group (4 years, 5 months to 5 years of age). All participants made substantial gains when assessed again at the end of the study (see Table 10). When the participants began the integrated phonemic awareness/ phonological speech sound intervention their scores on the Goldman Fristoe -2 Test of Articulation were $13 \%, 12 \%$, $21 \%$ and $18 \%$ respectively. When the Goldman Fristoe 2 Test of Articulation readministered at the end of the study, their scores improved to $81 \%, 29 \%, 85 \%$ and $63 \%$, respectively (see Table 10).

Table 10

Results of Pre-Study Post-Study Test of the Goldman-Fristoe 2 Test of Articulation

\begin{tabular}{cccc}
\hline Participant & $\begin{array}{c}\text { Pre-Study } \\
\text { Raw Score and } \\
\text { Percentile Pretest }\end{array}$ & $\begin{array}{c}\text { Post-Study } \\
\text { Raw Score and } \\
\text { Percentile Posttest }\end{array}$ & $\begin{array}{c}\text { Pre-Post Study } \\
\text { Raw Score and } \\
\text { Percentile } \\
\text { Differences }\end{array}$ \\
\hline 1 & 26 & 1 & 25 \\
2 & $13 \%$ & $81 \%$ & $68 \%$ \\
3 & 31 & 11 & 20 \\
& $12 \%$ & $29 \%$ & $17 \%$ \\
4 & 27 & 2 & 25 \\
& 23 & $85 \%$ & $64 \%$ \\
Group & $18 \%$ & 3 & 20 \\
& 26.75 & $63 \%$ & $45 \%$ \\
& $(12 \%-21 \%)$ & $(29 \%-81 \%)$ & 22.50 \\
\hline
\end{tabular}

Note. The top scores represent the raw score or number incorrect. The more sounds that are marked as incorrect, the higher the score. Subsequently, a lower score reflects better performance. The bottom row is the percentile ranking for the participant's age and gender. As the number of incorrect sounds decreases, the percentile ranking increases. 


\section{Results Summary}

The results of this study demonstrated that the participants improved their abilities to identify initial and final sounds (Phase I: Phoneme Identity), blend consonant and vowel sounds into two- and three-letter words (Phase II: Phoneme Blending), and segment two- and three-letter words into their component sounds (Phase III: Phoneme Segmentation).

During Phase I: Phoneme Identity, a same-day test consisting of 10 items was administered to each participant during baseline, intervention, and maintenance. During intervention, all four participants increased their mean number correct over baseline means by $4.85,3.94,5.25$, and 5.87 , respectively. After a minimum of 5 consecutive days of 10 out of 10 correct, each participant entered maintenance; a mean score of 10 out of 10 was achieved for all four participants during weekly and biweekly maintenance tests. Taken together, these scores indicate that all participants made substantial gains as a result of Phase I Phoneme Identity intervention.

Generalization probes were taken in Phase II during baseline, intervention, and maintenance in Phase I. While the participants were in Phase I baseline, the mean baseline scores in Phase II were 4.50, 3.50, 0.00, and .29 respectively. When Participants entered into Phase I intervention, there was an increase of $0.50,1.83,0.80$, and 2.51 respectively. When each of the four participants moved into Phase I maintenance, an additional increase of $1.33, .42, .53$, and 1.70 was observed respectively.

Generalization probes were taken in Phase III during baseline, intervention, and maintenance in Phase I. While the participants were in Phase I baseline, the mean baseline scores in Phase III were 2.50, 1.33, 3.00 and 1.14, respectively. When 
participants entered into Phase I intervention, participants 2, 3 and 4 had increases in Phase III baseline by $1.34,1.00$, and .36. There was a decrease in the mean baseline score for Participant 1 by 1.0. An additional increase in Phase III baseline occurred during Phase I maintenance for 3 students with increases of $1.83,1.00$, and 2.00 respectively. Participant 1 also increased from intervention to maintenance by 1.75 . Taken together, these scores indicate that each participant increased the mean total number correct in Phase III baseline as a result of the Phase I: Phoneme Identity intervention. During Phase II: Phoneme Blending, a same-day test consisting of 10 items was administered to each participant during baseline, intervention and maintenance. During intervention, all four participants increased their mean number correct over baseline means by $4.62,4.85,6.63$ and 7.20 respectively. After a minimum of 5 consecutive days of 10 out of 10 correct, each participant entered maintenance and a mean score of 10 out of 10 was achieved for Participants 1, 2 and 4 in weekly maintenance tests. Participant 3's mean maintenance score was 9.83 out of 10.00 in weekly maintenance tests. Taken together, these scores indicate that all participants made substantial gains as a result of Phase II: Phoneme Blending intervention.

Generalization probes were taken in Phase III during baseline, intervention and maintenance in Phase I. While the participants were in Phase II baseline, the mean baseline scores in Phase III were 2.44, 2.88, 3.88 and1.62 respectively. When the participants entered into Phase II intervention, there was an increase of 4.36, 4.45, 1.12, and 4.13 respectively. When Participant 1 moved into Phase II maintenance, an additional increase of 2.2 was observed. However, when Participants 2, 3 and 4 moved 
into Phase II maintenance, a mean baseline score could not be computed, as these participants had already started intervention in Phase III.

During Phase III: Phoneme Segmentation, a same-day test consisting of 10 items was administered to each participant during baseline, intervention, and maintenance. During intervention, all four participants increased their mean number correct over baseline means by $5.67,5.48,4.86$, and 6.50 respectively. After a minimum of 5 consecutive days of 10 out of 10 correct, each participant entered maintenance and a mean score of 10 out of 10 was achieved for participants 1,2 and 4. Participant 3 received a mean maintenance score of 9.67 out of 10.00 in weekly maintenance tests. Taken together, these scores indicate that all participants made substantial gains as a result of Phase III: Phoneme Segmentation intervention. 


\section{CHAPTER V \\ DISCUSSION}

This chapter provides a discussion of the results of this study. A brief study overview is followed by a summary of the results with respect to relevant literature in the phonemic awareness development in prekindergarten children with speech and language impairments. The study's implications for practice, delimitations, limitations, and suggestions for future research are also included.

This study examined the effects of a short-term intensive intervention in three phonemic-awareness skills, phoneme identity, phoneme blending, and phoneme segmentation on four prekindergarten children with expressive phonological delays. The research had three distinct studies referred to as Phase I: Phoneme Identity, Phase II: Phoneme Blending, and Phase III: Phoneme Segmentation. Each phase included its own multiple-baseline design across subjects with baseline, intervention (explicit instruction), and maintenance conditions, and data were collected across 77 sessions. Once each of the participants completed a minimum of 5 consecutive days of $100 \%$ criterion in Phase I, he or she moved independently into maintenance and into the second and then the third phase. Maintenance tests were then given to each participant weekly or biweekly from 3 to 10 weeks after the completion or each phase. In addition, periodic probes of the phases that had not yet received instruction were taken to measure generalization of learning.

The results of this study demonstrated that short-term intensive and explicit interventions in phoneme identity, phoneme blending, and phoneme segmentation were successful in teaching these three skills to four prekindergarten children with expressive 
phonological delays. These skills were learned quickly once interventions began and those skills learned were maintained during weekly and biweekly maintenance probes. Also, overall some generalization of learned skills were observed more so from Phase II: Phoneme Blending intervention to Phase III: Phoneme Segmentation performance than from Phase I: Phoneme Identity intervention to Phases II: Phoneme Blending and Phase III: Phoneme Segmentation. Probes taken in Phase II baseline from Phase I intervention demonstrated a range of marginal improvements for Participants 1-3, and substantial generalization for Participant 4 (4.21 more correct). Probes taken in Phase III baseline from Phase I intervention demonstrated marginal improvements for Participants 1, 3 and 4, and more substantial generalization for Participant 2 (3.17 more correct). In addition, generalization was more substantial in Phase III baseline while the participants were in Phase II intervention with scores of more than 4 more correct for participants 1, 2 and 4, and marginal generalization for Participant 3. According to Cooper et al. (2007), the principle of stimulus generalization states that a target response is likely to be emitted in the presence of stimuli with a high degree of similarity to the stimulus conditions under which it was previously reinforced. This was the case for Phases II and III, as phoneme blending and phoneme segmentation are similar and reciprocal skills which may have promoted increased generalization. Also, developing fluency in Phase I, phoneme identity, may have taught the participants to "listen for" phonemes at the beginning and end of words. Subsequently, this prior auditory training may have supported the increased generalization from Phase II to Phase III.

On the Goldman-Fristoe 2 Test of Articulation, all participants had gains from their pre-study scores to their post study scores. Although the study was not designed to 
analyze directly the effects of the intervention on this assessment, given that the intervention related to the skills being assessed on the Goldman-Fristoe 2 and that the participants' improvements are beyond those that would typically be expected during the study's time period, it is likely that intervention positively impacted the post-study scores.

Following is a detailed discussion of the results for each dependent variables, phoneme identity, phoneme blending, and phoneme segmentation. The discussions include connections to the related literature.

\section{Phase I: Phoneme Identity}

Each of the four participants in this phase of the study exhibited a phonological speech sound disorder, as well as weaknesses in phonemic awareness, including phoneme identity. Research has demonstrated that children with an impaired phonological processing system exhibit under-specified phonological representations in memory (Elbro et al., 1998; Gillon, 2004). This makes it difficult for these children to develop the lettersound connection (the alphabetic principle), and store this representation in memory so that they can identify specific sounds, and learn to discriminate between sounds.

In Phase I: Phoneme Identity, all four participants made substantial gains in their ability to identify initial and final sounds as a result of the explicit and intensive instruction in phoneme identity provided during intervention. Specifically, all four participants increased their mean number correct over baseline by $4.85,3.94,5.25$ and 5.87 responses correct out of 10 respectively. All participants learned to consistently apply the alphabetic principle and listen for and identify words that began or ended with the same sound (phoneme). Furthermore, the participants maintained 100\% performance 
$(10 / 10$ correct $)$ once the intervention was removed. Also, the explicit intervention in phoneme identify led to some marginal to substantial generalization of effects in both Phase II: Phoneme Blending baseline and Phase III: Phoneme Segmentation baseline. During explicit instruction in Phase I: Phoneme Identity all participants were exposed to the letters that represent the sounds to support the development of the alphabetic principle. Also, when the child misarticulated the word, the researcher modeled the correct production to support the development of a strong phonemic representation and correct production of the target sounds. The value of teaching the letter-sound connection to the participants supports the findings of Catts et al. (2002) who stated that the knowledge of the alphabet and the alphabetic principle (the letter-sound connection) in kindergarten are the strongest predictors of reading success.

Previous research emphasizes that the participants in the present study were at increased risk to learn the phoneme identity skill due to their phonological speech sound disorder (Gillon, 2000, 2005; Rvachew et al., 2003). The results of this research support Gillon's study (2000) as all four participants were able to successfully master initial and final phoneme identity with an intensive and explicit approach. In Gillon's study, children with phonological speech sound disorders resolved phonemic awareness deficits (such as phoneme identity) and accelerated early reading and spelling performance with direct and relatively intensive therapy ( 2 hours a week for 10 weeks). The use of explicit and intensive intervention is also supported by the previous research of Torgesen (2002) who stated that it is possible to teach phonemic awareness skills to at- risk children with early phonemically explicit and intensive intervention. 
Phase II: Phoneme Blending

In Phase II: Phoneme Blending, all four participants made substantial gains in their ability to blend two and three sounds (and letters) into simple words as a result of the explicit and intensive intervention in phoneme blending provided during intervention. Specifically, all four participants increased their mean number correct over baseline means by $4.62,4.85,6.63$ and 7.31 responses correct out of 10.00 respectively. They all learned to consistently apply the alphabetic principle and blend two and three sounds (and letters) into simple words. Furthermore, Participants 1,2 and 4 maintained 100\% performance (10/10) once the intervention was removed, and Participant 3 maintained $98.30 \%(9.83$ out of 10.00$)$ on weekly maintenance tests.

During explicit instruction in Phase II Phoneme Blending, all participants were exposed to the letters that represent the sounds to support the development of the alphabetic principle. Also, when the child misarticulated the word, the researcher modeled the correct production to support the development of a strong phonemic representation and correct production of the target sounds. The results of this study support the work of Gillon (2000) who demonstrated substantial gains using an integrated phonemic awareness instruction (blending) and phonological speech sound intervention. The research of Qi and O’Connor (2000) demonstrated that low-skilled kindergarten children who learned to connect phoneme awareness instruction (including blending) and the sound segments in words to their corresponding printed symbols became better readers than those who had difficulty learning these skills. The children in the present study have learned the same skills and are currently decoding two and three phoneme syllables/words. 
In addition, the explicit intervention in Phase II: Phoneme Blending led to some substantial generalization of effects which was measured as an increased mean number correct in Phase III: Phoneme Segmentation for Participants 1, 2 and 4. This finding contradicts the findings of Roth et al. (2006) who used a multiple baseline design across behaviors (i.e., rhyming, sound blending and sound segmentation) to investigate the effectiveness of the blending portion of phonological awareness program (PASS) developed by these authors. While all children made gains in their ability to blend sounds into words following explicit instruction, the results of their study indicated that the blending treatment effects were localized, and there was no substantial improvement in the untrained area of segmentation.

\section{Phase III: Phoneme Segmentation}

In Phase III: Phoneme Segmentation, all four participants made substantial gains in their abilities to segment words into two and three sounds (and letters) as a result of the explicit and intensive intervention in phoneme segmentation provided during intervention. Specifically, all four participants increased their mean number correct over baseline means by $5.67,5.55,4.86$ and 6.90 responses correct out of 10.00 respectively. Furthermore, Participants 1, 2 and 4 maintained 100\% performance (10/ 10 correct) once the intervention was removed, and Participant 3 received a mean maintenance score of $96.70 \%$ (9.67 out of 10$)$ in weekly maintenance tests.

During explicit instruction in Phase III: Phoneme Segmentation all participants were exposed to the letters that represent the sounds to support the development of the alphabetic principle. Also, when the child misarticulated the word, the researcher 
modeled the correct production to support the development of a strong phonemic representation and correct production of the target sounds.

This research in phoneme segmentation extends the work of previous researchers (Gillon, 2000; Qi \& O'Connor, 2000) who have included phoneme segmentation as part of a phonemic awareness intervention program. Qi and O'Connor (2000) provided 20-30 minutes of training twice a week for 10 weeks in segmenting and blending together to one group, and first sound identification and rhyming to the second group, and found that both tasks improved kindergarteners' phoneme awareness and letter knowledge. The Gillon (2000) study included phoneme segmentation as part of a 20-hour integrated phonological awareness intervention. In each 1-hour session, several tasks were presented for 5-10 minute periods each, and tasks such as phoneme segmentation were discontinued once the child reached $100 \%$ accuracy. The present study examined the effects of a more explicit and intensive intervention (4 days per week for 30 minutes) on the development of phoneme segmentation as a separate skill. This study extended the previous research as it continued intervention until $100 \%$ criterion was reached for all participants. A maintenance component measured the effects of training over time. In addition, this study also examined the generalization effects of phoneme identity and phoneme blending intervention on the baseline measures of phoneme segmentation.

\section{Results Summary Phases I, II, and III}

This study examined the effects of a short-term explicit and intensive intervention in three developmentally sequential phonemic awareness skills, phoneme identity, phoneme blending, and phoneme segmentation on four prekindergarten children with expressive phonological delays. The research had three distinct studies referred to as 
Phase I: Phoneme Identity, Phase II: Phoneme Blending, and Phase III: Phoneme Segmentation. The participants made substantial progress in all three phases, and these improvements were maintained during weekly and biweekly maintenance measures.

The findings of this study are meaningful on several levels. First, the selection of the phonological awareness skills for training in this study was important. While training in all phonological awareness skills is important, it appears that skills that focus on intervention at the phoneme level are most effective (Gillon, 2005b). According to Gillon (2005b), it is important to select skills at the phoneme level that integrate letter-sound knowledge in order to develop strong phonemic awareness and letter knowledge skills in order to facilitate successful decoding attempts at school entry. Research has demonstrated that phonemic awareness skills develop sequentially (Anthony et al., 2002). The three developmentally sequential phonemic awareness skills selected for this study focused on training at the phoneme level and consistently integrated letters with sounds during explicit intervention activities to support phonemic decoding. Previous studies (Gillon, 2000; Qi \& O'Connor, 2000; Roth et al., 2002; Van Kleeck et al., 1998) did not focus specifically at the phoneme level, but rather included other earlier phonological awareness skills including rhyming. The present study extended the previous literature by using the same four participants to focus only on phonemic awareness skills and providing a developmentally sequential intervention on one task at a time until criterion was reached.

As a result of intervention in the three phases, all participants learned to consistently identify initial and final sounds, blend sounds into two- and three-letter words, and segment two- and three-letter words into their component sounds. This is 
especially important considering that the participants exhibited a speech sound disorder which research has demonstrated is normally associated with weak phonological representations in memory (Gillon, 2005; Sutherland \& Gillon, 2005).

Second, it appears that the effects of an explicit and intensive intervention led to accelerated and maintained development of the three phonemic awareness skills. Each participant was seen individually 4 days per week for 30 minutes during intervention in each phase. All participants demonstrated an increased number of correct responses upon the implementation of the intervention, and reached $100 \%$ criterion (10 out of 10 correct) within 10 days of intervention for all three skills. Torgesen (1998) recommends the use of early explicit and intensive phonemic awareness intervention for children at risk for reading failure. The results of this research demonstrate and support Torgesen's findings that if educators are able to identify and remediate phonemic deficits early on using explicit and intensive interventions, children may benefit from a preventative rather than a remedial model of intervention.

Third, this study's results demonstrated that intensive and explicit intervention in one skill resulted in varying degrees of generalization to the other skills. Phase I: Phoneme Identity resulted in some generalization to Phase II: Phoneme Blending and Phase III: Phoneme Segmentation. In addition, intensive and explicit intervention in Phase II: Phoneme Blending resulted in more substantial generalization to Phase III: Phoneme Segmentation. These findings are important because it appears that letter knowledge and phoneme identity interventions stimulate the development of specific phoneme representations (Elbro et al., 1998), even for children who are at-risk because of phonological speech sound disorders. While phonological awareness and phonemic 
awareness are developmental skills, they can be acquired in overlapping rather than temporally discrete stages (Anthony et al., 2003). In this study, it appears that the intensive and explicit intervention in phoneme identity helped to stimulate the development of specific phoneme representations that led to some improvement in the baseline measurements of phoneme blending and phoneme segmentation skills. In addition, phoneme-blending intervention generalized to more substantial improvement in phoneme segmentation skills. These findings contradict the results of Roth et al. (2006), who stated that the effects of a blending intervention was localized, and there was no substantial improvement in the untrained area of segmentation.

\section{Goldman-Fristoe 2 Test of Articulation, 2000}

Prior to beginning this study, all four participants placed at or below the 21 st percentile in articulation development on the Goldman-Fristoe 2 Test of Articulation (2000) as compared to all children in their age group ( 4 years, 5 months to 5 years of age).While the participants began the integrated phonemic awareness/ phonological speech sound intervention their scores on the Goldman-Fristoe 2 Test of Articulation were $13 \%, 12 \%, 21 \%$ and $18 \%$ respectively. At the end of the study, their scores ---improved to $81 \%, 29 \%, 85 \%$ and $63 \%$ respectively. This is an average of $48.5 \%$ improvement for the four participants. These findings support previous research by Gillon (2000, 2005) and Roth et al. (2006). In the Gillon (2000) study, all children in the integrated phonological awareness group showed an average of $13.2 \%$ improvement over the course of the 20-hour individualized intervention as measured by the GoldmanFristoe Test of Articulation. In the current study, all participants made improvements greater than those reported by Gillon (2000). The participants in the current study 
received an integrated phonemic awareness/speech intervention 4 days per week (which totaled more than the 20 hours reported by Gillon), but in addition, also received one 30minute session per week of individualized speech therapy sessions designed to address each participant's specific needs. In the Gillon (2005) longitudinal study over a 3-year period, all children demonstrated improvements in articulation development while participating in a phoneme awareness intervention program with the greatest improvements noted during the first 8-12.months. In the Roth et al. study (2006), all the children in the reported cohorts who participated in the blending portion of the PASS program received individualized speech and language therapy; however, the effects of gains in blending skills were not compared specifically with changes in speech and/or language skills.

\section{Implications for Practice}

The results of this study have important implications for speech therapy intervention services and classroom emergent literacy/phonological awareness instruction. Research has determined that preschoolers' and kindergarteners' performance on phonological awareness tasks, particularly phonemic awareness tasks, is the single best predictor of their first and second grade decoding skills (Roth et al., 2002; Scarborough, 2005; Torgesen et al., 1994). In addition, children who have phonological speech sound errors are at risk for learning phonemic awareness skills and learning to read even if the disorder was normalized prior to school entry (Raitano et al., 2004).

The interventions used in this study were effective in improving phonemic awareness skills and speech sound errors concurrently with all of the participants. Research has demonstrated that if developing speech sounds are not related to the sound 
structure of spoken language, it may result in insufficiently developed phoneme representations and phonemic awareness skills (Gillon, 2004). Based upon Gillon's research and the findings of this study, speech-language pathologists should play an active role in the development of phonological awareness skills in the children in their caseloads, as well as all children with delayed phonological awareness skills.

The speech-language pathologist has knowledge of the development of normal and disordered speech and language acquisition, and the development of phonological processing. Speech-language pathologists are trained to develop individualized programs based upon each child's strengths and weaknesses, and therefore have the skills necessary to design the appropriate interventions to develop oral and written language (ASHA, 2001). The development of these skills are particularly important in order to close the literacy gaps present for many children when they enter kindergarten prior to the early years of reading instruction (Foster \& Miller, 2007). In order to do this, the speechlanguage pathologist should assess the development of phonological awareness skills and alphabet knowledge in all incoming kindergarten children with speech and language disorders as part of their overall speech and language evaluation. This assessment should include information including the child's development of the alphabetic principle, rhyming, phoneme identity, phoneme blending, and phoneme segmentation. The results of this assessment should be compared to developmental milestones for phonological awareness. For example, children are able to divide words into syllables and learn rhymes prior to developing phoneme level skills such as phoneme identity, phoneme blending and phoneme segmentation. If the child has demonstrated syllable awareness and rhyming, focused interventions should be at the phoneme level (Gillon, 2005). The 
speech-language pathologist can then plan interventions to include developing the child's phonological awareness skills along with goals for remediating speech and/or language deficits without too much additional time.

This research has demonstrated, teaching both skills concurrently are beneficial and reinforcing to the development of both skills. For example, as this study suggests, phoneme identity can be introduced during articulation drills by emphasizing the child's target sounds in initial and final sounds/letters. The child's target sounds can also be used to blend words and segment words into their component sounds.

Early elementary classroom teachers should be cognizant of students in their classrooms who present speech and/or language difficulties, and make the proper referrals to speech-language pathologists for further evaluation. Teachers also need to collaborate with speech-language pathologists and reading specialists in order to identify deficits and implement evidence-based phonemic awareness instruction such as the tasks chosen for this study in their classrooms. This instruction should be implemented explicitly and intensively, especially for at-risk students during the prekindergarten and kindergarten years (Justice, 2006). This is extremely important since longitudinal studies have typically presented persistent weakness in areas critical to reading and spelling (e.g., phonological awareness) for children with speech-language impairment (Gillon, 2005). Researchers state that it is critical to design and implement phonological awareness interventions that are explicit and draw on best practice evidence to date (Schuele \& Boudreau, 2008). The prevention of early reading and spelling difficulties for children who are at risk will only be realized if practitioners appropriately integrate research findings to modify or change their existing practice. 


\section{Limitations of Study}

The four participants in this study were selected from all three prekindergarten classrooms (two participants were in the same classroom). Although the preschool does not emphasize a phonological awareness curriculum, it is hard to determine whether each of the three teachers placed more or less emphasis on working with their students to develop the alphabetic principle in their classrooms. Whether this had an effect on the results of the intervention is difficult to determine, as all four participants made substantial gains and maintained them over weekly and biweekly sessions.

Another limitation was that the participants in this study were participating during the course of a normal preschool day. Although all four participants were pulled from their classrooms each day, depending upon what was happening at the school or in the classroom, the order of which participant was seen in which order was altered. Two of the students were in the same class, and sometimes the teacher asked that they did not follow each other if there was a particular activity going on in the classroom. In addition, two of the students received occupational therapy for fine motor development, and every effort was made that this intervention session did not follow their sessions, so that fatigue would not affect performance.

A final limitation concerned time constraints. Although each of the participants demonstrated a minimum of $100 \%$ criterion for a minimum of 5 days, the number of data points in the maintenance phase was fewer for Participant 3 and Participant 4 in the third phase of the study as the school year was drawing to an end. In addition, absences due to child illnesses affected the progression of the study and caused the study to be extended longer than anticipated. 


\section{Suggestions for Future Research}

The results of this study suggest several areas for future research. The demographic characteristics of the participants who took part in this study were restricted to four prekindergarten children with a combined phonemic awareness deficit and a phonological speech sound disorder. Additional research should repeat this study with larger groups of students, and compare the results with normally developing children. Future research might include students of other ages, from nursery-school through elementary age children. Additionally, adolescents with persisting speech sound disorders and reading deficits who exhibit a risk factor for phonological processing disorders (Preston \& Edwards, 2007) should be included in future research. Children with combined speech and language deficits might also be included in the future, as research has demonstrated that a combined deficit is additive in nature with even greater potential effects on reading development (Raitano et al., 2004). Also, additional research might include English Speakers of Other Language (ESOL) students to determine whether the interventions would be beneficial for students who do not learn English as their first language.

The results of this study demonstrated the effectiveness of the developed explicit and intensive intervention used to teach phoneme identity, phoneme blending and phoneme segmentation. Future research could vary the content, duration, level of explicitness and intensity of the intervention. In addition, the current study provided oneto-one intervention with a speech-language pathologist/researcher. Future research should examine the results of training teachers and support personnel to implement the developed explicit and intensive intervention with supervision by the speech-language 
pathologist. The effects of training on a one-to-one basis as compared to the effects of training in small groups also should be explored.

\section{Discussion Summary}

The results of this study demonstrated that short-term intensive and explicit interventions in three phonemic awareness skills, phoneme identity, phoneme blending, and phoneme segmentation were successful in teaching these three developmentally sequential skills to four prekindergarten children with expressive phonological delays.

The research had three distinct studies referred to as Phase I: Phoneme Identity, Phase II: Phoneme Blending, and Phase III: Segmentation. Each phase had its own multiplebaseline across subjects design that included baseline, intervention, and maintenance conditions. Each participant reached a $100 \%$ criterion before moving on to the next skill, and skills were maintained during weekly and biweekly maintenance measures. Some generalization of skills from Phase I intervention was noted in Phase II and Phase III baseline, and more substantial generalization of skills from Phase II intervention was noted in Phase III baseline.

The findings of this study are meaningful on several levels. First, the selection of three developmentally sequential tasks at the phoneme level integrated with letter-sound knowledge was important. As a result of the intervention in the three phases, all participants learned to consistently identify initial and final sounds, blend sounds into two- and three-letter words, and segment two- and three-letter words into their component sounds. Second, the effects of an explicit and intensive intervention led to accelerated and maintained development of phoneme identity, phoneme blending and phoneme segmentation skills. All participants demonstrated an increased number of 
correct responses upon the implementation of the intervention, and reached a $100 \%$ criterion within 10 days of intervention for all three skills. Third, this study demonstrated that intensive and explicit intervention in Phase I led to some generalization to Phase II and Phase III baseline skills, and intervention in Phase II led to more substantial generalization to Phase III baseline skills. From a behavior analytic perspective, the increased generalization from Phases II to III could likely be explained due to the response similarities in those two skills (Cooper et al., 2007). Also, it is unknown how much the learning of Phase I skills influenced the increased generalization from Phase II to Phase III

In this study all four participants concurrently received speech therapy on a one session per week basis and demonstrated significant improvement in their articulation development while concurrently improving their phonemic awareness skills. Previous research has demonstrated that an integrated phonological awareness intervention program for children between the ages of 5 to 7 had a significant effect on improving phoneme awareness and speech production concurrently (Gillon 2000). Gillon further stated that explicit phoneme awareness and the development of the alphabetic principle may assist children in establishing accurate phonological representations necessary for remediating phonologically based speech sound errors. Once the child becomes consciously aware of the number and order of phonemes in a word, the child may be able to realize the breakdown in his or her communication attempt, and learn to self-correct any errors. The results of this study support Gillon's (2000) findings. In addition, these findings extend Gillon's research by employing a preschool, rather than a school age sample, providing intensive and explicit intervention on a four-day a week basis rather 
than a total of 20 hours twice a week, and by including a separate weekly individualized speech therapy session in addition to the integrated phonemic awareness program.

Speech-language pathologists should play an active role in the development of phonological awareness skills in the children in their caseloads, as well as all children with delayed phonological awareness skills. The speech-language pathologist has knowledge of the development of normal and disordered speech and language acquisition, and therefore has the skills to help develop speech sounds as well as oral and written language (ASHA, 2001). In order to do this, the speech-language pathologist should assess the development of phonological awareness skills and alphabet knowledge in all incoming kindergarten children with speech and language disorders as part of their overall speech and language evaluation. The speech-language pathologist can then plan their intervention to include developing the child's phonological awareness skills along with their goals for speech and/or language deficits without taking much additional time. As this research has demonstrated, teaching both skills concurrently is beneficial and reinforcing to the development of both speech production skills and phonemic awareness development. In addition, classroom teachers need to identify and refer students with speech and/or language difficulties to the speech-language pathologist for further evaluation. Classroom teachers need to collaborate with speech-language pathologists in order to help identify students who exhibit phonological awareness delays, and develop explicit and intensive evidence-based phonemic awareness interventions.

Since this study explored the effects of three phonemic awareness skills to four prekindergarten children with phonological speech sound deficits, the results may not be generalized beyond this population. Future research should include children of different 
ages, larger groups of students, children with combined speech and/or language deficits, and ESOL students. In addition, future research might vary the content, duration, level of explicitness and intensity of the intervention. The intervention in this study was implemented on a one-to-one basis. Future research should examine the effects of training teachers and support staff to administer the phonemic awareness intervention individually and in small groups. 


\section{REFERENCES}

American Speech-Language and Hearing Association. (2001). Roles and responsibilities of speech-language pathologists with respect to reading and writing in children and adolescents (position statement, executive summary of guidelines, technical report). ASHA Supplement 21, 17-27. Rockville, MD: Author.

Anthony, J. L., Lonigan, C. J., Burgess, S. R., Driscoll, K., Phillips, B. M., \& Cantor, B.G. (2002). Structure of preschool phonological sensitivity: overlapping sensitivity to rhyme, words, syllables and phonemes. Journal of Experimental Child Psychology, 82, 65-92.

Anthony, J. L., Lonigan, C. J., Driscoll, K., Phillips, B. M., \& Burgess, S. R. (2003). Phonological sensitivity: A quasi-parallel progression of word structure and cognitive operations. Reading Research Quarterly, 38(4), 470-487.

Ball, E. W., \& Blachman, B. A. (1991). Does phoneme awareness training in kindergarten make a difference in early word recognition and developmental spelling? Reading Research Quarterly, 26(1), 49-65.

Bird, J., Bishop, D., \& Freeman, N. (1995).Phonological awareness and literacy development children with expressive phonological impairments. Journal of Speech and Hearing Research, 38, 446-462.

Bishop, D. V. M., \& Adams, C. (1990). A prospective study of the relationship between specific language impairment, phonological disorders and reading retardation. Journal of Child Psychology and Psychiatry, 31, 1027-1050.

Boada, R., \& Pennington, B. F., (2006). Deficient implicit phonological representations in children with dyslexia. Journal of Experimental Child Psychology, 95, 153193.

Bradley, L., \& Bryant, P (1983). Categorizing sounds and learning to read -A causal connection. Nature, 301, 419-421.

Carroll J., \& Snowling, M. (2004). Language and phonological skills in children at high risk of reading difficulties. Journal of Child Psychology and Psychiatry, 45(3), 631-645.

Catts, H. (1993). The relationship between speech-language impairments and reading disabilities. Journal of Speech and Hearing Research, 36, 948-958.

Catts, H. (1997). Clinical exchange: The early identification of language-based reading disabilities. Language, Speech, and Hearing Services in Schools, $28,86-89$. 
Catts, H., Fey, M., Tomblin, J. B., \& Zhang, X. (2002). A longitudinal investigation of reading outcomes in children with language impairments. Journal of Speech, Language, and Hearing Research, 45, 1142-1157.

Catts, H., Fey, M., Zhang, X., \& Tomblin, J. (2001). Estimating the risk of future reading difficulties in kindergarten children: A research-based model and its clinical implementation. Language, Speech and Hearing Services in Schools, 32. 38-50.

Catts, H., \& Kamhi, A. (1999). Language and reading disabilities. Boston: Allyn and Bacon.

Cooper, J. O., Heron, T. E., Heward, W.L. (2007). Applied behavior analysis. Upper Saddle River, NJ: Prentice Hall.

Cramer, E. D. (2006). In the beginning: Phonological Awareness. In J. S. Schumm (Ed.), Reading assessment and instruction for all learners, (pp. 89-117). New York: The Guilford Press.

Elbro, C., Borstrom, I., \& Petersen, D. K. (1998). Predicting dyslexia from kindergarten: The importance of distinctness of phonological representations of lexical items. Reading Research Quarterly, 33(1), 36-57.

Flahive, L.K. \& Lanza, J. R. (2004) Phonological Awareness Cards. East Moline, Ill.: LinguiSystems.

Foster, W. A., \& Miller, M. (2007). Development of the literacy achievement gap: A longitudinal study of kindergarten through third grade. Language, Speech and Hearing Services in Schools, 38(3), 173-181.

Gillon, G. (2000). The efficacy of phonological awareness intervention for children with spoken language impairment. Language, Speech and Hearing Services in Schools, $31,126-141$.

Gillon, G. (2002). Follow-up study investigating the benefits of phonological awareness intervention for children with spoken language impairment. International Journal of Language and Communication Disorders, 37(4), 381-400.

Gillon, G. (2004). Phonological awareness: From research to practice. New York: The Guilford Press.

Gillon, G. (2005a). Facilitating phoneme awareness development in 3- and 4- year-old children with speech impairment. Language, Speech and Hearing Services in Schools, 36(4), 308-324. 
Gillon, G. (2005b). Phonological awareness: effecting change through the integration of research findings. Language, Speech, and Hearing Services in Schools, 36(4), 346-349.

Horner, D. R., \& Baer, D. M. (1978). Multiple-probe technique: A variation of the multiple baseline. Journal of Applied Behavior Analysis, 11(1), 189-196.

Justice, L. M. (2006). Evidence-based practice, response to intervention, and the prevention of reading difficulties. Language, Speech and Hearing Services in Schools, 37(4), 284-297.

Kamhi, A. G. (2006). Epilogue: Some final thoughts on EBP. Language, Speech and Hearing Services in Schools, 37(4), 320-322.

Kirk, C., \& Gillon, G. (2007). Longitudinal effects of phonological awareness intervention on morphological awareness in children with speech impairment. Language, Speech and Hearing Services in Schools, 38(4), 342-352.

Larivee, L. S., \& Catts, H. (1999). Early reading achievement in children with expressive phonological disorders. American Journal of Speech-Language Pathology, 8(2), 118-128.

Lewis, A., Freebairn, L. A., \& Taylor, H. G. (2000). Follow-up of children with early expressive phonology disorders. Journal of Learning Disabilities, 33(5), 433-444.

Lonigan, C. J., Burgess, S. R., Anthony, J. L., \& Barker, T. A. (1998). Development of phonological sensitivity in 2 to 5 year old children. Journal of Educational Psychology, 90(2), 294-311.

Lonigan, C. J., Burgess, S. R., Anthony, J. L., \& Barker, T. A. (2000). Development of emergent literacy \& early reading skills: Evidence from a latent-variable longitudinal study. Developmental Psychiatry, 35, 596-613.

Manis, F. R., \& Keating, P. (2005). Speech perception in dyslexic children with and without language impairments. In H. W. Catts \& A. G. Kamhi (Eds.), The connection between language and reading disabilities (pp. 173-200).Mahwah, NJ: Lawrence Erlbaum Associates.

Mody, M. (2003). Phonological basis in reading disability: A review and analysis of the evidence. Reading and Writing: An Interdisciplinary Journal, 16, 21-39.

Mody, M. (2004). Neurobiological correlates of language and reading impairments. In C. A. Stone, E. R. Silliman, B. J. Ehren \& K. Apel (Eds.), Handbook of language and literacy (pp.25-48). New York: The Guilford Press 
Nathan, L., Stackhouse, J., Goulandris, N, \& Snowling, M. J. (2004). The development of early literacy skills among children with speech difficulties: A test of the "critical age hypothesis" Journal of Speech, Language and Hearing Research, 47, 377391.

Nation, K. (2005). Connections between language and reading in children with poor reading comprehension. In H. W. Catts \& A. G. Kamhi (Eds.), The connection between language and reading disabilities (pp. 173-200). Mahwah, NJ: Lawrence Erlbaum Associates.

National Dissemination Center for Children with Disabilities. (2004). Speech and language impairments (Fact Sheet 11). Retrieved November 1, 2007, from http:// www.nichcy.org/pubs/factshe/fs 1 1txt.htm

National Reading Panel (2000).Teaching children to read: An evidence-based assessment of the scientific research literature on reading and its implications for reading research. Washington, DC: National Institute of Child Health and Human Development.

No Child Left Behind Act of 2001. Pub. L. No. 107-110 115 Stat.1425 (2002).

Preston J. L., \& Edwards, M. L. (2007). Phonological processing skills of adolescents with residual speech sound errors. Language, Speech, and Hearing in Schools, 38(4), 297-308.

Pullen, P. C., \& Justice, L. M. (2003). Enhancing phonological awareness, print awareness, and oral language skills in preschool children. Intervention in School and Clinic, 39(2), 87-99.

Oi, S., \& O’Connor, R. (2000).Comparison of phonological training procedures in kindergarten classrooms. Journal of Educational Research, 93(4), 226-233.

Raitano, N. A., Pennington, B. F., Tunick, R. A., Boada, R., \&Shriberg, L. D. (2004). Preliteracy skills of subgroups of children with speech sound disorders. Journal of Child Psychology and Psychiatry, 45(4), 821-835.

Ratner, N. B., (2006). Evidence-based practice: An Examination of its ramifications for the practice of speech-language pathology. Language, Speech and Hearing Services in Schools, 37(4), 257-267.

Robertson, C. \& Salter, W. (2007). The Phonological Awareness Test-2. East Moline, Ill.: Linguisystems. 
Roth, F. P., Speece, D. L., \& Cooper, D. H.(2002). A longitudinal analysis of the connection between oral language and early reading. The Journal of Educational Research, 95(1), 259-272.

Roth, F. P., Troia, G. A., Worthington, C. K., \& Dow, K. A. (2002). Promoting awareness of sounds in speech: An initial report of an early intervention program for children with speech and language impairments. Applied Psycholinguistics, $23,535-565$.

Roth, F. P., Troia, G. A., Worthington, C. K., \& Handy, D. (2006). Promoting awareness of sounds in speech (PASS): The effects of intervention and stimulus characteristics on the blending performance of preschool children with communication disorders. Learning Disability Quarterly, 29, 67-88.

Rvachew, S., Chiang, P., \& Evans, N. (2007). Characteristics of speech errors produced by children with and without delayed phonological awareness skills. Language, Speech, and Hearing Services in Schools, 38(1), 60-71.

Rvachew, S., Ohberg, A., Grawburg, M., \&Heyding, J. (2003). Phonological awareness and phonemic perception in 4-year-old children with delayed expressive phonology skills. American Journal of Speech-Language Pathology, 12, 463-471.

Scarborough, H. (2005). Developmental relationships between language and reading: Reconciling a beautiful hypothesis with some ugly facts. In H. W. Catts\& A. G. Kamhi (Eds.), The connection between language and reading disabilities (pp. 173-200), Mahwah, NJ: Lawrence Erlbaum Associates.

Schuele, C. M., \& Boudreau, D. (2008). Phonological awareness intervention: Beyond the basics. Language, Speech and Hearing Services in Schools, 39(1), 3-20.

Shaywitz, S. (2003).Overcoming dyslexia. New York: Alfred A. Knopf/Random House.

Silliman, E. R., Wilkinson, L. C., \& Brea-Spahn, M. R. (2004). Policy and practice imperatives for language and literacy learning: Who will be left behind? In C. A. Stone, E. R. Silliman, B. J. Ehren \& K. Apel (Eds.), Handbook of language and literacy (pp. 25-48). New York: The Guilford Press.

Snowling, M. J. (2005) Literacy outcomes for children with oral language impairments: Developmental interactions between language skills and learning to read. In $\mathrm{H}$. W. Catts\& A. G. Kamhi (Eds.), The connection between language and reading disabilities (pp. 173-200). Mahwah, NJ: Lawrence Erlbaum Associates.

Stokes, T. F., \& Baer, D. M. (1977). An implicit technology of generalization. Journal of Applied Behavior Analysis, 10, 349-367. 
Sutherland, D. \& Gillon, G. T. (2005). Assessment of phonological representations in children with speech impairment. Language, Speech and Hearing Services in Schools, 36(4), 294-307.

Torgesen, J. (1998). Catch them before they fall: Identification and assessment to prevent reading failure in young children. American Educator, Spring/Summer, 32-39.

Torgesen, J., \& Mathes, P. (1998). What every teacher should know about phonological awareness. Tallahassee, FL: Florida Department of Education Division of Public Schools and Community Education Bureau of Instructional Support and Community Services.

Torgesen, J., Wagner, R., \& Rashotte, C. (1994). Longitudinal studies of phonological processing and reading. Journal of Learning Disabilities, 27, 276-286.

Torgesen, J. K. (1999). Assessment and instruction for phonemic awareness and word recognition skills. In $\mathrm{H}$. Catts, \& A. Kamhi, (Eds). Language and reading disabilities. (pp. 128-153). Boston: Allyn and Bacon.

Torgesen, J. K. (2002). Lessons learned from intervention research in reading: A way to go before we rest, The British Psychological Society, 89-103.

Torgesen, J. K. (2005). Recent discoveries from research on remedial interventions for children with dyslexia. In M. Snowling \& C. Hume (Eds.), The science of reading (pp. 521-537). Oxford: Blackwell Publishers.

U. S. Department of Education. (2005). Evaluation procedures. Federal Register, 70, 35800-35803.

Van Kleek, A., Gillam, R., \& McFadden, T. (1998). A study of classroom-based phonological awareness training for preschoolers with speech and/or language disorders. American Journal of Speech-Language Pathology, 7, 65-76.

Whitehurst, G. J.,\& Lonigan, C. J. (1998). Child development and emergent literacy. Child Development, 69(3), 848-872.

Wright Group. (2007). The Wright Skills Level A Decodable Books. Bothell, WA: Wright Group/McGraw Hill. 
APPENDIX A

PARENT/GUARDIAN CONSENT FORM 


\section{Parent/Guardian Consent Form}

Speech Pathologist's Role in Providing Phonemic Awareness Explicit Instruction to Preschool Children with Phonological Speech Sound Disorders.

I freely and voluntarily give consent for my child to be a participant in the study entitled, "Speech Pathologist's Role in Providing Phonemic Awareness Explicit Instruction to Preschool Children with Phonological Speech Sound Disorders" to be conducted by Susan L. Nullman, M. A., CCC, a doctoral candidate at the Florida International University.

I understand that the purpose of this research is to observe the effects of explicit instruction in phonemic awareness on preschool children with phonological speech sound disorders. I am aware that my child's personal information may be reviewed in order to establish descriptive data, and that his/her identity will be kept confidential. I am also aware that my child will be involved in instruction in phonemic awareness 4 days a week in addition to their regularly subscribed speech and language therapy sessions. He/She will also participate in quizzes at the end of each explicit instruction session to determine the retention of material learned during the explicit intervention. I understand that my child's participation in the study will last for approximately 9 to 12 weeks.

My consent for my child to participate in this study is entirely voluntary and my decision will involve no penalty or loss on benefits to my child or me, or to the school. I understand that if I have any questions regarding the study, I can contact Susan L. Nullman at (954)-349-1436, Dr. Patricia Barbetta at (305)-348-2552, and Dr.xxxxxxxx, Chairman Human Subjects Research, Florida International University, at (305)-348-3115.

Please sign below one of the following statements:

I give permission for to participate in this study.

Signature of Parent

I do not give permission for

Signature of Parent

I greatly appreciated your participation in this project.

\section{Date} to participate in this study.

Susan L. Nullman, M. A, CCC 
APPENDIX B

EARLY IDENTIFICATION OF LANGUAGE BASED READING

DISABILITIES: A CHECKLIST 


\section{EARLY IDENTIFICATION OF LANGUAGE-BASED READING DISABILTIES: A CHECKLIST (CATTS, 1997)}

This checklist is designed to identify children who are at risk for language based reading disabilities. It is intended for use with children at the end of kindergarten or beginning of first grade. Each of the descriptors listed below should be carefully considered and those that characterize the child's behavior/history should be checked. A child receiving a large number of checks should be referred for a more in-depth evaluation.

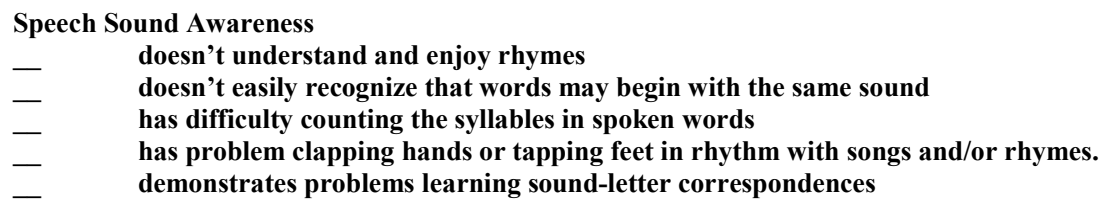

Word Retrieval

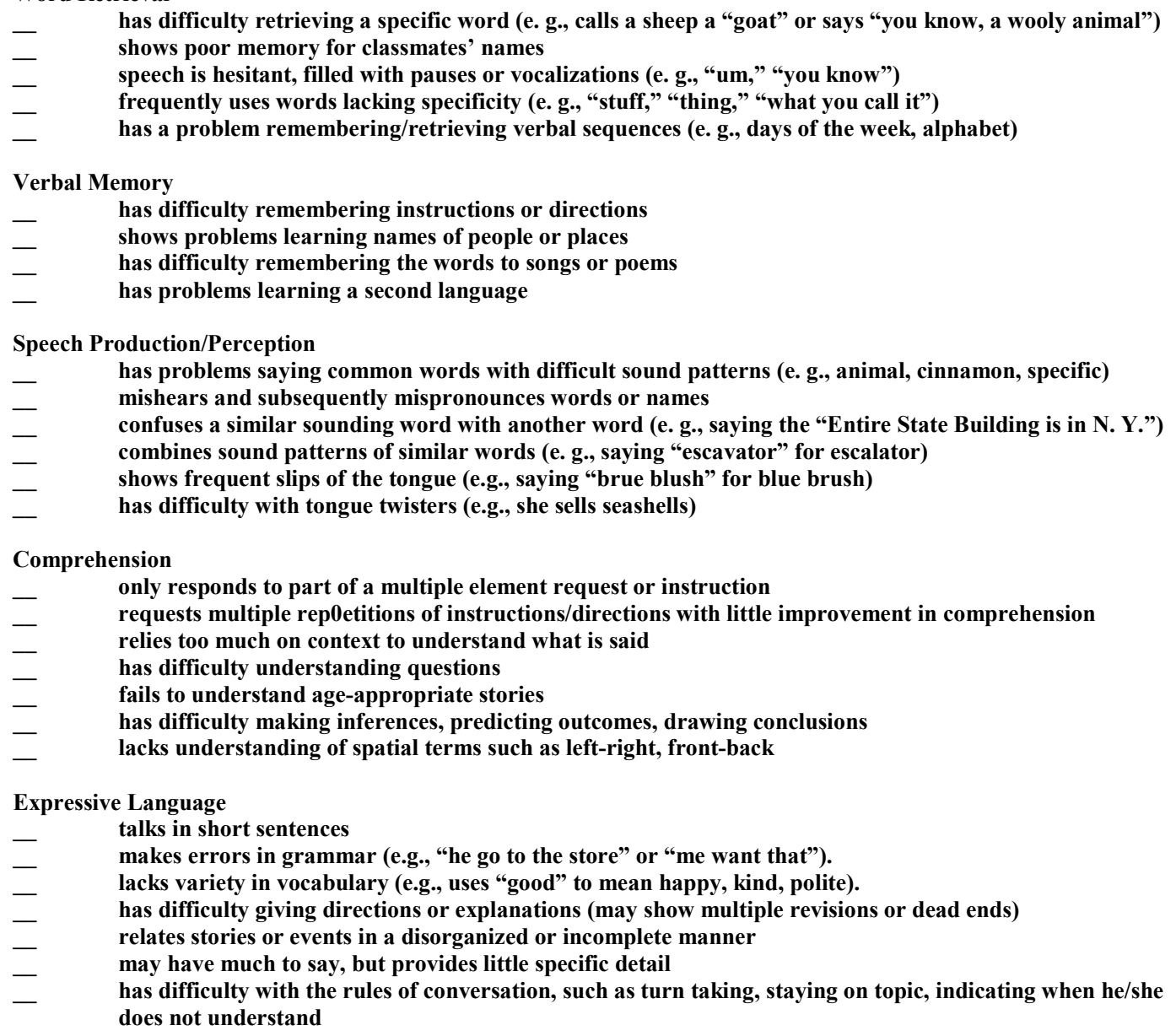

Important Factors

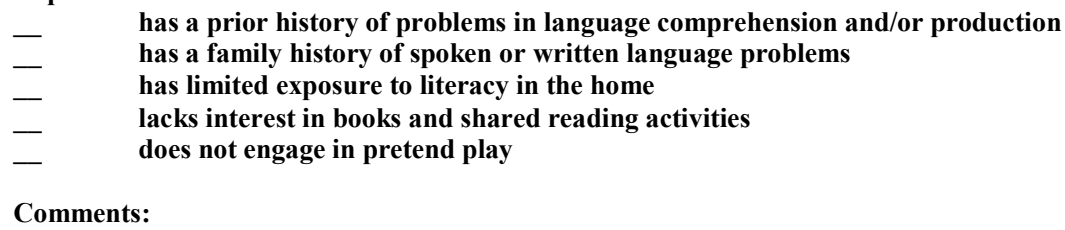




\section{APPENDIX C}

DESCRIPTION OF STANDARDIZED TESTS 


\section{Description of Standardized Tests}

Goldman-Fristoe-Test-Of-Articulation-2 (GFTA-2/English). The GFTA-2 assesses an individual's articulation of the consonant sounds of Standard American English.

Descriptive information about the child's spontaneous and imitative articulation skills are obtained through the three sections of the test: Sounds-In-Words, Sounds-In-Sentences, and Stimulability. Normative information is available for interpreting the results of the Sounds-In-Words section.

Reliability: Alpha reliabilities range from .92 to .98 for females and from .85 to .96 for males. Test-Retest reliability ranges from .89 to .100 .

Validity: Examination of the p-values or percent of correct production for each consonant sound reveals a close match to widely accepted patterns of development.

Peabody Picture Vocabulary Test- IV (PPVT/Eng.) The PPVT-IV is a test of listening comprehension for the spoken word in Standard English. It has two purposes: it measures an examinee's receptive vocabulary acquisition, and serves as a screening test of verbal ability, one element in a comprehensive test battery of cognitive processes.

Reliability: Split-half reliability across the entire age and grade ranges from .94 to .95 on each form; Alpha reliability is consistently high at .97 and .96 for forms A and B; mean Alternate form reliability is .89; Test-retest reliabilityaverage correlation of .93 .

Validity: Construct validity supported by correlations with other language tests a (CASL, CELF4 and PPVT III).

during the developmental stages of test construction; the validity of the items are reinforced by the results of differential item functioning analysis.

Phonological Awareness Test-2.This test is and individually administered assessment designed to diagnose deficits in phonological processing and phoneme-grapheme correspondence.

Reliability: Test-Retest reliability ranges from .60 to .90 for the different subtests.

Validity: Established by t-tests for differences between normal and at-risk readers; Point biserial correlations between item scores and task scores by age; Subtest intercorrelations and correlations between subjects, sections and total test by age. 
APPENDIX D

HEARING, VISION AND ORAL MOTOR ASSESSMENTS 
Hearing, Vision, and Oral Motor Assessments

Participant's Name

Date

Hearing Assessment

Hearing will be assessed using a Maico MI24/MI26 audiometer. A tympanogram will assess middle ear function, and a pure tone audiometric screening at $25 \mathrm{db}$ will determine normal hearing acuity. The audiometer will generate a printed tympanogram and audiogram for each participant.

\section{Vision Assessment}

An informal vision assessment will include the ability to visually identify 10 pictures, 10 capital letters, and 10 lower case letters (using the same materials used for the intervention and same-day tests).

Pictures:

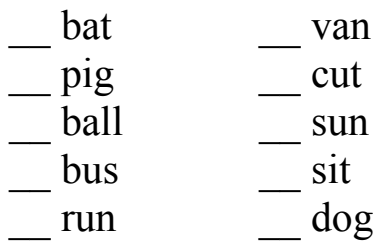

\section{Capital Letters:}

$\begin{aligned} \mathrm{A} & -\mathrm{W} \\ -\mathrm{D} & -\mathrm{C} \\ -\mathrm{T} & -\mathrm{P} \\ -\mathrm{F} & -\mathrm{Z} \\ -\mathrm{S} & -\mathrm{M}\end{aligned}$

Lower Case Letters

$\begin{aligned} \mathrm{e} & -\mathrm{b} \\ -\mathrm{d} & -\mathrm{o} \\ -\mathrm{g} & -\mathrm{h} \\ -\mathrm{u} & -\mathrm{m} \\ -\mathrm{j} & -1\end{aligned}$




\section{Oral Motor Skills Assessment}

Each participant will be asked to demonstrate age-appropriate oral motor development. The skills are listed below:

Observation Guidelines:

Are there a variety of lip and facial movements?

Does the tongue remain in the participant's mouth?

Is there lip closure when the participant is not speaking?

Lips:

Can the child purse and retract his lips?

Can the child hold a tongue depressor between his lips?

Tongue:

Can the child protrude and retract his tongue?

Can the child protrude his tongue and hold it for $10 \mathrm{sec}$ ?

Can the child elevate his tongue tip? Touch his nose?

Can the child lift his tongue tip behind his upper teeth?

Can the child lower his tongue tip behind his lower teeth?

Can the child lateralize his tongue from side to side?

Jaw:

Can the child open and close his mouth in a slow, controlled manner without head or body movements?

Velopharyngeal Mechanism:

Is there any accompanying nasality when speaking?

Does the velopharyngeal speech mechanism function normally?
Yes

No

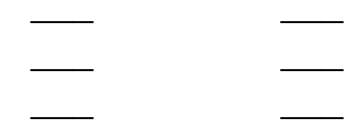


APPENDIX E

BASELINE, INTERVENTION AND SAME DAY TEST MATERIALS 
Baseline, Intervention and Same Day Test Materials

\section{Materials}

Same color one inch cubes

Wooden letter tiles

Phonological Awareness Cards (Linguisystems, 2004)

Elkonin box with three spaces (see example below):

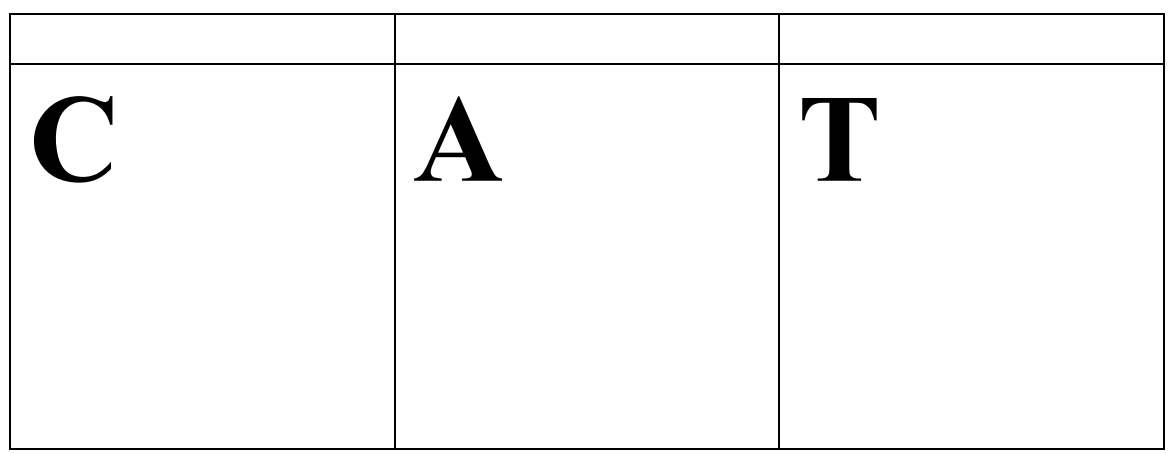

Books: Selected from The Wright Skills (1999) Level A Decodable Books.

One book was selected for each day of the study. Some books were repeated. The selections include:

1. Sam and Nan by Ned Jensen

2. Dan and the Fan by Jan Duden

3. A Pan for Pam by Carrie Waters

4. Can I See the Wind by Cass Hollander

5. A Pan of Jam by Cory Knowlen

6. A Nap is Not Fun by Sophie Harris

7. Hap and the Hat by Charles Wood

8. A Can of Gas by Ian Lennox

9. Come On Dot by Sophie Harris

10. Jog to the Dam by Amy Williams

11. Hop, Jog and Tap by Ned Jensen

12. Go, Go, Go by Eric Michaels

13. A Bad Job by Cory Knowlen

14. We Can by Charles Wood

15. Jim Pig is Mad by Nora Voutas

16. Pigs and Dogs Play Ball By Amy Williams

17. A Hat for Nan by Jane Duden

18. Come and Get It by Sophie Harris

19. A Rag for Miss Rat by Cary Knowlen

20. Can I Have a Cat by Charles Wood

21. A Bug in a Rug by Jane Duden 
22. A Cup for a Cub by Ned Jensen

23. I can Get Dressed by Doreen Beauregard

24. Can Kim and Kip Play? By Ian Lennox

25. A Van in the Mud by Sophie Harris

26. Yip and Yap by Charles Wood

27. Are They Here Yet? By Charles Wood

28. No, Not Yet by Rory Tomasaaaaa

29. Jen and the Pets by Ned Jensen

30. Pets by Cass Hollander

31. Quit It! By Charles Wood

32. The Ox in the Pit by Ian Lennox

33. The Buzz in the Box by Cory Knowlen

34. Max is Sick by Ned Jensen

35. The Fox by Rory Tomas

36. Who Am I? by Eric Michaels

37. Who is Quick? By Cory Knowlen

38. The Big, Fun Hat by Sophie Harris

39. Red Fox Cub by Celeste White

40. Pups, Cubs and Chicks by Eric Michaels 
APPENDIX F

PHASE SCORE SHEETS 


\section{Phase Score Sheets}

Participant

Date

Date of Birth

Data Collector

Researcher

Secondary/ IOA

Circle one from each line below:

Phase: Phoneme Identity Blending Segmentation

Test: $\quad$ Baseline Same Day Test Generalization Maintenance

\begin{tabular}{|l|l|l|}
\hline Question & Correct & Incorrect \\
\hline 1 & & \\
\hline 2 & & \\
\hline 3 & & \\
\hline 4 & & \\
\hline 5 & & \\
\hline
\end{tabular}

Circle one below

Initial Block

Raw Score 15

\begin{tabular}{|l|l|l|}
\hline Question & Correct & Incorrect \\
\hline 1 & & \\
\hline 2 & & \\
\hline 3 & & \\
\hline 4 & & \\
\hline 5 & & \\
\hline
\end{tabular}

Circle one below

Final Letters

\section{Raw Score $\quad / 5=$}

Total Raw Score $/ 10$ 
APPENDIX G

DATA LOG 


Participant's Name: $\quad$ DATA LOG

\begin{tabular}{|c|c|c|c|c|}
\hline DATE & CONDITION & SCORES & IOA Y/N & COMMENT \\
\hline & & & & \\
\hline & & & & \\
\hline & & & & \\
\hline & & & & \\
\hline & & & & \\
\hline & & & & \\
\hline & & & & \\
\hline & & & & \\
\hline & & & & \\
\hline & & & & \\
\hline & & & & \\
\hline & & & & \\
\hline & & & & \\
\hline & & & & \\
\hline & & & & \\
\hline & & & & \\
\hline & & & & \\
\hline & & & & \\
\hline & & & & \\
\hline & & & & \\
\hline & & & & \\
\hline & & & & \\
\hline & & & & \\
\hline & & & & \\
\hline & & & & \\
\hline & & & & \\
\hline & & & & \\
\hline & & & & \\
\hline & & & & \\
\hline & & & & \\
\hline & & & & \\
\hline & & & & \\
\hline & & & & \\
\hline & & & & \\
\hline & & & & \\
\hline & & & & \\
\hline & & & & \\
\hline & & & & \\
\hline & & & & \\
\hline & & & & \\
\hline
\end{tabular}


APPENDIX H

TREATMENT INTEGRITY CHECKLIST 


\section{Treatment Integrity Checklist}

Date:

Phase:

1. Warm up materials prepared

yes no

2. Explicit instruction materials prepared

yes no

3. Materials selected for Same Day Test

yes no

4. Conduct warm up activity

yes no

5. Conduct explicit instruction

yes no

6. Random selection of cards/words for Same Day Test

yes no

7. Student receives instruction for Same Day Test

yes no

8. Administer Same Day Test

yes no

9. Student responses made within 5 seconds

yes no

10. Student responses recorded on the Phase Score Sheets

yes no

11. Student responses recorded on the Data Log

yes no

12. Student responses graphed

yes no

Number of occurrences

$/ 12$

Number of nonoccurences

$/ 12$ 
APPENDIX I

PHONEME IDENTITY SAME DAY TEST CARDS 


\section{Phoneme Identity Same Day Test Cards}

Listed below are the phoneme identity same day test cards that will be used for initial sound phoneme identity. The participant will be asked to identify two words on each card that begin with the same phoneme.

$\underline{\text { Initial Sound Cards (30) }}$

\begin{tabular}{ll} 
nose-chair-nest & neck-jam-night \\
duck-desk-phone & corn-log-laugh \\
hat-toe-ten & bed-bun-line \\
cone-seed-sail & sad-boy-sun \\
shirt-sheep-tail & bear-sink-bird \\
log-leaf-rain & peel-nine-neck \\
rake-roof-table & fish-fan-house \\
door-soap-soup & moon-mouse-bush \\
light-zoo-zebra & chain-map-moose \\
cane-cup-fish & dog-doll-sour \\
tie-paw-pick & web-bat-witch \\
pull-push-hold & pan-cut-cup \\
shirt-goose-gate & horse-hand-nail \\
bike-boat-van & \\
shirt-goose-gate & \\
\hline Ship-shell-sun & \\
\hline
\end{tabular}




\section{Phoneme Identity Same Day Test Cards}

Listed below are the phoneme identity same day test cards that will be used for final sound phoneme identity. The participant will be asked to identify two words on each card that end with the same phoneme.

Final Sound Cards (30)

$\begin{array}{ll}\text { peach-hose-march } & \text { two-shoe-three } \\ \text { toe-boat-goat } & \text { van-car-fan } \\ \text { seal-wheel-face } & \text { sit-sun-run } \\ \text { rope-hit-cut } & \text { car-jar-bike } \\ \text { tooth-girl-path } & \text { ball-tall-tail } \\ \text { leg-knife-safe } & \text { whale-hair-chair } \\ \text { tub-bib-ball } & \text { knit-ten-feet } \\ \text { cup-mouse-mop } & \text { beak-fan-bake } \\ \text { bees-rug-cheese } & \text { neck-face-cheek } \\ \text { up-bush-wash } & \text { cat-dog-pig } \\ \text { tooth-heel-wreath } & \text { up-bush-wash } \\ \text { bag-kite-cat } & \text { boot-shoes-hat } \\ \text { hike-run-kick } & \\ \text { head-cheek-back } & \\ \text { cat-dog-pig } & \\ \text { bed-head-comb } & \\ \text { boat-can-run } & \\ \text { bus-kiss-kick } & \end{array}$




\section{APPENDIX J}

BLENDING SAME DAY TEST WORDS 


\section{Blending Same Day Test Words}

The words listed below comprise the pool of 60 words to be used for the Blending Same Day Test. Each day 10 cards will be randomly selected from this pool.

$\begin{array}{llllll}\text { bet } & \text { get } & \text { let } & \text { met } & \text { net } & \text { pet } \\ \text { set } & \text { wet } & \text { vet } & \text { den } & \text { hen } & \text { men } \\ \text { ten } & \text { pen } & \text { bed } & \text { fed } & \text { led } & \text { red } \\ \text { wed } & \text { beg } & \text { peg } & \text { leg } & \text { bit } & \text { kit } \\ \text { fit } & \text { hit } & \text { lit } & \text { pit } & \text { big } & \text { dig } \\ \text { fig } & \text { pit } & \text { wig } & \text { bin } & \text { fin } & \text { pin } \\ \text { tin } & \text { win } & \text { dip } & \text { hip } & \text { lip } & \text { rip } \\ \text { sip } & \text { tip } & \text { zip } & \text { cot } & \text { dot } & \text { got } \\ \text { hot } & \text { jot } & \text { lot } & \text { not } & \text { pot } & \text { cob } \\ \text { job } & \text { rob } & \text { mob } & \text { sob } & \text { dog } & \text { fog }\end{array}$


APPENDIX K

SEGMENTATION SAME DAY TEST CARDS 


\section{Segmentation Same Day Test Cards}

The words listed below comprise the pool of 60 words to be used for the Segmentation Same Day Test. Each day 10 cards will be randomly selected from this pool.

$\begin{array}{llllll}\text { hot } & \text { pan } & \text { hit } & \text { bat } & \text { dog } & \text { leg } \\ \text { hop } & \text { top } & \text { tag } & \text { hat } & \text { egg } & \text { hen } \\ \text { mop } & \text { cap } & \text { bell } & \text { ham } & \text { bag } & \text { net } \\ \text { web } & \text { pig } & \text { ant } & \text { run } & \text { sun } & \text { rug } \\ \text { bus } & \text { up } & \text { bag } & \text { fan } & \text { log } & \text { tub } \\ \text { dog } & \text { hop } & \text { map } & \text { van } & \text { sad } & \text { mop } \\ \text { sit } & \text { cup } & \text { cut } & \text { sun } & \text { bib } & \text { hug }\end{array}$


VITA

Susan L. Nullman

August 23, 1953

1970-1971

1971-1973

1973-1975

1974-1975

1975-1976

1975-1976

1976-1977

1978

1978-1979
Born, Brooklyn, New York

University of Maryland

College Park, Maryland

Bachelor of Arts, Magna Cum Laude

Speech Pathology

State University of New York at Buffalo

Buffalo, New York

Elected to Phi Beta Kappa

Master of Arts

Speech Pathology

State University of New York at Buffalo

Buffalo, New York

Teaching Assistant for undergraduate

Courses: Phonetics and Disorders of Speech, Hearing and

Language

State University of New York at Buffalo

Buffalo, New York

National Examination in Speech Pathology passed, 99th percentile. Certificate of Clinical Competence received (CCC).

Full Time Speech Pathologist

Speech and Hearing Unit

Mt. View Hospital

Lockport, New York

Full Time Speech Pathologist- Cleft Palate Program

Children's Hospital

Buffalo, New York

Part Time Speech Pathologist

Stephanie Stryker and Associates

Clinical Supervisor- Speech Pathology Department

University of Miami

Coral Gables, Florida 
1989-1995

Part Time Speech Pathologist

Kendall Speech and Language Center

Miami, Florida

1997-1998

Adjunct Professor

Graduate course: Language Disorders in Children

Nova Southeastern University

Davie, Florida

1999-present

Private Practice

Susan L. Nullman, M. A., CCC

Speech and Language Pathology

Weston, Florida

2000

Admitted to the Exceptional Student Education

Doctoral Program

College of Education

Florida International University

Miami, Florida

\section{PUBLICATIONS AND PRESENTATIONS}

1975

Master's Thesis

The Assessment of Hypernasality in Young Children

With Repaired Cleft Palate.

1999-present Yearly inservice training for preschool teachers Speech and Language Development in Preschoolers Temple Dor Dorim Preschool

Weston, Florida

2003

Program Entry, International Reading Association

Poster Session

Dr. Fran Falk-Ross, Susan Nullman

Language Lessons for Struggling Readers: Technology

Programs to Enhance Phonological Awareness

Intended for classroom teachers K-3

2004

COERC Presentation

Nullman, S. (2004, April). Universal Design and Differentiated Instruction:

Resolving Competing Mandates from IDEA and NCLB. Paper presented at Florida International University $3^{\text {rd }}$ Annual Research Conference, Miami, Florida (April) (with Nevin, A., Falkenberg, C., Salazar, L, \& Silio, M.) 